IZA DP No. 8727

Baby-Boom, Baby-Bust and the Great Depression

Andriana Bellou

Emanuela Cardia

December 2014

Forschungsinstitut zur Zukunft der Arbeit Institute for the Study of Labor 


\title{
Baby-Boom, Baby-Bust and the Great Depression
}

\author{
Andriana Bellou \\ Université de Montréal, \\ CIREQ and IZA
}

Emanuela Cardia

Université de Montréal,

CIREQ

\section{Discussion Paper No. 8727 \\ December 2014}

\author{
IZA \\ P.O. Box 7240 \\ 53072 Bonn \\ Germany \\ Phone: +49-228-3894-0 \\ Fax: +49-228-3894-180 \\ E-mail: iza@iza.org
}

Any opinions expressed here are those of the author(s) and not those of IZA. Research published in this series may include views on policy, but the institute itself takes no institutional policy positions. The IZA research network is committed to the IZA Guiding Principles of Research Integrity.

The Institute for the Study of Labor (IZA) in Bonn is a local and virtual international research center and a place of communication between science, politics and business. IZA is an independent nonprofit organization supported by Deutsche Post Foundation. The center is associated with the University of Bonn and offers a stimulating research environment through its international network, workshops and conferences, data service, project support, research visits and doctoral program. IZA engages in (i) original and internationally competitive research in all fields of labor economics, (ii) development of policy concepts, and (iii) dissemination of research results and concepts to the interested public.

IZA Discussion Papers often represent preliminary work and are circulated to encourage discussion. Citation of such a paper should account for its provisional character. A revised version may be available directly from the author. 
IZA Discussion Paper No. 8727

December 2014

\section{ABSTRACT \\ Baby-Boom, Baby-Bust and the Great Depression ${ }^{*}$}

The baby-boom and subsequent baby-bust have shaped much of the history of the second half of the 20th century; yet it is still largely unclear what caused them. This paper presents a new unified explanation of the fertility Boom-Bust that links the latter to the Great Depression and the subsequent economic recovery. We show that the 1929 Crash attracted young married women 20 to 34 years old in 1930 (whom we name D-cohort) in the labor market possibly via an added worker effect. Using several years of Census micro data, we further document that the same cohort kept entering into the market in the 1940s and 1950s as economic conditions improved, decreasing wages and reducing work incentives for younger women. Its retirement in the late 1950s and in the 1960s instead freed positions and created employment opportunities. Finally, we show that the entry of the $D$-cohort is associated with increased births in the 1950s, while its retirement turned the fertility Boom into a Bust in the 1960s. The work behavior of this cohort explains a large share of the changes in both yearly births and completed fertility of all cohorts involved.

JEL Classification: J11, J12, J13, J21, J24, J26, J31

Keywords: baby boom, baby bust, Great Depression, added worker effect, retirement, fertility

Corresponding author:

Andriana Bellou

Département de sciences économiques

Université de Montréal

Pavillon Lionel-Groulx

Université de Montréal

3150, rue Jean-Brillant

Montréal (QC) H3T1N8

Canada

E-mail: andriana.bellou@umontreal.ca

\footnotetext{
* The authors gratefully acknowledge financial support from SSHRC and FQRSC. We thank Fabian Lange, Martha Bailey, Robert Margo, Edson Severnini, Uta Shoenberg and participants at the Queens Economic History Workshop (2014), University of Bologna, University of Southampton and University College London for their helpful comments.
} 


\section{Introduction}

It is still unclear what caused the unprecedented increase in fertility between 1946 and 1964, the official dates of the baby-boom: from the cohorts of women born between 1906 and 1910, to the cohorts born between 1931 and 1935, fertility increased by $40 \%$. What is equally surprising is that the spectacular increase then evaporated within a decade. Women born between 1946 and 1950 had an average of only 2.22 children, lower than the average of the cohorts born between 1906 and 1910.

While most studies of the baby-boom have typically focused on completed fertility, annual fertility rates also evolved in a very particular way. Births began to soar in the early 1950s, levelled off between 1958 and 1960 and declined rapidly thereafter. Interestingly, the timing of the boom and bust is similar across women of different childbearing ages in the 1950s and 1960s. Even more intriguing: women born between 1936 and 1940 had on average more births in 1960, when 20 to 24 years old, than all other baby-boom cohorts, yet overall they had on average fewer children than the previous cohort born between 1931 and 1935 (3.02 versus 3.21). These facts suggest that something happened between the end of the 1950s and the beginning of the 1960s that led all cohorts to reduce births. Although there were two official recessions between 1957 and 1958 and between 1960 and 1961, they were both fairly mild and brief and overall the 1960s was a period of growth and economic prosperity.

In this paper we propose a new explanation of the baby-boom and baby-bust that fits the timing of the increase and decrease in both yearly births and completed fertility. Our explanation links the fertility boom-bust to the Great Depression. We show that the Great Depression drew into the labor market a group of young married women, 20 to 34 years old in 1930, henceforth called the D-cohort. In the following decades this same cohort either remained in the labor market or exited to re-enter as economic conditions improved. Its entry in the 1940s and 1950s was massive and decreased wages and employment opportunities for all women, including the very young. Lower wages, in turn, implied a lower opportunity cost of having children and hence a substitution effect that discouraged work and encouraged family formation. The (re-) entry of the $D$-cohort also coincided with a period of substantial economic expansion, greater job security for men and possibly rising male incomes. We argue that this positive income effect together with a weakened substitution effect (via lower female wages and lower employment) generated the dramatic increase in fertility observed during the Baby-Boom. Born between 1896 and 1910, women in the D-cohort retired in the late 1950s and throughout the 1960s. In 1970 they were 60 to 74 years old and few were still working. Their massive exit from the labor market freed positions and increased the opportunity cost of 
having children for younger women. This explains why in a period of economic prosperity we witnessed both a boom and a bust. $^{2}$

Our explanation links the fertility boom-bust to the Great Depression via a different channel than the well-known "relative income hypothesis” proposed by Easterlin (1961). Our mechanism is the labor market behavior of women who were of working age during the depression years. Easterlin hypothesis instead relies on a preference shift, whereby young women who grew up during the Depression had low material aspirations and responded to the post-WWII economic recovery with renewed optimism and a desire for larger families. This hypothesis has received less attention recently, partly because the cohort with the highest average birth rate was born between 1936 and 1940 and was too young to have been directly affected by the Great Depression. The behavior of this cohort is instead well explained by the labor market channel we propose. Jones and Schoonbroodt (2014) also link the boom-bust to the Great Depression. Using a Barro-Becker model with dynastic altruism, they show that a large decline in income (as during the Great Depression) leads to a decline in contemporaneous fertility and to higher transfers per child later on. As a result, the next generation increases both consumption and fertility.

WWII could seem the most obvious alternative explanation of the baby-boom, as this occurred soon after the return of soldiers from the war. From the official entry of the US into the war, 16 million men were drafted and it took three and half years for the war to end. This alone could have triggered a catch-up effect and a baby-boom. But could this have been sufficient to explain the observed baby-boom, which spanned nearly two decades, and the subsequent bust? More importantly, even if delayed fertility could explain the boom and bust, this should not affect completed fertility, while the latter increased substantially. It is possible, however, that the war affected fertility via other channels.

Doepke, Hazan and Maoz (2013) use a calibrated macro model to show that the large entry of women (45 to 55 years old in 1960) into the workforce during WWII could have crowded-out younger women with less experience and led to a large increase in births. Their model and simulations show the important role of labor markets for fertility. Evidence that is not consistent with the war crowding-out young women is provided by Fernandez, Fogli and Olivetti (2007). They show that WWII increased the proportion of men brought up by working mothers as well as the labor supply of their daughters, 25 to 29 years old in 1960.

\footnotetext{
${ }^{2}$ Jones and Tertilt (2006) find a negative relation between income and fertility, which would explain most of the fertility decline in the late 19th and 20th century, but does not adequately explain the baby-boom that occurred during a period of prosperity. Our hypothesis suggests that this relation was altered due to a temporarily weaker substitution effect.
} 
They also find no long term labor supply effects of WWII for the mothers themselves, 45 to 50 years old in 1960. Goldin and Olivetti (2013) show that WWII increased the participation of white married women, 25 to 49 years old in 1950 and 35 to 44 years old in 1960, but find no effects for older women. In addition, they show that this increase only applies to women with at least 12 years of schooling. ${ }^{3}$ In this paper, we also find that young women work more in high mobilization states in 1960 and no significant effects for older women (our D-cohort). Moreover, annual data from the Current Population Survey do not indicate a decline in the presence of 45 to 55 years old women in the labor market in the 1960s (Figure 6 in this paper). This suggests that their retirement cannot explain the baby-bust in the early 1960s. Our thesis is instead that an older cohort of women, 50 to 64 years old in 1960 and right at the time to retire, triggered a fertility boom and a bust by crowding-out and then crowding-in younger female labor market entrants.

Several other studies link the baby-boom to a decrease in the cost of raising children during the 1950s consistent with the quality-quantity tradeoff formulated by Becker (1960) and Becker and Lewis (1973). Greenwood, Seshadri and Vandenbroucke (2005) credit the dramatic transformations in home production since the early 20th century and the rapid diffusion of modern appliances in the 1940s and 1950s for freeing time and increasing the demand for children. Bailey and Collins (2011) using county data on appliances and fertility show, however, that the link between home technology and fertility is either negative or insignificant. Murphy, Simon and Tamura (2008) attribute the baby-boom to the suburbanization of the population and to the declining price of housing, as proxied by population density. Albanesi and Olivetti (2014) instead link the baby-boom to improvements in health that significantly decreased maternal mortality in the early 20th century. The babybust is attributed to increased parental investments in the education of the daughters as life expectancy of women increased. Although the first pill was released in 1960 and it took time till its broad use, Bailey (2010) shows that it accelerated the post-1960 decline in marital fertility and contributed to the baby-bust. ${ }^{4}$ Nevertheless, these explanations neither provide a unique mechanism for both the boom and the bust nor account for the quick reversal from the fertility boom to the bust that affected the yearly births of women of all ages.

This paper instead presents instead a "unified” explanation of the boom-bust that does

\footnotetext{
${ }^{3}$ Goldin (1991), using the Palmer survey to examine the impact of WWII on women's work between 1940 and 1951 , finds evidence consistent with the view that the war did not greatly increase women's employment. Acemoglu et al. (2004) find a strong positive relation between mobilization rates and women's employment which, however, fades substantially with time (Figure10, their paper). This is also in line with the results in Fernandez et al. (2007).

${ }^{4}$ Bailey (2006) shows that greater fertility control contributed to the increase in young unmarried women's market work from 1970 to 1990. Bailey (2010) shows that the pill also played an important role in the baby-bust. Among other explanations of the bust, the introduction of divorce laws in the 1970 s does not fit the timing of the reversal.
} 
not rely on other mechanisms for the boom to turn into a bust. Moreover, it is consistent with the timing of the rise and fall in annual births as well as completed fertility and it also explains why fertility changed simultaneously across all women of childbearing age. While other factors influencing the effective cost of raising children, as highlighted in the aforementioned studies, may have contributed to the fertility changes over the 1950s and 1960s, our channel alone explains a large part of both the boom and the bust.

Our empirical strategy is twofold. It relies on 1) using several panels of micro data from 1920 to 1970 to examine the work patterns of women of different ages in response to economic conditions during the Great Depression and afterwards (first part of the paper), 2) constructing a measure of crowding-out and crowding-in to test whether the entry and exit from the labor market of the D-cohort can explain the boom/bust in yearly births and completed fertility (second part of the paper). One difficulty lies in how to consistently measure changes in economic conditions during the first half of the century. Unemployment is not available annually before 1961 while information on income is not available prior to 1929. The only measure we are aware of, that is both at state and annual level since the start of the century, is the ratio of commercial failures to business concerns (US Statistical Abstracts). This covers failures in all commercial businesses.

The first part of the paper uncovers a set of interesting facts. We show that the market entry of the $D$-cohort can be traced to the late 1920s and early 1930s and is significantly higher in states where the Depression was more severe. Interestingly, only married women increased their presence in the early phase. A potential explanation for their entry is an added worker effect, whereby decreased family income and credit market constraints pushed women into the workforce. Consistently with this interpretation, Finegan and Margo (1994) calculate that in 1940 the participation of women whose husbands were unemployed (and not on work relief), was $50 \%$ higher than that of women whose husbands were employed in the private sector.

Using the 1940-1950 and 1940-1960 census panels we present strong evidence that economic conditions in the 1930s had a lasting impact on the employment of the D-cohort and also affected much younger women who were just children in the 1930s. These are the women who had some of the highest birth rates in the $20^{\text {th }}$ century. We find instead no lasting significant effects on the employment of men. In both sets of panels we consistently find an opposite entry/exit response for old/young cohorts, with the D-cohort solely entering the labor market and the young cohorts exiting in states with more commercial failures in the early 
1930s. ${ }^{5}$ The same striking entry/exit pattern is further reinforced by the subsequent economic recovery. The negative impact of the Depression on the young cohorts can only be indirect as they were not of working age in the early 1930s, some not even born.

We also show that in states more severely affected by the Great Depression, the wages of all women were lower decades later. Lower wages reduced the opportunity cost of raising children and the incentive for young women to enter the workforce. We verify if the market entry of the $D$-cohort is a plausible explanation for these findings by using instead of failures during the Great Depression, the share of women in the D-cohort working in 1930 . The results are consistent with the proposed channel: a higher share lowers the ratio of young women working in 1950 and 1960, as well as the wages of nearly all women in 1950 and 1960. We perform several falsification tests to insure that we are not picking up spurious correlation with the business cycle but find no such pattern in response to economic changes that preceded the Great Depression.

These findings are in line with aggregate life-cycle employment trends. Figure 1 plots work shares of women by age from 1930 to 1970. As can be seen, the employment of older cohorts, and in particular of the D-cohort, increased tremendously throughout the decades. In the 1930s and earlier, women tended to withdraw from the labor force after marriage and not to re-enter. This changed drastically afterwards, but the increase is even more remarkable between 1950 and 1960, well after WWII was over. For example, 39\% of the women in the D-cohort were working in 1960, while only $18.6 \%$ in that age bracket were working in 1940 . This also implies that a large number of women was about to retire in the 1960s. It is only then that the employment of younger cohorts increased.

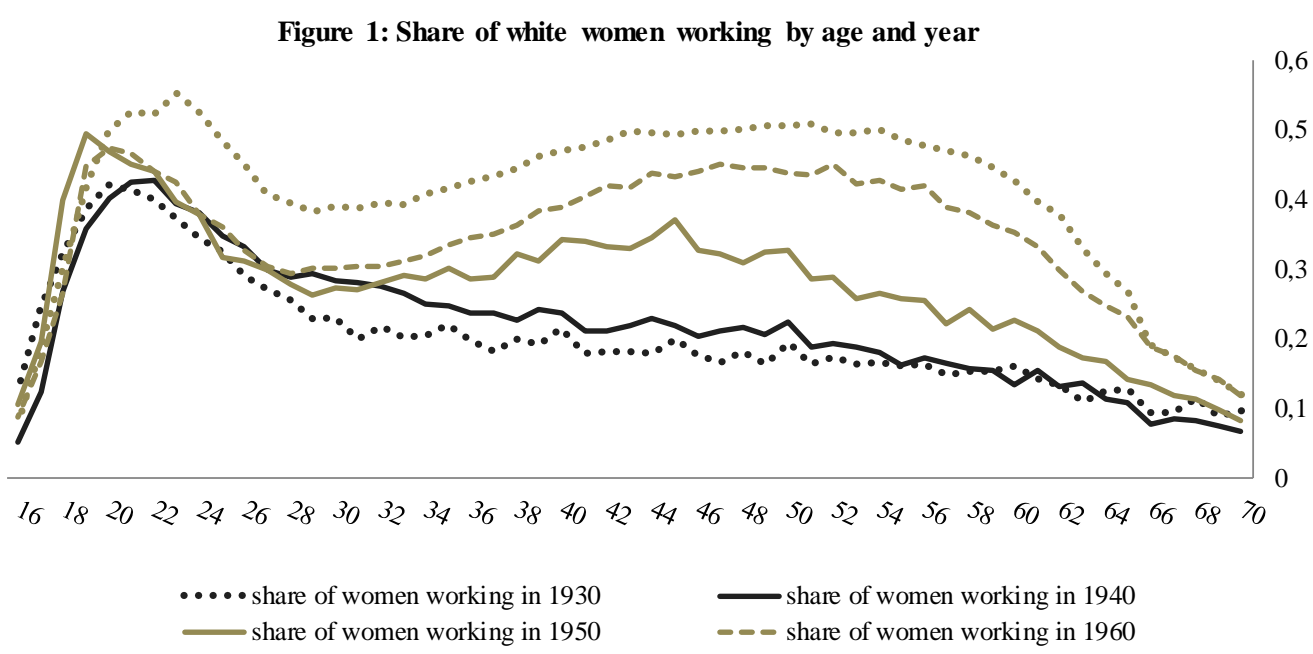

\footnotetext{
${ }^{5}$ Also younger cohorts of married women entered the labor market between 1930 and 1940, but the link to the Great Depression weakens and is not significant in the 1940-1950-1960 panels.
} 
In the second part of the paper we explore whether there is a link between the work behavior of the D-cohort and the fertility of the younger cohorts that contributed the most to the baby-boom and bust. To do this, we construct measures of the share of women in the $D$ cohort entering or exiting the labor market in the 1950s and 1960s. First, we show that these measures predict a decline (increase) in the work propensity of women 20 to 29 years old in 1960 (1970) relative to women of the same age in 1940, our base and pre-baby-boom reference point. Second, we show that these measures also predict significantly more births in the 1950s, and significantly fewer in the 1960s. In both cases these effects explain $30 \%$ to $67 \%$ of the increase and decline in yearly births. Finally, we study whether these measures can predict higher/fewer cumulative births by a certain age for women responsible for the boom and bust, relative to women in the same age brackets in the base year. We find similar results as for yearly births. Numerous falsifications are performed to assess whether by isolating the impact of one cohort, the $D$-cohort, we are not overestimating its impact. To address this issue, we examine the crowding-out and crowding-in impact of other cohorts. In all cases we find that the $D$ - is the only cohort that produces such significant effects on births.

In the next-to-last section of the paper we discuss how other plausible mechanisms of the Baby-Boom fit within our framework. First, we consider the Easterlin hypothesis by explicitly examining the relative impact of economic conditions during childhood and adulthood on completed fertility. We do not find that relative improvements in the economic status of the Baby-Boom cohorts are associated with increases in their lifetime fertility. Second, we test whether the retirement of the $D$-cohort can account for the post-1960 sudden fertility change of the 1926-1940 Baby-Boom cohorts. The 1936-1940 "pivotal” cohort, for instance, had the highest average birth rate when 20 to 24 years old in 1960 but then drastically reduced its births within the next 5 years (see Figure 3 below). It would be difficult to reconcile these within-cohort own fertility switches with hypotheses that solely focus on changes in education or shifts in the preferences of the younger cohorts. We show, instead, that our mechanism can explain this fact.

Finally, in the last section of the paper, we use data on yearly birth rates and completed fertility for a sample of 18 countries, to test the impact of the Great Depression and WWII on fertility. Our estimates indicate that the Great Depression significantly increased and decreased births between 1949 and 1963 and led the cohorts born between 1925 and 1932 to have higher completed fertility and the cohorts born between 1942 and 1950, to have lower completed fertility. WWII, instead, has non-significant effects. 
We proceed as follows. In Section 2, we describe the data and samples. Section 3 analyses the impact of economic conditions on work and wages. Section 4 describes our measures of crowding-out and crowding-in. Section 5 contains the main results on the impact of the crowding-out and crowding-in on the yearly births of different cohorts. Section 6 discusses their effect on cumulative births, Section 7 assesses alternative interpretations and Section 8 presents evidence on the role of the Great Depression on the fertility boom-bust across a sample of 18 countries. Section 9 concludes.

\section{Data and Samples}

Our main data sources are the 1\% IPUMS files, between 1920 and 1970 (Ruggles et al., 2010), and the Statistical Abstracts of the United States. The first source is used to obtain micro-level information on the labor supply of women (and men), their fertility (annual and completed) and other demographic characteristics. The second source is used to collect temporal and geographic information on economic conditions. For this, we use state-level data on commercial failures and exploit differences in the extent of such failures within states over time and across states. This data was originally reported in Dun and Bradstreet Inc., NY. It is available on a state and yearly basis between 1900 and 1968 . We plot the series by state and by the four census regions in Figure 2. As can be seen, there is considerable variation in the failure rate within and across states and over time but in general there are more failures in the early 1930s and very few during WWII. The economic boom of the 1950s, and to some extent of the 1960s, is also characterized by fairly low levels of business failures. Although we cannot use unemployment as a business cycle indicator due to data limitations, there are reasons to prefer commercial failures when examining the impact of economic conditions on labor markets. ${ }^{6}$ While unemployment is affected by shifts in both labor demand and supply, commercial failures are more akin to labor demand shifts that lead to layoffs than to labor supply shifts.

Fertility information from the IPUMS is exploited in two distinct ways. In the yearly fertility analysis, our strategy relies on comparing births in every year from 1950 till 1969 to births occurring in 1940 to women in the same age brackets. To compute yearly births in the 1950s and 1960s we use the 1960 and 1970 censuses respectively. We link young mothers up to 39 years of age in 1960 and 1970 respectively to their own children present in the household. The census reports the birth year of each family member in the household, and hence of all surviving children, which allows us to infer whether a woman gave birth in any of

\footnotetext{
${ }^{6}$ Unemployment rate is reported every 10 years until 1960 by the census and can be calculated annually since 1962 from the Current Population Survey. Due to changes in the employment definition, however, unemployment rate estimates from the census before and after 1940 are not strictly comparable.
} 
the intercensal years (1951, 1952 etc. and similarly 1961, 1962 etc.). We follow a similar procedure to infer births taking place in 1940.

Finally, our entire analysis focuses exclusively on white, native American women, not in group quarters. We further restrict attention to the ever-married when studying changes in completed fertility. Moreover, for sample comparability reasons across years, we produce our estimates using sample line weights as some of our core variables are only recorded for sample-line respondents (wages in 1950 and completed fertility in 1940-1950). Our results, however, are qualitatively and quantitatively robust to using person weights.

We choose 1940 as the base year as this precedes the baby-boom and also significant improvements in economic conditions. It also precedes WWII, which is one of the factors we take into account. Moreover, the year 1940 is a relevant reference point because women who were then 20 to 29 years old had nearly the lowest yearly and completed fertility since the beginning of the 20th century. Women instead who were 20 to 29 years old throughout the 1950s contributed the most to the baby-boom. Hence, our analysis is conducted to make more difficult the explanation of the change in births, from one of its lowest levels to the highest. In addition, prior to 1940 there are no individual data on wages and the definition of work is less comparable to the definition used for 1950 and 1960. For these reasons, to examine the impact of the D-cohort on work, wages and fertility within the same framework and assess the quantitative relevance of our mechanism, we chose 1940 as the base case throughout. ${ }^{7}$

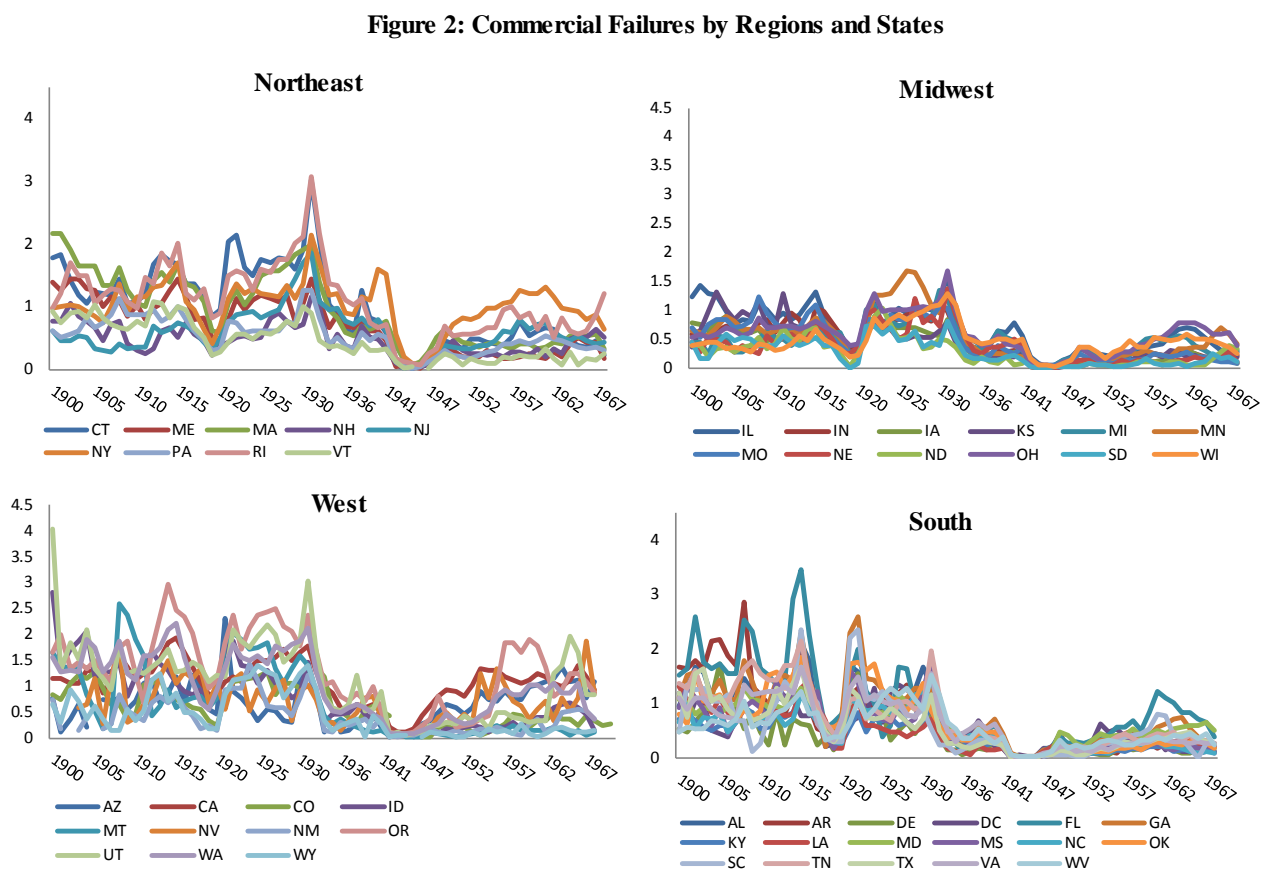

${ }^{7}$ Having said this, we experiment with 1910 as the base year for the fertility analysis and show that our results hold in the 1910-1960 and 1910-1970 panels. 
Table 1 shows the birth year of the cohorts included in the analysis and their ages between 1930 and 1975. We also report their average completed fertility (number of children ever born to white women aged 40 to 49 years old) on the right side of the table. We distinguish three broad cohort groups. The first is the D-cohort born between 1896 and 1910 . The second is the Middle-cohort, our reference cohort, born between 1911 and 1920. The third, the B-cohort, includes all women who contributed to the baby-boom and bust; they were born between 1921 and 1945. The shaded light grey box between the $D$ - and the $B$ cohorts highlights the age of the Middle-cohort in 1940, our base year (marked by a *) to which we compare changes in work and annual births in the 1950s and 1960s. We also highlight in light grey the cohorts that experienced the baby-boom and bust when 20 to 29 years old. These are the cohorts and age groups we focus on in our yearly fertility analysis. Finally, the cohorts whose cumulative fertility by age 30 to 34 we track over time are highlighted in darker grey. Women 30 to 34 years old in 1945 (marked by a *) are our reference point in that case. The $B$ - and the $D$ - cohorts are two groups removed from each other. Moreover, the reference cohort is neither part of the $D$-, nor part of the $B$ - cohorts. This ensures that the results are not contaminated by within-cohort overlaps. The two-cohort cushion we keep between the D-cohort and the baby-boomers is justified by our finding of no persistent effects of the Great Depression on its entry into the labor market in the 1950s (see Section 3).

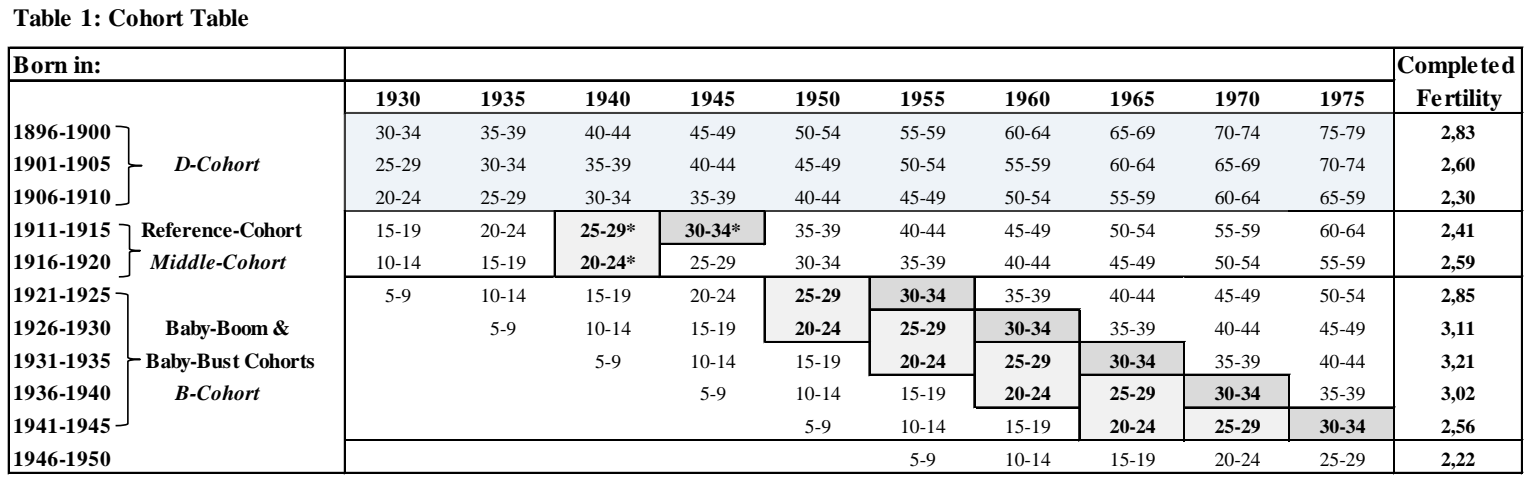

Figure 3 plots mean completed fertility by cohort (solid line) and the average births these cohorts had when 20 to 24 (dotted line), 25 to 29 (small dashed line) and 30 to 34 (long dashed line) years old in the years reported below or above the lines. The graph is rescaled: information about completed fertility is on the left and about births, on the right. Reading the graph vertically one can find the completed fertility of a given cohort and its average fertility rate at different points in time. The dotted (average births to 20 to 24 year-olds) and the small dashed lines (average births to 25 to 29 year-olds) cross over: earlier in the 1950s more children were on average born to 25 to 29 than to 20 to 24 years old women; later in the 
1950s, this pattern is reversed. The change is striking for women born between 1936 and 1940. With respect to previous cohorts, they drastically decreased average births within few years of having had the highest average fertility rate. Our crowding-out and crowding-in hypothesis can reconcile the remarkable shift in the fertility of this same cohort.

Figure 3: Completed Fertility and Yearly Births

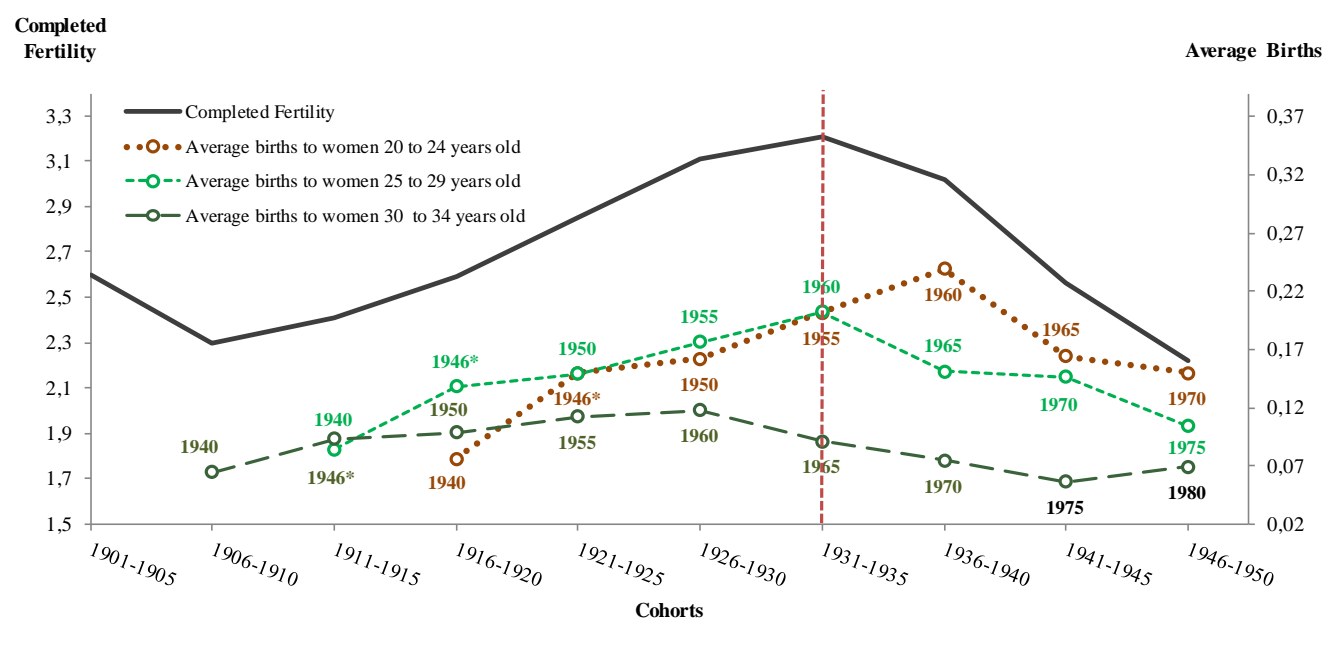

* In 1946 we take births of women in the same cohort but one year older

Finally, the $D$-cohort was also fairly large in terms of relative population size and hence capable of generating such dramatic changes in the fertility of younger cohorts. In 1950 (1960) the share of the D-cohort to the population of all women 20 to 64 years old was 30\% (25\%), while the share of women 20 to 29 years old was 14\% (11\%). Although the D-cohort was not exceptionally big population-wise, it was substantially larger than the younger cohorts in their prime fertility years.

\section{Economic Conditions, Great Depression, Work and Wages}

In this section we use three panels of data, 1930-1940, 1940-1950 and 1940-1960 to examine the impact of the Great Depression and of the subsequent economic recovery on labor markets.

\subsection{Great Depression, Economic Conditions and Female Labor Supply: 1930-1940}

To examine the short-run effects of the Great Depression on labor supply we turn to the 1930-1940 censuses. We compare responses of women in various age groups in 1940 relative to women in the same age groups in 1930. We estimate the following specification:

$$
y_{i t s}=\alpha_{o}+\alpha_{1} \text { Failures }_{\text {st }}+\alpha_{2} \text { Failures_1930 } 0_{\text {st-k }}^{d}+\varphi_{\text {ia }}+f_{s}+g_{t}+\varepsilon_{i t s}
$$

$y_{i t s}$ is an indicator for whether a woman $i$ in state of residence $s$ is employed in year $t(t=1930$, 
1940). Failures ts $_{\text {measure contemporaneous economic conditions. }}^{8}$ To capture the economic environment during the Great Depression we include 10-year lagged failures (Failures_1930), allowing for the 1929-1930 average failure rate to affect the 1940 labor supply and symmetrically the 1919-1920 average failure rate to affect the 1930 labor supply. Business failures substantially increased between the late 1910s and late 1920s.

The results are reported in Table 2. In response to improving current economic conditions, all women in the D-cohort worked less. However, economic conditions dating back to the onset of the Great Depression had a lasting impact on the current work propensity of only married women. This is also true when we isolate women in this cohort in 1940 that got married before the onset of the crisis in 1929 (relative to women of the same age in 1930 that got married symmetrically before 1919). The timing of their marriage could not have been affected by the timing of the Great Depression and their marriage likely preceded their entry in the market. This is consistent with the 1929 Crash inducing an added worker effect, whereby married women, previously not working, had to enter the market and make up for the loss in family income. Evidently, their initial entry was not a temporary adjustment to extreme events, but entailed a more substantial change in their work behavior, which effects were still present a decade later in 1940. These effects are also quantitatively important. The share of women 30 to 44 years old working was 15.75 in 1940 and 10.22 in 1930, an increase of 0.055. Hence, the higher rate of failures at the onset of the Great Depression explains 62.3\% of this increase $(0.623=0.049 * 0.70 / 0.055)$. Interestingly, older women did not display employment patterns similar to the D-cohort. On the other hand, much younger women also worked more where the downturn was more severe. Nevertheless, as will be shown subsequently and in contrast to the D-cohort, the link between the labor supply and the Great Depression for these younger women will not persist in future decades.

Next, we estimate equation (1) including average commercial failures in the early 1920s instead of failures during the Great Depression. ${ }^{9}$ As can be seen the estimates are not significant, confirming that our findings are unique to the Great Depression. Finally, in the last section of Table 2, we present estimates of (1) for men. We find no significant link between past economic conditions and the work behavior of men in the D-cohort. ${ }^{10}$

Finally, in Appendix Table A1 we provide a similar analysis using the 1920-1930 panels. As the employment status is not available in the 1920 Census, we use as dependent

\footnotetext{
${ }^{8}$ These are averages over the last 3 years: 1938 through 1940 for 1940 and 1928 through 1930 for 1930.

${ }^{9}$ For the exercise presented in the second section of Table 2, instead of a 10-year, we use a 20-year lag in failures. We allow for 1940 (1930) work to be affected by average economic conditions from 1919 to 1920 (1909 to 1910 for 1930).

${ }^{10}$ Men 45 to 64 years old also increased participation in states more affected by the Great Depression. We find, however, that these effects do not extend to later decades.
} 


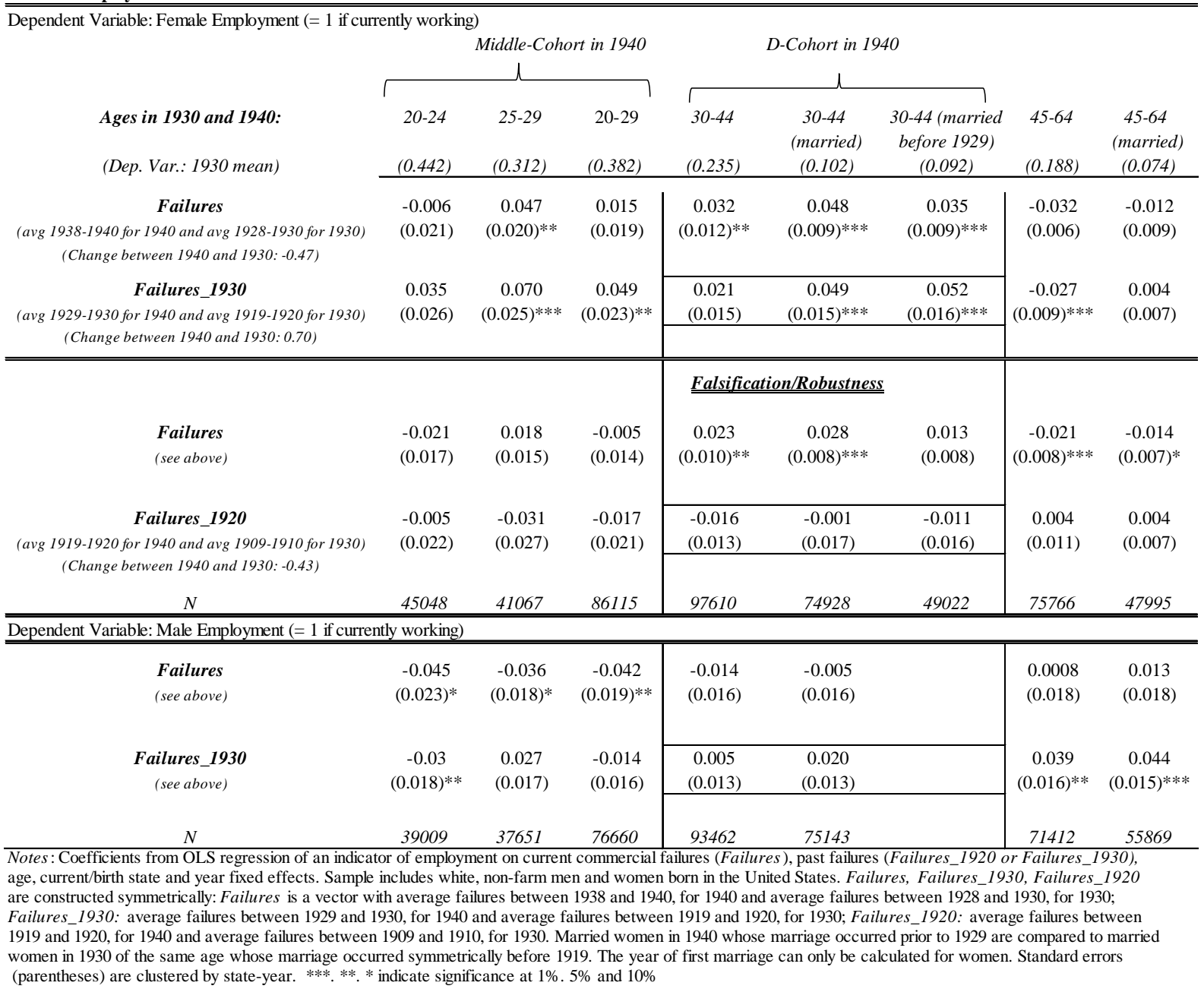

variable an indicator for whether the individual reports having a gainful occupation. This analysis, therefore, is not strictly comparable to the previous one. Despite this, we obtain qualitatively similar results: the Great Depression drew into the labor market young married women from the D-cohort. The consistency of the employment patterns for the particular cohort in both panels and in relation only to the Great Depression further confirms the robustness of the findings obtained so far.

\subsection{Great Depression, Economic Conditions and Female Labor Supply: 1940-1950, 1940-1960}

In this section we pool data from the 1940 and 1950 and the 1940 and 1960 censuses to examine the long-term effects of the Great Depression on labor supply. We estimate equations of the following general form:

$$
y_{i t s}=\alpha_{o}+\alpha_{1} \text { Mobrate }_{s}+\alpha_{2} \text { Failures }_{t s}+\alpha_{3} \text { Failures_1930 }_{s t-k}^{d}+\alpha_{4} Z_{1940, s}+\varphi_{i a}+f_{s}+g_{t}+\varepsilon_{i t s}
$$

$y_{i t s}$ is an indicator for whether a woman $i$ in state $s$ is employed at time $t$ ( $t=1940,1950$ or 1940, 1960). In a second set of regressions we use as dependent variable the log of real 
weekly wages. Equation (3) is a slightly modified version of (2) augmented with controls for WWII and 1940 covariates. Following Acemoglu et al. (2004) and Goldin and Olivetti (2013), we measure the labor supply effects of WWII using the share of registered men 18-44 years old who were drafted or enlisted in the war in a given state (Mobrate). We further control for the 1940 state share of men who were farmers, non-white, and for the average male education in 1940 (vector $Z_{1940}$ ). These regressors have been shown to be significant determinants of mobilization rates across states (Acemoglu et al., 2004). All state covariates as well as individual age and its square (vector $\varphi_{i a}$ ) are interacted with a year dummy to allow for the effects of these controls to vary over time. $f_{s}$ and $g_{t}$ are state of residence/birth and year fixed effects. As before, we restrict our analysis to white non-farm men and women born in the US and not residing in group quarters.

To control for changes in current economic conditions we include Failures s, $_{\text {, while to }}$ capture the potentially lasting impact of the Great Depression we include as regressor $k$-year lagged failures (Failures_1930 ${ }_{\text {st-k }}^{d}$ ). Again, we construct these variables symmetrically. For contemporary failures (Failures) we use the average failure rate over the previous three years: 1938 through 1940 if $t=1940,1948$ through 1950 if $t=1950$ in the 1940-1950 panel, and 1958 through 1960 if $t=1960$ in the 1940-1960 panel. For failures during the Great Depression (Failures_1930 ${ }_{s t-k}$ ) we use average failures from 1920 to 1923 if $t=1940$ and from 1930 to 1933 (core depression years) if $t=1950$ in the 1940-1950 panel. In the 1940-1960 panel, we use average failures from 1910 to 1913 for $t=1940$ and from 1930 to 1933 for $t=1960$. This way we allow for 1940 work (or wages) to be symmetrically affected by events as far removed as the Great Depression is to 1950 (lag $k=20$ ) or to 1960 (lag $k=30){ }^{11}$

Tables 3 and 4 report estimates of eq. (3) using the 1940-1950 and 1940-1960 crosssections. As before, we examine the differential impact of the variables of interest on women who were in the same age bracket in 1950 (1960) and in 1940. At the top of each age bracket we report the cohorts these women belong to when they are in the indicated age bracket in 1950 (1960).

Table 3 presents results for employment. The 1940-1950 estimates show that in states with more failures during the Great Depression, 40 to 54 years old ever married women worked significantly more in 1950 than in 1940. For women 45 to 54 years old the results

\footnotetext{
${ }^{11}$ However, 1940 itself could be affected by the Great Depression. We chose 1940 as the base year throughout because for the fertility analysis it precedes WWII and is also characterized by low births (also see Section 2 for a justification). To control for the potential impact of the Great Depression on the base year, we run specification (3) augmented by the average failures between 1930 and 1933 interacted with a 1940 year dummy. In all cases this additional regressor is not significant and the results are similar to what we report here. As a robustness check we also estimate the same regressions using the 1920-1950 and 1920-1960 panels. The results are again similar to the ones reported in the main analysis, and the effects of the Great Depression are even stronger in the 1920-1960 sample. Results are available upon request.
} 
extend to all women, independently of their marital status. In contrast to the $D$-cohort, young women in the B-cohort (20 to 24 years old) were less likely to work in states with worse past economic conditions. The 30 to 39 year-olds, our Middle-cohort, for which we found an increased labor market presence linked to the Great Depression between 1930 and 1940, is instead not responsive to changes in economic conditions, current or past. Interestingly, women 20 to 24 years old are only affected by past but not by current conditions. This, along with the fact that these young women were not of working age during the Great Depression, suggests that the $D$-cohort could have crowded them out but not vice versa.

The right side of Table 3 reports estimates for the 1940-1960 panels. The most striking result is the similarity in the exit/entry pattern for young/old cohorts of women across the two panels. If anything, this pattern is stronger in 1960, as is also the link to the Great Depression. For the D-cohort, now 50 to 64 years old, this link extends to the 50 to 54 years old group for which we found no significant effects in the 1940-1950 samples (unless we focused on ever married women). Again this entry does not extend to the Middle-cohort. Instead, women in the B-cohort (20 to 39 years old), worked significantly less in states with more failures during the Great Depression. Relative to the 1940-1950 results, several cohorts also respond to improvements in contemporaneous economic conditions. These responses reinforce the impact of the Great Depression as both increase the work propensity of the D-cohort while they decrease it for women in the B-cohort. ${ }^{12}$

Regarding the impact of WWII, the estimates do not support the hypothesis that the latter led to a crowding-out of young cohorts. This would imply a decrease in their share working, while in both panels, 20 to 24 and 30 to 39 years old women were more likely to work in states with higher mobilization. Also, in both panels we find no significant link between the increased presence of the D-cohort in the labor market in the 1940s or 1950s and WWII mobilization. ${ }^{13}$

In the lower panel of the table we estimate eq. (3) but instead of commercial failures during the Great Depression, we use the state share of women in the D-cohort in the labor force in 1930 interacted with a year dummy. If the work response of the B-cohort to the Great Depression is due to the labor market behavior of the $D$-cohort, we would expect its

\footnotetext{
${ }^{12}$ In an unreported analysis but available upon request we studied what the patterns documented in Table 3 imply in terms of occupations. Simple summary statistics suggest that the D-cohort occupied both blue-collar and white-collar jobs at all times and at proportions that remain remarkably stable over time (roughly 30\% in blue-collar (operatives \& services) and 50\% in white-collar (professional/managerial \& clerical) jobs. Among the white-collar occupations, $40 \%$ of these women were present in clerical jobs. Using a multinomial logit to model the presence of women across occupations, and where "out of the labor force" is our excluded category, we find that this opposite exit/entry pattern is observed most strongly in operatives as well as in clerical jobs. We also find similar patterns in professional/managerial jobs and services.

${ }^{13}$ In Appendix Table A2, we examine the sensitivity of our estimates of interest, including the estimate of "mobrate", in the $1940-1960$ panels to different model specifications (addition/omission of covariates) and sample considerations (women of all nativities, races, farm statuses).
} 
employment share in 1930 to produce effects similar to the "Failures_1930" variable in the baseline regression. The results corroborate our hypothesis: the higher the share of the $D$ cohort working in 1930, the higher the share of these same women working in 1950 (1960) and the lower the share of the B-cohort working in 1950 (1960). There are instead no effects for the Middle-cohort, which is also what we found with Failures_1930. The similarity of the results by cohort across the two panels is remarkable: they indicate a robust and persistent response pattern that is cohort-specific, still significant three decades after the 1929 Crash.

At the bottom of Table 3 we report results for men. In 1950, men in the D-cohort tend to work less in states where the Great Depression was more severe. This is consistent with an added worker effect interpretation or possibly with older women crowding-out older men in the labor market. While it is possible that women in the D-cohort who entered during the Great Depression acquired experience and work attachment that led them to also crowd-out men in the D-cohort, these effects are not as important as the ones found for young women and do not persist till 1960. Young men instead have a higher work propensity in states with improving contemporaneous economic conditions, which is consistent with them having the prerequisite for marriage and family life at an earlier age than men in the previous decade.

In the Appendix (Table A4) we present additional robustness checks for the 19401960 panels. First, we examine the impact of pre-1929 Crash conditions (Failures_1920) and find significant effects only in relation to conditions that date back to the Great Depression. Second, instead of the participation of women in the D-cohort in 1930, we use the participation of men in the same age bracket in 1930. Similarly, we find no significant effects.

Next, we turn our attention to wages. The entry/exit work patterns we have documented could be consistent with a demand and/or supply shift. Exploring the link between past conditions and contemporaneous wages could allow us to gain more insight about the nature of this shift. Table 4 reports results from the estimation of specification (3) for the 1940-1950 and 1940-1960 samples, when the dependent variable is the log of real weekly wages. ${ }^{14}$ We present estimates produced using the Heckman two-step procedure in Appendix Table A3. The latter will account for possible selection of women in the labor force. Our exclusion restriction is the number of own children present in the household.

The estimates convey three main messages. First, the most striking observation is the negative and significant estimate associated with failures in the 1930s for nearly all women in 1950 and 1960. When we use the share of women in the D-cohort working in 1930 interacted

\footnotetext{
14 The censuses prior to 1940 do not report wages and therefore a similar analysis for these years is not feasible. We restrict attention to respondents who worked more than 26 weeks in the previous year in order to obtain a sample of individuals that display some level of attachment to the labor market. Our results, however, go through even in the absence of this restriction (see Table A3).
} 
with a year dummy, we find similar results. These results are consistent with the hypothesis that the channel via which the Great Depression decreased female wages was an outward shift in the labor supply of women in the D-cohort.

Improvements in current economic conditions either do not significantly affect older cohorts, or decrease their wages in 1950. This suggests that the entry of the D-cohort in the labor market was not due to a labor demand shift driven by contemporaneous labor market shortages. If the labor demand for older women had shifted out to compensate for the exit of the younger that choose to form families, in a reverse causality sense, we would have expected some upward pressure on their wages in relation to changes in current economic conditions.

Second, in 1950 the wages of 20 to 24 years old women were subject to two opposite forces: a decrease due to conditions in the early 1930s and an increase due to the current 
economic boom. However, the quantitative impact of the Great Depression on their wages was more than twice as important as that due to improving current conditions. In 1960, the positive impact of current conditions becomes more relevant; possibly starting to reflect the effect of the retirement of the older cohort on labor markets. ${ }^{15}$

Third, the Heckman-corrected estimates further confirm that the uniformly negative effect of past conditions on current wages is not due to selection. Such a selection would occur if, for instance, the Great Depression drew in the labor market women with "worse" unobservable characteristics, possibly employed in lower-skill, more "brawn"-type occupations. In response, women with "better" unobservable characteristics would drop-out of the workforce. This selection mechanism could manifest as a decrease in women's wages, conditional on their observable characteristics. Thus, the changing composition in the female workforce linked to the Great Depression could in part or entirely explain our finding of lower wages decades after the 1929 Crash in the OLS regressions. Our results show, however, that, although there has been negative selection in the workforce across all cohorts of women entering in 1950 and 1960, this selection neither significantly alters our previous findings of a persistent wage decline linked to the Great Depression nor contradicts our interpretation of a labor supply shift. In fact, the adjusted estimates suggest an even stronger effect of the Depression in lowering contemporaneous wages for women in all age groups. Our findings are consistent with Mulligan and Rubinstein (2008), who also uncover a negative selection in the female workforce in the 1970s and a reversal later on in the 1980s. Our findings suggest that this negative selection predated the 1970s.

To summarize, we have presented a series of newly documented facts that highlight the pervasive role of the Great Depression on labor markets. This event drew into the workforce young married women, 20 to 34 years old at the time of the 1929 Crash (D-cohort), likely via an added worker effect. Their entry, persistently linked to the Depression and reinforced by the subsequent economic boom, was remarkably sustained in the 1940s and 1950s. It also led to a decline in the wages of all women, including the very young. We interpret these findings as supportive of a labor supply shift for the $D$-cohort that crowded-out younger women. The entry of the D-cohort is not surprising given the age of these women at the time of the Crash. Their husbands may have been unemployed for long periods in the 1930s and their salary may have suffered permanently; they may have lost homes with mortgages, businesses or savings. Sufficiently large wealth and income losses could have

\footnotetext{
${ }^{15}$ When we performed the same wage analysis for men as for women, we found no significant link related to current or past conditions.
} 
permanently shifted out labor supply. ${ }^{16}$

\begin{tabular}{|c|c|c|c|c|c|c|c|c|c|c|}
\hline \multirow[b]{3}{*}{$\begin{array}{l}\text { Ages in } 1940 \text { and } 1950 \text { (left section): } \\
\text { Ages in } 1940 \text { and } 1960 \text { (right section): }\end{array}$} & \multicolumn{5}{|c|}{ Panel 1940-1950 } & \multicolumn{5}{|c|}{ Panel 1940-1960 } \\
\hline & \multicolumn{2}{|c|}{ B-Cohort in 1950} & $\begin{array}{c}\begin{array}{c}\text { Middle- } \\
\text { Cohort in } 1950\end{array} \\
\end{array}$ & \multicolumn{2}{|c|}{ D-Cohort in 1950} & \multicolumn{3}{|c|}{ B-Cohort in 1960} & \multirow{2}{*}{$\overbrace{40-49}^{\begin{array}{c}\text { Middle- } \\
\text { Cohort in } 1960\end{array}}$} & \multirow{2}{*}{$\overbrace{50-64}^{\begin{array}{c}\text { D-Cohort } \\
\text { in } 1960\end{array}}$} \\
\hline & $20-24$ & $25-29$ & $30-39$ & $40-54$ & $45-54$ & $20-24$ & $25-29$ & $30-39$ & & \\
\hline Mobrate & $\begin{array}{l}-0.644 \\
(0.421)\end{array}$ & $\begin{array}{l}-0.683 \\
(0.426)\end{array}$ & $\begin{array}{c}0.386 \\
(0.367)\end{array}$ & $\begin{array}{l}-0.690 \\
(0.553)\end{array}$ & $\begin{array}{c}0.337 \\
(0.883)\end{array}$ & $\begin{array}{c}-1.152 \\
(0.353)^{* * *}\end{array}$ & $\begin{array}{l}-0.467 \\
(0.391)\end{array}$ & $\begin{array}{c}-0.968 \\
(0.326)^{* * *}\end{array}$ & $\begin{array}{c}-1.718 \\
(0.662)^{* *}\end{array}$ & $\begin{array}{l}-1.351 \\
(0.819)\end{array}$ \\
\hline $\begin{array}{c}\text { Failures } \\
\text { (see Table 3) }\end{array}$ & $\begin{array}{c}-0.099 \\
(0.033)^{* * *}\end{array}$ & $\begin{array}{c}0.074 \\
(0.026)^{* * *}\end{array}$ & $\begin{array}{l}-0.009 \\
(0.039)\end{array}$ & $\begin{array}{c}0.025 \\
(0.031)^{* *}\end{array}$ & $\begin{array}{c}0.005 \\
(0.055)\end{array}$ & $\begin{array}{c}-0.171 \\
(0.045)^{* * *}\end{array}$ & $\begin{array}{l}-0.054 \\
(0.037)\end{array}$ & $\begin{array}{l}-0.025 \\
(0.043)\end{array}$ & $\begin{array}{l}-0.004 \\
(0.050)\end{array}$ & $\begin{array}{c}0.101 \\
(0.091)\end{array}$ \\
\hline $\begin{array}{c}\text { Failures_1930 } \\
\text { (see Table 3) }\end{array}$ & \begin{tabular}{|c|}
-0.196 \\
$(0.038) * * *$ \\
\end{tabular} & $\begin{array}{c}-0.110 \\
(0.037)^{* * *}\end{array}$ & $\begin{array}{c}-0.063 \\
(0.035)^{*}\end{array}$ & $\begin{array}{c}-0.140 \\
(0.050)^{* * * *}\end{array}$ & $\begin{array}{c}-0.197 \\
(0.067) * * *\end{array}$ & $\begin{array}{c}-0.063 \\
(0.036)^{*}\end{array}$ & $\begin{array}{c}-0.082 \\
(0.042)^{*}\end{array}$ & $\begin{array}{c}-0.075 \\
(0.027)^{* * *}\end{array}$ & $\begin{array}{c}-0.183 \\
(0.057)^{* * *}\end{array}$ & $\begin{array}{l}-0.072 \\
(0.081) \\
\end{array}$ \\
\hline $\begin{array}{c}\text { Failures } \\
\text { (see Table 3) }\end{array}$ & $\begin{array}{c}-0.122 \\
(0.036)^{* * *}\end{array}$ & $\begin{array}{c}0.081 \\
(0.034)^{* *}\end{array}$ & $\begin{array}{l}-0.042 \\
(0.039)\end{array}$ & $\begin{array}{l}-0.026 \\
(0.033)\end{array}$ & $\begin{array}{l}-0.047 \\
(0.048)\end{array}$ & $\begin{array}{c}-0.165 \\
(0.049)^{* * *}\end{array}$ & $\begin{array}{l}-0.039 \\
(0.041)\end{array}$ & $\begin{array}{l}-0.037 \\
(0.046)\end{array}$ & $\begin{array}{l}-0.061 \\
(0.054)\end{array}$ & $\begin{array}{c}0.029 \\
(0.100)\end{array}$ \\
\hline $\begin{array}{l}1930 \text { Share women 20-34 yrs old } \\
\left.\text { in labor force ( } L F W_{-} 1930\right)\end{array}$ & \begin{tabular}{|c|}
-0.523 \\
$(0.172)^{* * *}$
\end{tabular} & $\begin{array}{l}-0.021 \\
(0.178) \\
\end{array}$ & $\begin{array}{c}-0.554 \\
(0.198)^{* * *} \\
\end{array}$ & $\begin{array}{c}-0.953 \\
(0.273)^{* * *} \\
\end{array}$ & $\begin{array}{c}-1.005 \\
(0.383)^{* *} \\
\end{array}$ & $\begin{array}{l}-0.102 \\
(0.187) \\
\end{array}$ & $\begin{array}{l}-0.054 \\
(0.213) \\
\end{array}$ & $\begin{array}{c}-0.421 \\
(0.231)^{*} \\
\end{array}$ & $\begin{array}{c}-1.384 \\
(0.255)^{* * *} \\
\end{array}$ & $\begin{array}{c}-1.280 \\
(0.347)^{* * *} \\
\end{array}$ \\
\hline$N$ & 8956 & 7268 & 11172 & 12148 & 7297 & 19320 & 14766 & 30888 & 33819 & 31325 \\
\hline
\end{tabular}

Notes: Dependent variable: log weekly wages. Worked more than 26 weeks in previous year. For details see footnote to Table 3.

\section{A Measure of Crowding-Out and Crowding-In}

As Figure 1 shows, in no other previous decades had so many older women been part of the workforce as in the 1940s and 1950s. Relative to the past, there is a sharp change between 1940 and the later years. Our analysis traces the entry of these women back to the Great Depression and the subsequent economic recovery. No employment link is found to WWII. While these effects were confined to married women in this cohort until 1940, they became pervasive in the later decades.

To assess the impact of the work behavior of the $D$-cohort on yearly and completed fertility, we proceed in three steps. First, we construct state measures that summarize our crowding-out/crowding-in hypothesis as a function of the life-cycle labor supply changes of the $D$-cohort. Second, we show that these measures can successfully predict the employment behavior of women in the B-cohort: relative to 1940 they work significantly less in 1960 and more in 1970. Third, we show that the same measures can predict a baby-boom in the 1950s and later on a baby-bust for the B-cohort. In line with the analysis of Section 3, our reference point for births also remains their level in 1940.

To motivate our first step, we provide a visual representation of the life cycle labor supply profile of the $D$-cohort. We also contrast it to the profiles of other contiguous cohorts,

\footnotetext{
${ }^{16}$ In separate work that is currently in progress, we examine plausible channels through which the Great Depression led to the persistent increase in the work propensity of the $D$-cohort in 1950 and 1960.
} 
Figure 4: Female Employment by Age (all white women)

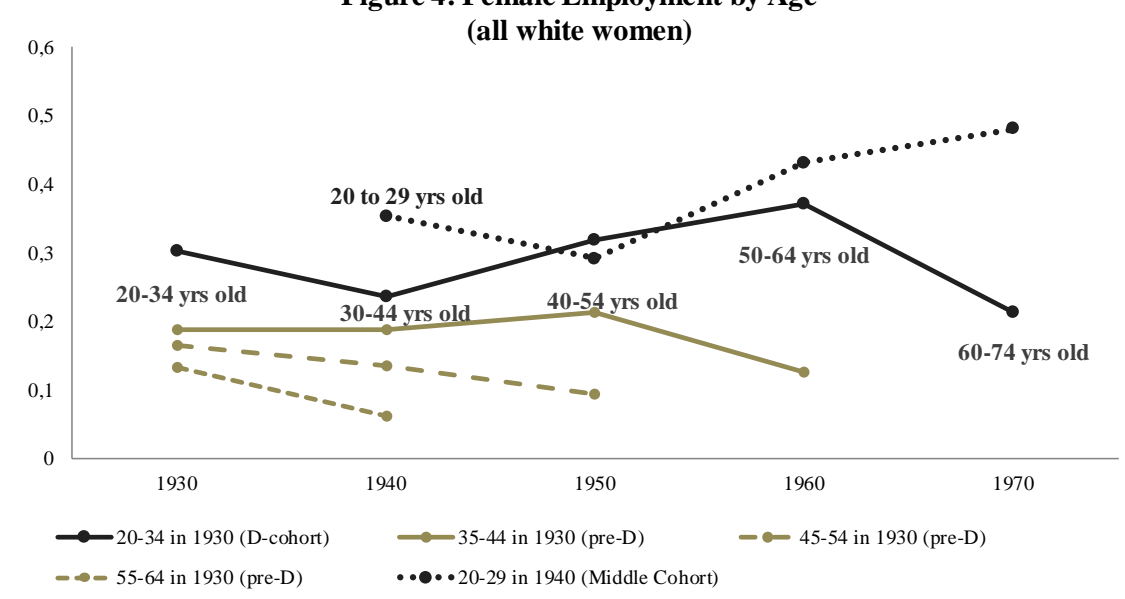

Figure 5: Female Employment by Age (white married women)

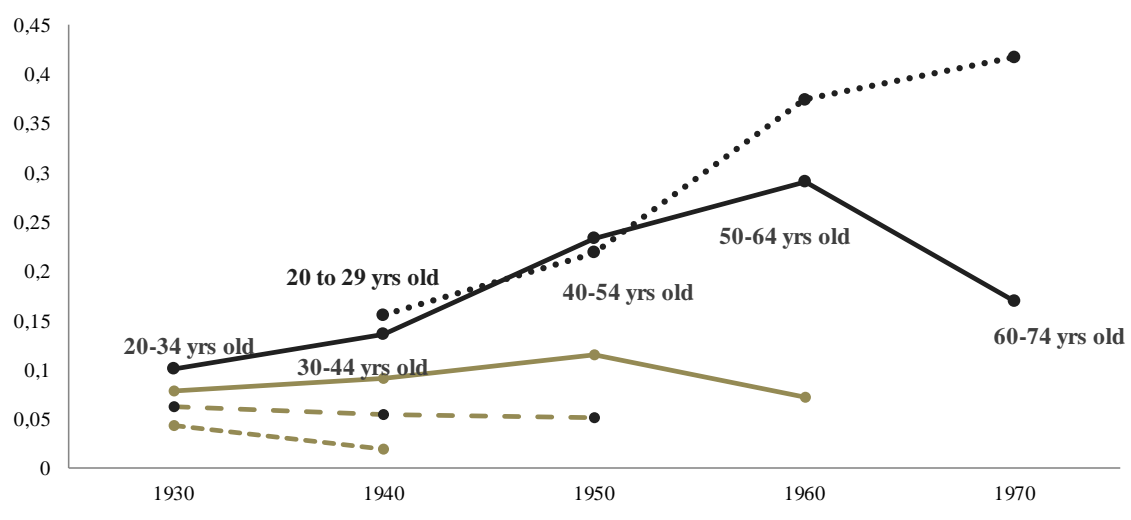

Figure 6: Employment Shares of the D-Cohort in the 1960s (CPS)

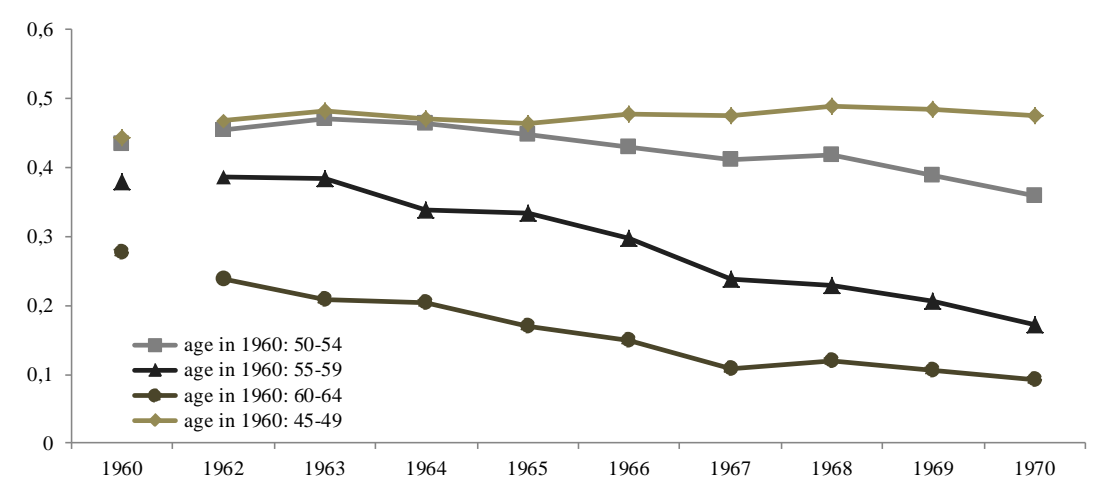

three older and one younger. These are summarized in Figures 4 (all women) and 5 (married). Between 1930 and 1940, overall fewer women in the D-cohort worked, while married women worked more in the spirit of the added worker effect. The year 1940 marks the beginning of their increased aggregate presence in the market, as all work more regardless of their marital status. Interestingly, the time-frame of the entry/exit of the D-cohort is the mirror image of the baby-boom/ bust. 
Figures 1 and 4 also illustrate two other important trends, on the basis of which we construct our measures. First, between 1930 and 1940, there is essentially only one cohort significantly exiting the labor market and hence freeing up positions for the new entrants. These are women 30 to 44 years old in 1940 (20 to 34 years old in 1930), our D-cohort. The labor market presence of older women remains instead roughly the same between 1930 and 1940 as older cohorts did not significantly re-enter the labor market after having had children. This means that the behavior of the $D$-cohort when young adequately describes the most important changes in the labor market in the 1930s. Second, in later decades this same $D$ cohort, when older, instead re-enters the workforce filling up positions and likely limiting opportunities for the new entrants. ${ }^{17}$ This suggests that the entire life-cycle labor supply of the $D$-cohort has the potential to affect work and fertility decisions of younger women over a period of several decades.

Our next task is to construct $C O$ and $C I$ measures reflecting these observations. Young entrants' perception of their market options comes from observing wages and other labor market indicators. The entry of the D-cohort in the 1940s and 1950s decreased wages and market opportunities for young women entering the workforce in the 1950s. In absence of data on wages prior to 1940 or other annual indicators of labor market tightness, we use statelevel changes across decades in the share of women in the D-cohort working to predict the market exit/entry of the younger cohorts. ${ }^{18}$ To predict the work (and births) of the B-cohort in the 1950s we use the change in the share of women in the D-cohort working between 1950 and 1940:

$$
C O_{1950}=\sum_{i=40}^{54} \text { work }_{s, i, 1950} / \sum_{i=40}^{54} \operatorname{pop}_{s, i, 1950}-\sum_{i=30}^{44} \text { work }_{s, i, 1940} / \sum_{i=30}^{44} \operatorname{pop}_{s, i, 1940}
$$

An increase in CO means that there were more women working in 1950 than in 1940. The larger $C \mathrm{O}_{1950}$, the bigger the increase in the share of women in the $D$-cohort entering in the1940s, the lower the wages and the fewer the labor market opportunities for the younger potential entrants.

To capture the impact of the retirement of the D-cohort we adopt a similar strategy and use the change in its work shares between 1960 and 1970:

\footnotetext{
${ }^{17}$ Aside from the D-cohort, women 30-39 years old in 1950 also enter the market in the 1950s. As discussed, however, in the robustness analysis of Section 5 (estimates presented in the Appendix), the impact of the D-cohort on fertility remains unaffected when considering the entry/exit into/from the market of other cohorts.

${ }^{18}$ In a two-period world, with both young $\left(\mathrm{N}_{\mathrm{t}}^{\mathrm{y}}\right)$ and old women $\left(\mathrm{N}_{\mathrm{t}}^{\mathrm{o}}\right)$ in the workforce, young women entering into the labor market are not directly competing with the older who entered in the previous period $\left(\mathrm{N}_{\mathrm{t}-1}^{\mathrm{r}}\right)$, as the latter have more experience. Rather they compete more closely with older women who are entering for the first time or re-entering after a long absence $\left(\mathrm{N}_{\mathrm{t}}^{\mathrm{o}}\right.$ - $\left.\mathrm{N}_{\mathrm{t}-1}^{\mathrm{o}}\right)$. Using the change over a decade in the share of older women working $\left(\mathrm{N}_{\mathrm{t}}^{\mathrm{o}}-\mathrm{N}_{\mathrm{t}-1}^{\mathrm{o}}=\right.$ older new entrants) rather than the share of all older women working $\left(\mathrm{N}^{\mathrm{o}}{ }_{\mathrm{t}}\right)$, which also includes $\mathrm{N}_{\mathrm{t}-1 \text {, captures this idea. }}^{\mathrm{o}}$
} 


$$
C I_{1970}=\sum_{i=50}^{64} \text { work }_{i, 1960} / \sum_{i=50}^{64} \text { pop }_{i, 1960}-\sum_{i=60}^{74} \text { work }_{i, 1970} / \sum_{i=60}^{74} \operatorname{pop}_{i, 1970}
$$

As the $D$-cohort retires, we expect its work share in 1970 to decline and the $C I$ measure to increase. The higher its retirement, the more work opportunities should arise for younger women and the higher the likelihood that they will enter the market thus reducing births. Figure 6 provides a more detailed description of the retirement process of the $D$-cohort using annual micro data on employment from the Current Population Survey (March CPS). ${ }^{19}$ Within the $D$-cohort we distinguish three groups. The oldest will likely retire in the early part of the 1960s, the youngest in the later part. The figure indeed shows a significant decline in the work shares of the oldest cohorts in the early 1960s, when we start to observe a reversal of the baby-boom. We also report the work shares of younger women, 45 to 49 years old in 1960, who as can be seen do not retire in the 1960s.

Finally, to predict the work patterns (and births) of the B-cohort in 1940 we use the change in the share of the $D$-cohort working between 1940 and 1930:

$$
C O_{1940}=\sum_{i=30}^{44} \text { work }_{s, i, 1940} / \sum_{i=30}^{44} \operatorname{pop}_{s, i, 1940}-\sum_{i=20}^{34} \text { work }_{s, i, 1930} / \sum_{i=20}^{34} \operatorname{pop}_{s, i, 1930}
$$

There is a slight asymmetry between the $C_{1970}$ and the $C O_{1950}$ measures. The $C_{1950}$ uses changing work shares between 1940 and 1950 to predict crowding-out and births in each year in the 1950s, while the $C I_{1970}$ uses actual retirement occurring between 1960 and 1970 . The $C O_{1950}$ allows a separation between the (past) entry of the $D$-cohort and the (future) births of the $B$ cohort, which should reduce the possibility of reverse causality or simultaneity between the decision of the old and of the young. A simultaneity issue would arise if we were to use as our measure the change in the 1950-1960 work shares of the D-cohort, the period when the babyboom is observed. On the other hand, between 1950 and 1960, the $D$-cohort kept entering into the labor market (Figures 4 and 5). This entry cannot predict their retirement a decade later. For this reason, we need to use the change in their employment between 1960 and 1970, over which period most of the $D$-cohort actually retired. Since retirement decisions are mostly driven by age, we feel that there is less of an endogeneity issue, or possible reverse causality, in approximating their retirement with the change in their work shares between 1960 and 1970.

Before using these measures to assess their impact on births, we examine if they can predict changes in the share of the B-cohort working between 1940-1960 and 1940-1970. This

\footnotetext{
${ }^{19}$ The first cross-section became available in 1962. Information on 1960 employment shares is computed from the 1960 IPUMS.
} 
is the channel via which we hypothesize that the $D$-cohort should affect the fertility of women in the B-cohort. For the panels 1940-1960, we estimate:

$$
y_{i t s}=\beta_{o}+\beta_{1} \text { Mobrate }_{s}+\beta_{3} C O_{\text {st }}+\beta_{5} Z_{1940, s}+\varphi_{i a}+f_{s}+g_{t}+\varepsilon_{i t s}
$$

For the panels 1940-1970, we instead include the crowding-in measure:

$$
y_{i t s}=\beta_{o}+\beta_{1} \text { Mobrate }_{s}+\beta_{3} C l_{\mathrm{st}}+\beta_{5} Z_{1940, \mathrm{~s}}+\varphi_{\text {ia }}+f_{\mathrm{s}}+g_{t}+\varepsilon_{i t s}
$$

The dependent variable is 1 if a woman is currently working. CO and CI are our measures of crowding-out and crowding-in respectively. ${ }^{20}$ The other variables have been defined previously. We don't include $C O$ and $C I$ in the same regression because they will be highly correlated as they summarize the behavior of the same cohort at different points in time. The estimates presented in Table 5 show that the entry of the $D$-cohort into the labor market between 1940 and 1950 predicts a decrease in the share of young women working in 1960 . Between 1940 and 1970, instead, the crowding-in term induces the opposite effect: as the $D$ cohort exits, significantly more young women enter the labor market. Therefore, the measures devised capture the labor market changes we have hypothesized.

Table 5: Crowding-Out, Crowding-In \& Labor Supply of Young Women (1940-1960, 1940-1970)

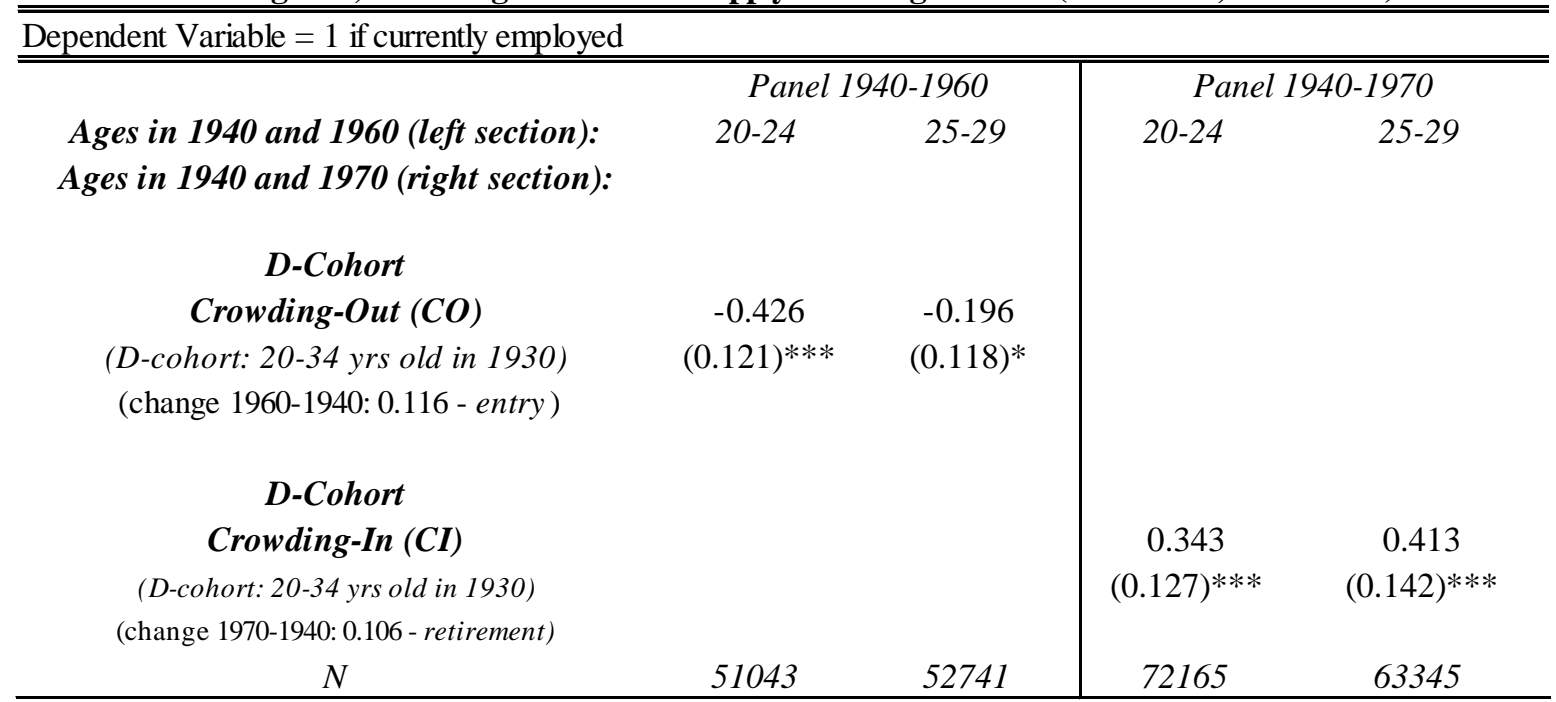

Notes: Coefficients from OLS regression of work indicator on WWII mobilization rates, age, share of males in 1940 that are nonwhites, share of males in 1940 that are farmers, 1940 average male education, state and year fixed effects. Sample includes white, non-farm women born in the United States. Standard errors (parentheses) clustered by stateyear. $* * *, * *, *$ indicate significance at $1 \%, 5 \%$ and $10 \%$ respectively.

As a final related remark, Figure 4 shows there are few cohorts which could rival or diminish the impact of the D-cohort. The Middle-cohort is evidently the most important, but

\footnotetext{
${ }^{20}$ In the 1940-1970 panel, we use $C I_{1940}=-C O_{1940}$ for the base year.
} 
Figure 7: Change in Births to Women 20 to 24 years old (averages by state)

Work Measure 1940-1960: Crowding-Out (horizontal axis) Change in Births of 20 to 24 yrs old 1940-1960 (vertical axis)

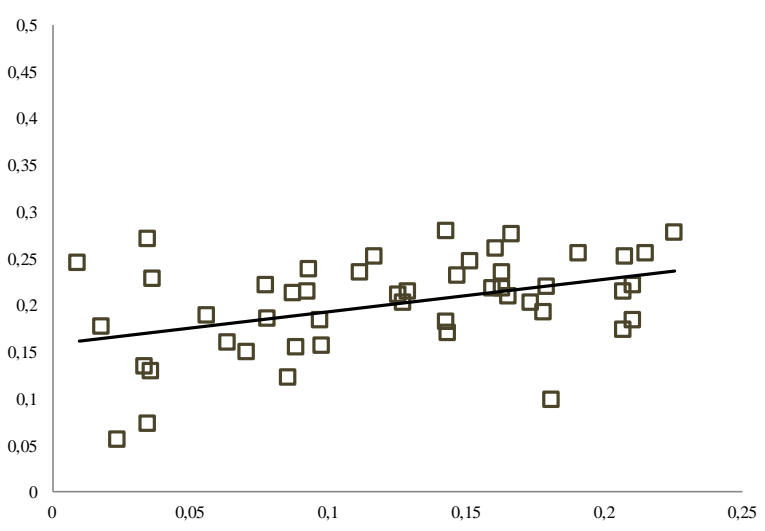

Work Measure 1940-1970: Crowding-In (horizontal axis)

Change in Births of 20 to 24 yrs old 1940-1970 (vertical axis)

0,5

0,4

0,3

0,2

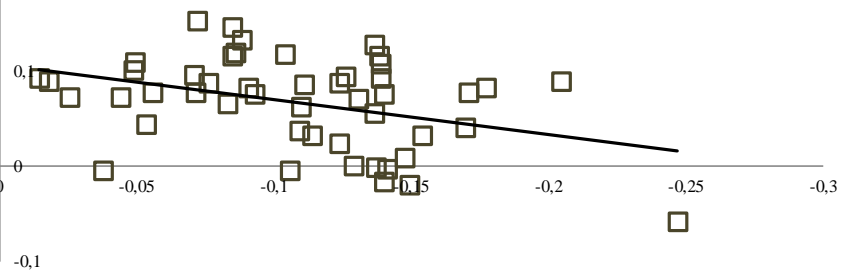

Figure 8: Change in Completed Fertility of Women 25 to 29 years old (averages by state)

Work Measure 1940-1960: Crowding-Out (horizontal axis) Change in Comple ted Fertility of 25 to 29 yrs old 1940-1960 (vertical axis)

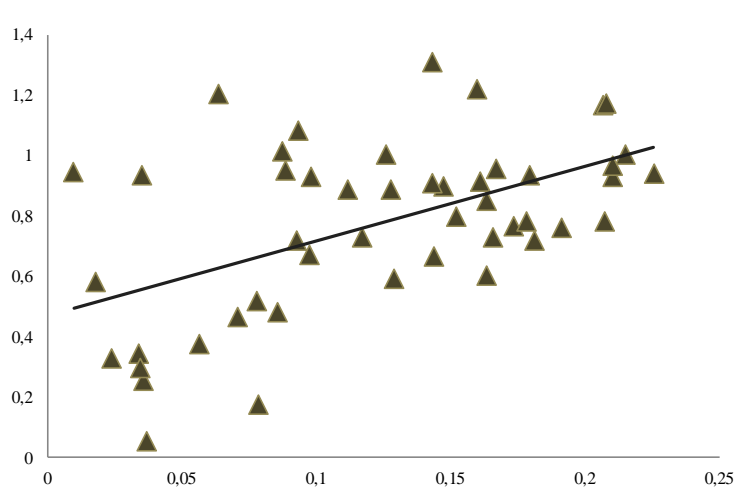

Work Measure 1940-1970: Crowding-In (horizontal axis)

Change in Completed Fertility of 25 to 29 yrs old 1940-1970 (vertical axis)

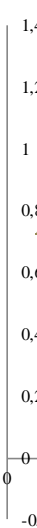

its role in the 1950s is more difficult to assess as it exited the labor market between 1940 and 1950 and we don't have data allowing us to pinpoint the exact timing of its re-entry. The results from Table 3 (1940-1960), however, suggest that independently of the timing, its entry in the 1950s was neither linked to the Great Depression nor to WWII but instead to concurrent economic recovery. Moreover, although this cohort worked more in the 1950s, its work pattern cannot explain the decline in births in the 1960s as these women retired much later. Overall, while we do not dismiss the fact that other cohorts could have also affected labor markets, our thesis is that the $D$-cohort had a major impact. We later show that when considering all other potential cohorts entering or exiting, this is the only one capable of generating a baby-boom in the 1950s and a bust in the 1960s. 
Our last task is to examine whether the constructed measures have the potential to explain the fertility boom/bust. While in the next section we formally estimate models that allow us to answer this question, here we provide a visual cue of this relationship. In Figure 7, we plot state-level averages for the crowding-out ( $\mathrm{CO}_{1950}-\mathrm{CO}_{1940}$, left side) and the crowdingin ( $C I_{1970}-C I_{1940}$, right side) measures against the change in the state average number of births of 20 to 24 years old women between 1940 and 1960 (left side) and between 1940 and 1970 (right side). In Figure 8 we plot both measures against the change in the state average cumulative fertility of women 25 to 29 years old over the same periods. Women in this age bracket in 1960 had the highest completed fertility during the baby-boom, while women in the same age bracket in 1970 were responsible for the baby-bust and had an average of only 2.57 children. In line with our hypothesis, the scatter plots show that there is a strong positive fertility link with the entry of the $D$-cohort into the labor market (figures on the right) and that this link becomes negative with its retirement (figures on the right).

\section{Crowding-out, Crowding-in and Yearly Births}

In this section we formally test whether the work behavior of the $D$-cohort can explain the baby-boom and the subsequent baby-bust. For this, we re-estimate equations (4) and (5) using as dependent variable an indicator of whether a woman gave birth in a particular year. When we use the panels 1940-1960, we compare births in 1950, 1951, 1952,.., 1959 to births in 1940 for women in the same age bracket. ${ }^{21}$ When we use the panels 1940-1970, we instead compare births in 1960, 1961, 1962,..., 1969 to births in 1940.

Table 6 presents the results for births to women who were 20 to 29 years old throughout the 1950s. In addition to the crowding-out measure (CO) we also include WWII mobilization rates and previous year commercial failures to reflect economic conditions at the time of conception. These are also interacted with a 1960 dummy to allow for differential effects over time. For women 20 to 24 years old in the 1950s, the group that on average produced the most yearly births, the results are striking. In all years, the crowding-out measure predicts substantially more births relative to 1940 and in all years, but one, the effects are statistically significant at the $1 \%$ level. The crowding-out is also quantitatively important. Let's take the example of women 20 to 24 years old in 1959. The estimated coefficient is 0.466 and the change in the crowding-out measure between 1940 and 1960,

\footnotetext{
${ }^{21}$ In relation to the $\mathrm{CO}_{1950}$ measure, note that, while the latter is symmetric in the sense of using the same time-lag to predict work patterns for younger women in 1940 and 1950, there is an asymmetry when we use this measure to predict the change in births between 1940 and the 1950s. Since we compare births in the 1950s with births in 1940, for births in the 1950s we use a less precise predictor of work behavior than for 1940. This is because we have employment data only every 10 years, and we do not have annual employment shares for years between 1950 and 1960. We show, however, in Table 6 that this measure can predict the change in young women's work behavior between 1940 and 1960 , thus likely making the entry of the $D$-cohort in the 1940 s a good predictor of their entry in the 1950 s.
} 
0.116 (entry). This means that the crowding-out from women in the $D$-cohort predicts, ceteris paribus, 67\% $\left(0.466^{*} 0.116 / 0.08\right)$ higher births in 1959 (the peak of the baby-boom) relative to 1940 (one of the pre-baby-boom lowest fertility levels). The effects are also significant in most years for women 25 to 29 years old in the 1950s. In 1958, for example, the crowding-out predicts $40 \%$ more births for this age group relative to 1940 . These effects are probably a lower bound as by construction our $C O$ measure refers to the entry of the $D$-cohort in the 1940s and not in the 1950s, a period that also witnessed an important increase in its presence in the labor market. Finally, WWII has modest positive effects on births in the medium-run.

Table 7 presents the results for births to women 20 to 29 years old in the 1960s. Our goal is to examine whether the retirement of the same cohort can explain declining births in the 1960s. The results are again striking. While the crowding-out measure predicted an increase, the crowding-in (retirement) measure predicts a decrease in births in almost every year for all age groups. Consider the year 1964 and women 20 to 24 years old. The coefficient is -0.256 and the change in the crowding-in measure between 1940 and 1970, 0.106 (exit). This means that, ceteris paribus, the retirement of the $D$-cohort predicts a $34 \%$ decrease in births relative to 1940 . Similar effects are obtained for women 25 to 29 years old. ${ }^{22}$

One could argue that isolating a cohort may induce effects that could disappear if one also included the concurrent entry and exit of other groups of women. To examine the robustness of the crowding-out/-in effects of the D-cohort, we perform several robustness checks by using broader sets of cohorts and isolating the role of the D-cohort. These are reported in the Appendix. In all cases, these exercises reinforce our hypothesis that the contribution of the $D$-cohort to the baby-boom and bust was measurable and unique.

In the first exercise, we consider all women (30 to 59 years old in 1950) whose entry or exit could have affected the labor market opportunities and the fertility of the B-cohort in the 1950s, and separately older women possibly retiring over the decade (60 to 64 years old in1950). Our estimates suggest that, even when we consider the net impact of all women entering and exiting, the effects we had previously found are not washed out. The overall net entry of these cohorts induces significant increases on the births of the 20 to 24 year-olds throughout the 1950s (see Tables A5 and A6). When subsequently we add our crowding-out term, as in Table 6, the aggregate measure (of entry/exit of the 30 to 59 year-olds) becomes largely insignificant, while the crowding-out by the $D$-cohort is significant and its quantitative

\footnotetext{
${ }^{22}$ In an unreported analysis, we conducted a robustness exercise, analogous to that of Tables 6 and 7 , but which uses 1910 as a base year. The advantage of this approach is that in 1910, the D-cohort was unborn and therefore we have a pre-D cohort and pre-Boom/Bust point of reference. We find that the D-cohort generates a boom in the 1950s and a bust in the 1960s. Although, this exercise predicts qualitatively the direction of the changes, it is less relevant from a quantitative point of view since in the base year fertility rates were even higher than during the 1950 s.
} 
Table 6: Annual Births (white women) \& "Crowding-Out": 1940-1960 Dependent Variable $=1$ if a birth took place in a given year (base year 1940)

\begin{tabular}{|c|c|c|c|c|c|c|c|c|c|c|c|}
\hline \multirow{2}{*}{$\begin{array}{l}\text { Age group: } 20-24 \text { years old } \\
\text { Age } 20 \text { to } 24 \text { yrs old in: } \\
\text { Age in 1940: } 20 \text { to } 24 \text { yrs old }\end{array}$} & \multicolumn{11}{|c|}{ average birth rate of 20-24 year olds in 1940: 0.08} \\
\hline & 1950 & 1951 & 1952 & 1953 & 1954 & 1955 & 1956 & 1957 & 1958 & 1959 & 1960 \\
\hline Mobrate & $\begin{array}{l}-0.170 \\
(0.107)\end{array}$ & $\begin{array}{l}-0.253 \\
(0.104)^{* *}\end{array}$ & $\begin{array}{c}-0.139 \\
(0.092)^{* *}\end{array}$ & $\begin{array}{l}-0.026 \\
(0.107)\end{array}$ & $\begin{array}{l}-0.07 \\
(0.112)\end{array}$ & $\begin{array}{c}-0.271 \\
(0.112)^{* *}\end{array}$ & $\begin{array}{c}-0.301 \\
(0.106)^{* * *}\end{array}$ & $\begin{array}{l}-0.423 \\
(0.101)^{* * *}\end{array}$ & $\begin{array}{c}-0.358 \\
(0.109)^{* * *}\end{array}$ & $\begin{array}{c}-0.498 \\
(0.104)^{* * *}\end{array}$ & $\begin{array}{l}-0.419 \\
(0.164)^{* * *}\end{array}$ \\
\hline $\begin{array}{c}\text { D-Cohort } \\
\text { Crowding-Out (CO) }\end{array}$ & $\begin{array}{c}0.194 \\
(0.081)^{* *} \\
\end{array}$ & $\begin{array}{c}0.215 \\
(0.078)^{* * *} \\
\end{array}$ & $\begin{array}{c}0.213 \\
(0.064)^{* * *} \\
\end{array}$ & $\begin{array}{l}0.226 \\
(0.073)^{* * *} \\
\end{array}$ & $\begin{array}{c}0.256 \\
(0.088)^{* * *} \\
\end{array}$ & $\begin{array}{c}0.339 \\
(0.089)^{* * *} \\
\end{array}$ & $\begin{array}{c}0.301 \\
(0.072)^{* * *} \\
\end{array}$ & $\begin{array}{c}0.330 \\
(0.095) * * * \\
\end{array}$ & $\begin{array}{c}0.358 \\
(0.082)^{* * *} \\
\end{array}$ & $\begin{array}{c}0.466 \\
(0.094)^{* * *} \\
\end{array}$ & $\begin{array}{c}0.376 \\
(0.137)^{* * *} \\
\end{array}$ \\
\hline$N$ & 62056 & 61183 & 60157 & 58760 & 58330 & 57731 & 57339 & 56724 & 56935 & 56364 & 56242 \\
\hline Age group: $25-29$ years old & & & & $a$ & ge virth & of 25-29 yea & olds in 1940: & 0.08 & & & \\
\hline $\begin{array}{c}\text { Age } 25 \text { to } 29 \text { yrs old in: } \\
\text { Age in 1940: } 25 \text { to } 29 \text { yrs old }\end{array}$ & 1950 & 1951 & 1952 & 1953 & 1954 & 1955 & 1956 & 1957 & 1958 & 1959 & 1960 \\
\hline Mobrate & $\begin{array}{l}0.250 \\
(0.114)^{* *}\end{array}$ & $\begin{array}{l}0.053 \\
(0.094)\end{array}$ & $\begin{array}{c}0.295 \\
(0.116)^{* *}\end{array}$ & $\begin{array}{c}0.092 \\
(0.115)\end{array}$ & $\begin{array}{l}0.130 \\
(0.131)\end{array}$ & $\begin{array}{l}0.139 \\
(0.126)\end{array}$ & $\begin{array}{c}0.126 \\
(0.142)\end{array}$ & $\begin{array}{l}-0.025 \\
(0.129)\end{array}$ & $\begin{array}{l}-0.010 \\
(0.108)\end{array}$ & $\begin{array}{c}0.114 \\
(0.122)\end{array}$ & $\begin{array}{l}-0.123 \\
(0.160)\end{array}$ \\
\hline $\begin{array}{c}\text { D-Cohort } \\
\text { Crowding-Out (CO) }\end{array}$ & $\begin{array}{c}0.14 \\
(0.073)^{*} \\
\end{array}$ & $\begin{array}{c}0.204 \\
(0.074)^{* * *} \\
\end{array}$ & $\begin{array}{c}0.072 \\
(0.100) \\
\end{array}$ & $\begin{array}{c}0.277 \\
(0.081)^{* * *} \\
\end{array}$ & $\begin{array}{c}0.245 \\
(0.111)^{* *} \\
\end{array}$ & $\begin{array}{c}0.139 \\
(0.073)^{*}\end{array}$ & $\begin{array}{c}0.316 \\
(0.089)^{* * * *}\end{array}$ & $\begin{array}{c}0.221 \\
(0.105)^{* *} \\
\end{array}$ & $\begin{array}{c}0.274 \\
(0.083)^{* * *} \\
\end{array}$ & $\begin{array}{c}0.161 \\
(0.090)^{*}\end{array}$ & $\begin{array}{c}0.223 \\
(0.116)^{*} \\
\end{array}$ \\
\hline$N$ & 64797 & 65207 & 66216 & 58132 & 58562 & 59959 & 60985 & 61858 & 62841 & 64232 & 57926 \\
\hline rowding-Out Predictor: & & & mean 1940: & -0.05 & & mean 1960: & 0.066 & & change: & 0.116 & \\
\hline
\end{tabular}

Notes : Reported coefficients are OLS estimates from a regression of an indicator of whether a birth took place in a given year $(1940-1951,1940-1952, \ldots, 1940-1960$ with 1940 the year of reference). See also notes to Table 7.

Table 7: Annual Births (white women) \& "Crowding-In": 1940-1970

Dependent Variable $=1$ if a birth took place in a given year (base year 1940) Age group: 20-24 years old

average birth rate of 20-24 year olds in 1940: 0.08

Age 20 to 24 yrs old in:
Age in 1940: 20 to 24 yrs old

\begin{tabular}{lcccccccc}
1961 & 1962 & 1963 & 1964 & 1965 & 1966 & 1967 & 1968 & 1969 \\
& & & & & & & & \\
-0.041 & -0.090 & -0.199 & $-0,205$ & -0.288 & -0.267 & -0.196 & -0.181 & -0.203 \\
$(0.101)$ & $(0.103)$ & $(0.088)^{* *}$ & $(0.080)^{* *}$ & $(0.084)^{* * *}$ & $(0.091)^{* * *}$ & $(0.112)^{*}$ & $(0.097)^{*}$ & $(0.093)^{* *}$ \\
\hline-0.170 & -0.064 & -0.175 & -0.256 & -0.221 & -0.282 & -0.215 & -0.243 & -0.229
\end{tabular}

Mobrate

D-Cohort

Crowding-In (CI)

\begin{tabular}{|ccccccccc|}
\hline-0.170 & -0.064 & -0.175 & -0.256 & -0.221 & -0.282 & -0.215 & -0.243 & -0.229 \\
$(0.078)^{* *}$ & $(0.082)$ & $(0.070)^{* *}$ & $(0.069)^{* * *}$ & $(0.066)^{* * *}$ & $(0.076)^{* * *}$ & $(0.089)^{* *}$ & $(0.077)^{* * *}$ & $(0.080)^{* * *}$ \\
\hline
\end{tabular}

$N$

$\begin{array}{lllllllll}60254 & 62814 & 65415 & 67060 & 68090 & 70771 & 73371 & 74500 & 75700\end{array}$

Age group: 25-29 years old

Age 25 to 29 yrs old in:

Age in 1940: 25 to 29 yrs old

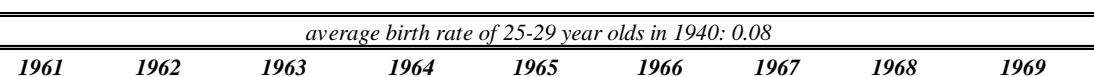

Mobrate

D-Cohort

Crowding-In (CI)

$N$

\begin{tabular}{|c|c|c|c|c|c|c|c|c|}
\hline $\begin{array}{c}0.076 \\
(0.124)\end{array}$ & $\begin{array}{c}0.186 \\
(0.113)^{*}\end{array}$ & $\begin{array}{c}0.049 \\
(0.123)\end{array}$ & $\begin{array}{c}0.184 \\
(0.120)\end{array}$ & $\begin{array}{c}0.169 \\
(0.100)^{*}\end{array}$ & $\begin{array}{c}0.387 \\
(0.120)^{* * *}\end{array}$ & $\begin{array}{l}-0.014 \\
(0130)\end{array}$ & $\begin{array}{c}0.205 \\
(0.112)^{*}\end{array}$ & $\begin{array}{c}0.090 \\
(0.104)\end{array}$ \\
\hline $\begin{array}{c}-0.295 \\
(0.088)^{* * * *}\end{array}$ & $\begin{array}{c}-0.235 \\
(0.088)^{* * *}\end{array}$ & $\begin{array}{c}-0.310 \\
(0.088)^{* * * *}\end{array}$ & $\begin{array}{c}-0.187 \\
(0.078)^{* *}\end{array}$ & $\begin{array}{c}-0.293 \\
(0.066)^{* * * *}\end{array}$ & $\begin{array}{c}-0.137 \\
(0.076)^{*}\end{array}$ & $\begin{array}{c}-0.312 \\
(0.076) * * *\end{array}$ & $\begin{array}{c}-0.164 \\
(0.070)^{* *}\end{array}$ & $\begin{array}{c}-0.268 \\
(0.072)^{* * *}\end{array}$ \\
\hline
\end{tabular}

Crowding-In (retirement) Predictor

$56926 \quad 56812 \quad 57314$

$58754-60056$

Notes : Reported coefficients are OLS estimates from a regression of an indicator of whether a birth took place in a given year (1940-1961, 1940-1962, ..., 1940-1969 with

1940 being the year of reference) on WWII mobilization rates and a measure of the change in work behavior of the $D$-cohort (named Crowding-Out in Table 6 and Crowding-In in Table 7). See text for a detailed definition of this variable. The "D-cohort" consists of women 20-34 years old in 1930. Other controls: age dymmies, 1940 share of men that are farmers, 1940 share of nonwhite men, average male education in 1940, state of residence and state of birth dummies, year fixed effects. All controls except the state and year dummies as well as the "crowding" variable are interacted with a year dummy. Sample includes white women born in the United States. Standard errors are clustered at the state of residence-year level. ***, **, * refer to $1 \%, 5 \%$ and $10 \%$ significance level respectively.

importance is not diminished by the inclusion of other cohorts.

For the panel 1940-1970 we consider a different robustness scheme (Tables A7 and A8). We use the same aggregate measure as for 1940-1960 but move it forward a decade to predict births in the 1960s. In particular, we consider the change between the work shares of the 30 to 64 years old in 1960 and 20 to 54 years old women in 1950 . We then add our measure of crowding-in (by the $D$-) and check whether the large labor market entry of all other cohorts in the 1950s could diminish the role of the retirement of the D-cohort in the 1960s. The aggregate entry of women in the 1950s increases births of 20 to 24 year-olds in several years. The effects are also quantitatively important. When the retirement measure is 
added, the latter predicts a significant decline in the births of all women 20 to 29 years old. Quantitatively the impact of the retirement term is similar to what we obtained in Table $7 .^{23}$

\section{Crowding-out, Crowding-in and Completed Fertility}

Since data on labor shares are only available at a decennial frequency until 1960, we cannot construct our measures for different cohorts and examine the impact of the entry and retirement of the $D$-cohort on completed fertility using a more standard cohort approach. ${ }^{24}$ We instead apply a methodology conceptually similar to the one we used for yearly births retaining as point of reference a pre-baby boom cohort, the Middle-cohort, which also had very low completed fertility.

We compare the cumulative fertility of women 30 to 34 years old (older group of the Middle-cohort) in 1945 (pre-baby boom reference year) to the one of women of the same age in 1955, 1960, 1965, 1970 and 1975, thus covering all baby-boom and baby-bust cohorts (birth cohorts 1921-1945). Table 1 illustrates our reference cohort in 1945 (in darker grey and marked with $\mathrm{a}^{*}$ ) and the subsequent cohorts whose completed fertility we track over time (in darker grey as well). Using 1945 as reference point is not straightforward as there is no census data for that year. To obviate this, we use information on children ever born to women 35 to 39 years old from the 1950 census and subtract the number of children born in the previous five years (using NCHLT5). This will give us the approximate number of children ever born by 1945 to women who were then 30 to 34 years old. Similarly, we use the 1960, 1970 and 1980 censuses to calculate the completed fertility of women who were 30 to 34 years old in 1955, 1965 or 1975.

Figure 9 plots the completed fertility of various cohorts (horizontal axis) when 20 to 24, 25 to 29, 30 to 34 and 40 to 44 years old. As can be seen, the completed fertility of women 30 to 34 years old gives a good representation of their overall completed fertility. For the 1921-1930 cohorts more children were on average born to women in their 30s than for later cohorts. This could be because WWII led them to postpone births. While for yearly births the decline in fertility is visible by 1960, for completed fertility the effects are delayed and the turning point is between 1965 and 1970. The cohorts born between 1936 and 1940 had the highest average completed fertility across all baby-boom cohorts, conditional on age,

\footnotetext{
${ }^{23}$ We have performed several other checks to see whether other cohorts could individually play a similar role to or diffuse the role of the $D$ cohort. All our experiments confirm the results in Tables 6 and 7. In the same vein, we have estimated all specifications underlying Tables 6 , 7 and A5 through A8 using respective crowding-out/-in measures for men. We do not find that that their work behavior is relevant for the fertility boom-bust in any of these cases. This is consistent with our results from Section 3 showing that male employment either does not significantly and systematically respond to changes in current and/or past conditions or, if anything, declines. Given this, and if our mechanism is valid, we would not expect changes in their labor supply to affect births in the direction observed in the data, and this is what we find. Results are available upon request.

${ }^{24}$ We cannot implement a research design whereby, for instance, the completed fertility of a woman from a given birth cohort is a function of the average employment share of the $D$-cohort when she was 15-29 years old, that is during her prime fertility years.
} 


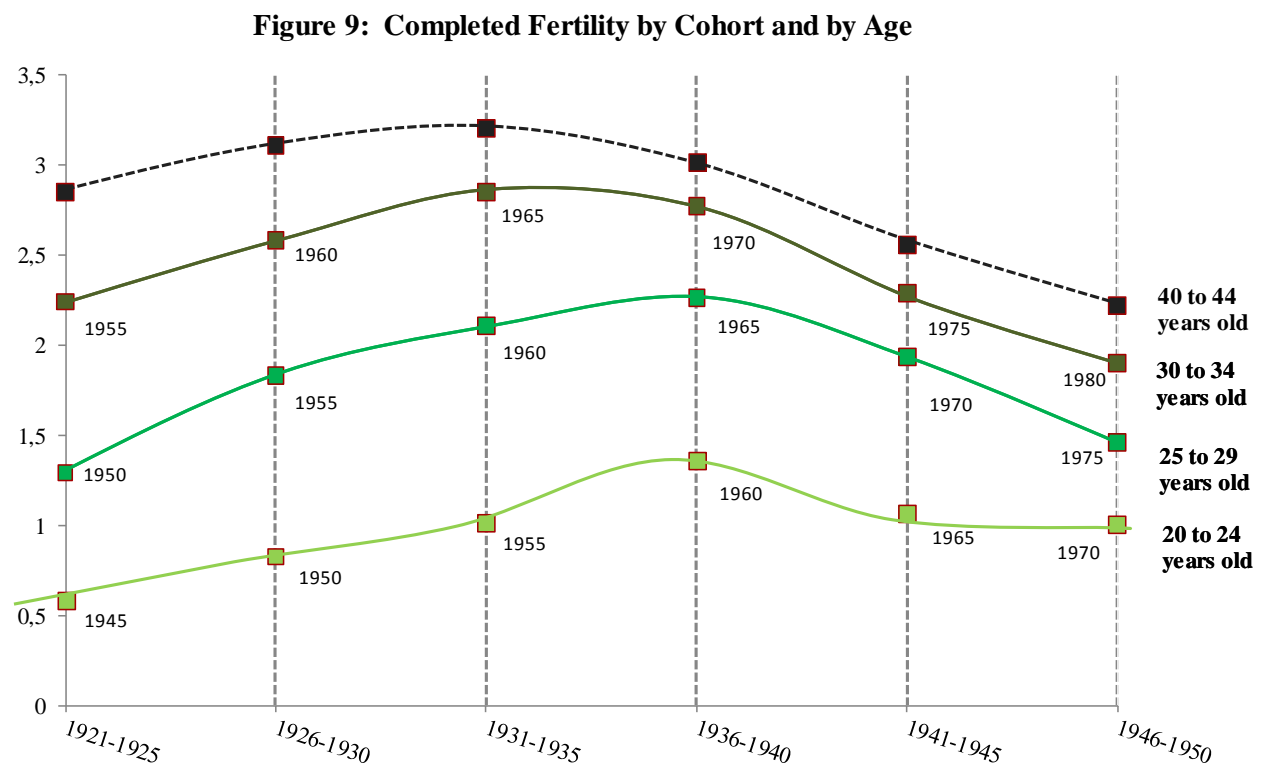

when they were 20 to 29 years old. The lower completed fertility of these women relative to the older ones is due to fewer babies being born in the mid-to-late 1960s when they were in their 30s. For the cohorts born between 1941 and 1945, the decline in completed fertility relative to previous cohorts is visible by 1965, when they are 20 to 24 years old. This suggests that something happened between 1960 and 1970 that affected the family planning of cohorts that were at different points of their reproductive cycle. The hypothesis that the retirement of the $D$-cohort created job opportunities that led women in different age brackets to enter the market fits these stylized facts of the bust.

For our experiment, we estimate equations similar to (4) and (5) with completed fertility as the dependent variable. We consider three alternative definitions for the latter: (i) the total number of children ever born by a given age, (ii) whether a woman had given birth to more than 3, or (iii) to more than 2 children, by a given age. The rationale for the last two specifications is the following. Women born, for instance, between 1931 and 1935 had an average of 3.2 children, the highest average completed fertility during the baby-boom. While completed fertility is typically measured at the end of a woman's fertility horizon (at the age of 40 or later), a finding where by the age of 30 to 34 a woman has surpassed the average of 3 children, would suggest that most of her lifetime fertility has been realized by that age. Our question is whether the labor market behavior of the D-cohort induced younger cohorts to attain this threshold during the boom, or fall short of that during the bust.

In Table 8 we examine the impact of the crowding-out and crowding-in on the cumulative fertility by age 30 to 34 of five different cohorts. Their cumulative fertility, 
Table 8: Cumulative Fertility (white women) 30 to 34 years old : Crowding-Out \& Crowding-In

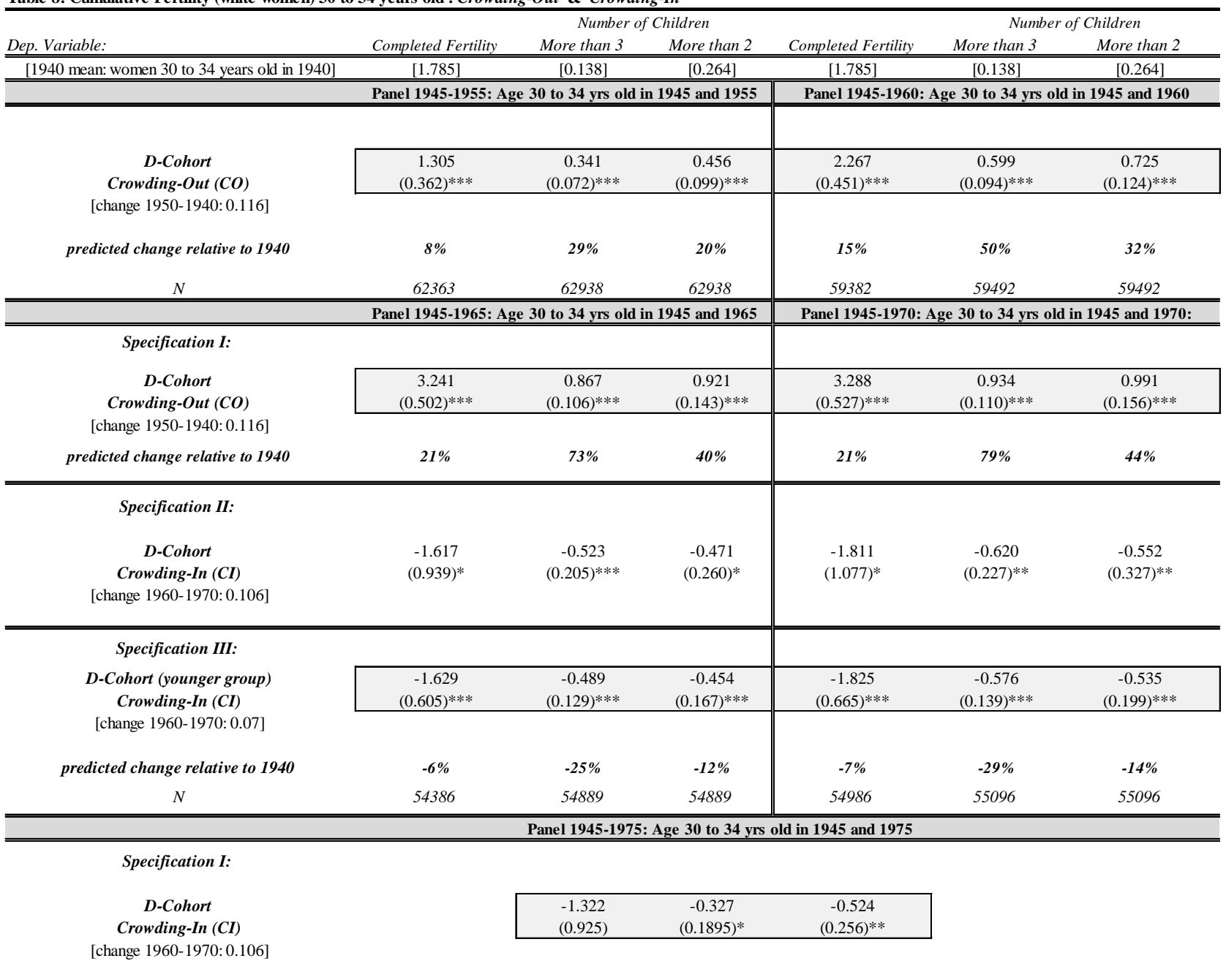

Specification II:

D-Cohort (younger group)

Crowding-In (CI)

[change 1960-1970: 0.07]

predicted change relative to 1940

\begin{tabular}{|ccc|}
\hline-1.328 & -0.324 & -0.479 \\
$(0.672)^{* *}$ & $(0.134)^{* *}$ & $(0.184)^{* * *}$ \\
\hline
\end{tabular}

$-5 \%-16 \% \quad-13 \%$

$55667 \quad 55963 \quad 55963$

Notes: Reported coefficients are OLS estimates from a regression of the number of children ever born to a woman of a given age on a measure of the change in work behavior of the "D-cohort" ( See text for a definition of these variables). The "D-cohort" consists of women 20-34 years old in 1930. D-Cohort (younger group) only include women who are 20 to 30 years old in 1930. All regressions also control for state of residence, state of birth, age and calendar year dummies. Age effects are also interacted with year dummies. Sample includes white women born in the United States. Standard errors are clustered by state of residence and year. ***, **, * refer to $1 \%, 5 \%$ and $10 \%$ significance level respectively.

according to our hypothesis, should have been shaped by two opposite forces: the crowdingout till 1960 (Specification I) and the retirement (crowding-in) since the late 1950s-early1960s (Specifications II and III). ${ }^{25}$ Relative to the cohorts born between 1911 and 1915 (30 to 34 years old in 1945), our crowding-out measure predicts that by age 30 to 34 the cohorts born between 1921 and 1925 had 8\% higher completed fertility, while the cohorts between 1926

\footnotetext{
${ }^{25}$ (i) Specification II captures the effects of the retirement of the entire D-cohort. Specification III considers the retirement of a subset of the $D$-cohort (30 to 40 years old in 1940), excluding women who may have retired in the early 1960s and may have had little effect on the fertility of women who were 30-34 years old in 1965, 1970 or 1975. (ii) Notice that for the cohorts born between 1941 and 1945, we have only included a crowding-in term to explain cumulative births by 1975. These women where 15 to 19 years old in 1960 and hence should have produced most of their children after 1960. This suggests that the retirement term is probably more relevant for shaping their births than the crowding-out. For cohorts born between 1931 and 1940 both effects should be relevant.
} 
and 1930, 1931 and 1935, and 1936 and 1940 had 15\%, 21\% and 21\% more children respectively. If we compare the completed fertility of these cohorts when they were 40 to 44 years old (2.85, 3.11, 3.21 and 3.02 respectively, see Table 1) to the completed fertility of the base cohort at the same age (2.41, see Table 1), the implied increase is $18 \%, 29 \%, 33 \%$ and $25 \%$ respectively. This shows that our mechanism is capable of explaining a large part of the increase in completed fertility while these women were still in their early 30s. For women born between 1931 and 1935, it also predicts a 73\% and a 40\% increase in their propensity to have more than 3 or more than 2 children respectively, relative to women in the base year. The crowding-in takes away a little bit of the increase, and is quantitatively more important for the cohorts born between 1936 and 1940 than for the previous ones. Overall, these results further confirm that the labor market channel we have uncovered is empirically relevant and can explain a substantive part of the boom-bust in both annual births and completed fertility for the cohorts involved, while respecting the particular timing in which these events took place. $^{26}$

\section{Discussion of Alternative Interpretations}

Our hypothesis is that the Baby-Boom-Bust in fertility was a repercussion of the Great Depression. Due to the severity and persistence of the economic contraction a large group of young married women entered the labor market in order to supplement family resources. These women remained or re-entered the labor market in large numbers in the 1940s and 1950s depressing the wages of all women, including the very-young. We argue that the lower wages decreased the opportunity cost of raising children, discouraging work and encouraging family formation. The re-entry of the D-cohort coincided with a period of economic prosperity, greater job security for men and possibly rising male incomes, which would all tend to generate and sustain a positive income effect. This, together with a weakened substitution effect (via lower female wages) led to the increase in fertility observed during the Baby-Boom. The retirement of the D-cohort in the 1960s created labor market opportunities that increased the opportunity cost of having children and led to lower births in the 1960s.

In this section we challenge this explanation and discuss alternative hypotheses. First, we examine a scenario where younger women leave the labor market due to a preference shift of the type described by Easterlin, and linked to the Great Depression. This hypothesis implies a labor market behavior running from the young to the old. We find that

\footnotetext{
${ }^{26}$ (i) Appendix Table A8 presents analogous estimates for women 25 to 29 years old in 1960 and 1970 relative to women of the same age in 1940. The base group in this case consists of the younger women in the Middle-cohort (see Table 1). The results are in line with those in Table 8. (ii) In an omitted analysis but available upon request, we experimented with an IV strategy where we instrumented $C O$ with the population share of the $D$-cohort in 1940 (for $\mathrm{CO}_{1950}$ ) and in 1930 (for $\mathrm{CO}_{1940}$ ). Similarly we instrumented $C I$ with the population share of the D-cohort in 1960 (for $\mathrm{CI}_{1970}$ ) and in 1930 (for $\mathrm{CO}_{1940}$ ). We obtained results qualitatively similar to those presented in Table 8.
} 
improvements in the relative economic conditions between when young and older cannot explain fertility changes of the baby-boom cohorts.

Second, we examine the within-cohort fertility responses of the baby-boom cohorts over their prime fertility cycle. The same women that produced a lot of children in the 1950s, subsequently and suddenly reverted their behavior and declined their fertility after 1960. The 1936-1940 birth-cohort provides a striking example: although this cohort had the highest average birth rate in 1960 (when 20 to 24 years old) among all boomers, it drastically reduced births in 1965 when 25 to 29 years old (Figure 3). A shift in preferences related to the Great Depression or to WWII or changes in home technology or maternal mortality could not easily account for this abrupt fertility change of these same women within a very short time period. Our labor market mechanism, however, is consistent with these same women reducing fertility as employment prospects improve.

\subsection{Crowding-Out or Easterlin?}

Easterlin's “relative income” hypothesis (1961) postulates that women who grew up during the Great Depression had low material aspirations. However, as they witnessed substantially improved economic conditions during their childbearing years, they revised upwards their earnings expectations and had overall more children. Following this rational, we compare the average economic conditions a woman experienced when 15 to 29 years old, during her prime fertility years, to the average conditions during her childhood. The latter is defined by the period when she was 5 to 10 years old. ${ }^{27}$ We proxy the state of the economy with the rate of commercial failures, and assume that the higher the failures during her formative years, the lower her material aspirations. We calculate the ratio between average failures when 15 to 29 years old and when 5 to 10 years old. The lower this ratio, the more important the improvements in women's relative economic status between childhood and adulthood. This, following Easterlin's interpretation, should lead to a preference shift towards larger families.

To test this hypothesis, we estimate versions of the following specification:

$$
y_{i c s}=\alpha_{o}+\sum_{c=1}^{8} \alpha_{1 c} * \text { Failures }_{c s} * d_{c s}+\sum_{c=1}^{8} \alpha_{2 c} * \text { Ratio }_{c s} * d_{c t}+f_{s}+f_{s} * c+g_{c}+\varepsilon_{i c s}
$$

The dependent variable is the total number of children ever born to woman $i$ (40 to 49 years old at survey year) from cohort $c$ born in state $s$. The latter is regressed on our measures of average economic conditions during childhood and/or adulthood as well as fixed effects for

\footnotetext{
${ }^{27}$ The Easterlin hypothesis has generated a vast literature and produced different interpretations of the theory; see Macunovich (1998) for a survey and a critical assessment.
} 
her birth cohort $\left(g_{c}\right)$, state of birth $\left(f_{s}\right)$ as well as a state-specific linear time trend $\left(f_{s} * c\right)$. Our measures of past conditions are interacted with birth cohort dummies to allow for these effects to vary across generations. We group women born between 1901 and 1939 into 8 different 5-year birth cohorts. A finding of a negative and significant relationship between completed fertility and the ratio of failures when older versus when a child, especially for the cohorts born between 1931 and 1939, would be consistent with the Easterlin's hypothesis.

Table 9: Completed Fertility: The Role of Economic Conditions \& the Easterlin Hypothesis Dep. Variable: children ever born

\begin{tabular}{|c|c|c|c|c|c|c|c|}
\hline *d1901_1905 & *d1906_1910 & *d1911_1915 & *d1916_1920 & *d1921_1925 & *d1926_1930 & *d1931_1935 & *d1936plus \\
\hline \multicolumn{8}{|c|}{ Specification I: Average Failures when 15-29 years old } \\
\hline $\begin{array}{c}-0.226 \\
(0.120)^{*}\end{array}$ & $\begin{array}{l}-0.079 \\
(0.098)\end{array}$ & $\begin{array}{c}-0.170 \\
(0.071)^{* *}\end{array}$ & $\begin{array}{c}-0.163 \\
(0.095)^{*}\end{array}$ & $\begin{array}{c}-0.404 \\
(0.128)^{* * *}\end{array}$ & $\begin{array}{c}-0.338 \\
(0.141)^{* *}\end{array}$ & $\begin{array}{c}-0.330 \\
(0.124)^{* * *}\end{array}$ & $\begin{array}{c}-0.360 \\
(0.132)^{* * *}\end{array}$ \\
\hline \multicolumn{8}{|c|}{ Specification II : Average Failures when 15-29 years old } \\
\hline $\begin{array}{c}-0.463 \\
(0.184)^{* *}\end{array}$ & $\begin{array}{l}-0.209 \\
(0.144)\end{array}$ & $\begin{array}{c}-0.274 \\
(0.092)^{* * *}\end{array}$ & $\begin{array}{c}-0.278 \\
(0.108)^{* * *}\end{array}$ & $\begin{array}{c}-0.498 \\
(0.142)^{* * *}\end{array}$ & $\begin{array}{c}-0.280 \\
(0.149)^{*}\end{array}$ & $\begin{array}{c}-0.321 \\
(0.136)^{* *}\end{array}$ & $\begin{array}{c}-0.478 \\
(0.142)^{* * *}\end{array}$ \\
\hline \multicolumn{8}{|c|}{ Average Failures when 5-10 years old } \\
\hline $\begin{array}{c}0.248 \\
(0.097)^{* *}\end{array}$ & $\begin{array}{c}0.092 \\
(0.083)\end{array}$ & $\begin{array}{c}0.041 \\
(0.066)\end{array}$ & $\begin{array}{l}-0.010 \\
(0.057)\end{array}$ & $\begin{array}{l}-0.046 \\
(0.056)\end{array}$ & $\begin{array}{c}-0.186 \\
(0.067)^{* * *}\end{array}$ & $\begin{array}{c}-0.199 \\
(0.068)^{* * *}\end{array}$ & $\begin{array}{l}-0.049 \\
(0.197)\end{array}$ \\
\hline \multicolumn{8}{|c|}{ Specification III: Average Failures when $15-29$ years old } \\
\hline $\begin{array}{c}-0.164 \\
(0.146)\end{array}$ & $\begin{array}{l}-0.036 \\
(0.123)\end{array}$ & $\begin{array}{l}-0.133 \\
(0.108)\end{array}$ & $\begin{array}{l}-0.187 \\
(0.160)\end{array}$ & $\begin{array}{c}-0.471 \\
(0.219)^{* *}\end{array}$ & $\begin{array}{c}-0.507 \\
(0.164)^{* * *}\end{array}$ & $\begin{array}{c}-0.434 \\
(0.134)^{* * *}\end{array}$ & $\begin{array}{c}-0.427 \\
(0.139)^{* * *}\end{array}$ \\
\hline \multicolumn{8}{|c|}{ Ratio: Average Failures when 15-29 years old/Average Failures when 5-10 years old } \\
\hline $\begin{array}{c}-0.151 \\
(0.069)^{* *}\end{array}$ & $\begin{array}{l}-0.114 \\
(0.069)\end{array}$ & $\begin{array}{c}-0.083 \\
(0.059)^{* *}\end{array}$ & $\begin{array}{r}-0.028 \\
(0.144)\end{array}$ & $\begin{array}{c}0.021 \\
(0.254)\end{array}$ & $\begin{array}{c}0.140 \\
(0.055)^{* *}\end{array}$ & $\begin{array}{c}0.048 \\
(0.024)^{* *}\end{array}$ & $\begin{array}{c}-0.002 \\
(0.004)\end{array}$ \\
\hline \multicolumn{8}{|c|}{$N \quad 262681$} \\
\hline $\begin{array}{l}\text { Notes : Reported } \\
\text { conditions experi } \\
\text { when 5-10 years } \\
5-10 \text { years old (st } \\
\text { specific linear tim } \\
\text { errors are cluster }\end{array}$ & $\begin{array}{l}\text { coefficients are } 0 \\
\text { nced when } 15-29 \\
\text { old (specification }\end{array}$ & $\begin{array}{l}\text { LS coefficients } \\
\text { years old (basel } \\
\text { II), the ratio of } \\
\text { Economic condit } \\
\text { ed in all specifica }\end{array}$ & $\begin{array}{l}\text { om a regression } \\
\text { ne-specification }\end{array}$ & $\begin{array}{l}\text { f the number of } \\
I \text { ). Additional cov } \\
\text { conditions when } \\
\text { lividual's state of } \\
\text { ides white, ever } \\
\text { " indicate significa }\end{array}$ & $\begin{array}{l}\text { hildren ever bo } \\
\text { zariates: averag } \\
\text { 15-29 years old } \\
\text { birth. Birth yeal }\end{array}$ & $\begin{array}{l}\text { a woman on } \\
\text { onomic condit } \\
\text { average econo }\end{array}$ & $\begin{array}{l}\text { verage econom } \\
\text { experienced } \\
\text { conditions when } \\
\text { cts and a state- } \\
\text { es. Standard } \\
\text { levels rspectivel }\end{array}$ \\
\hline
\end{tabular}

The results are presented in Table 9. We report three specifications. In the first one we include only average failures when 15 to 29 years old (Specification I). As can be seen these are always negative and significant, especially for cohorts born after 1920, suggesting that as economic conditions improved women were more likely to have more children. Specification II also controls for average failures when 5 to 10 years old. Failures when 15 to 29 years old remain significant, while failures when 5 to 10 years old are not except for the cohorts born between 1926 and 1935 and between 1901 and 1905. In Specification III, we include the constructed ratio, while still accounting for the economic conditions during adulthood. The ratio is significant for the 1926-1935 cohorts, but the sign is opposite than one would expect if 
the Easterlin theory were to explain the high completed fertility of these cohorts. Economic conditions when older remain instead a powerful predictor. Although this result is not a direct test or proof of our hypothesis, it is in line with previous findings that improvements in economic conditions entailed lower employment for the baby-boom cohorts and therefore more children. It also provides more support to our hypothesis that the causality runs from the old to the young rather than vice versa via a preference shift.

\subsection{Between the Boom and the Bust: within-cohort fertility declines}

As Figure 3 suggests, between 1960 and 1965, something happened that made all fertile women reduce their fertility. This decline occurred in a particular way. For instance, the 1936-1940 birth-cohort was fertile both during the baby-boom and the bust but experienced a drastic fall in its birth rate between when 25 to 29 (in 1965) and 20 to 24 (in 1960) years old relative to the 1931-1935 birth-cohort (or previous ones) in the same ages. Similarly, it experienced a more moderate drop in its birth rate between when 30 to 34 (in 1970) and 25 to 29 (in 1965) relative to the previous cohort. Moreover, these striking fertility shifts took place within a very short time period of just 5 years. Their occurrence could be a coincidence or else due to a gradual reversal in the factor(s) that led to the boom, and is especially interesting because it challenges the plausibility of alternative, comprehensive theories for the fertility boom-bust, such as that of home technology, or of a preference shift for younger cohorts. It would be difficult to explain how any of the above factors first induced a dramatic fertility upturn and then, within a very short time period, a marked decline in fertility for the same cohorts.

Our proposed mechanism could account for this change: as the D-cohort retires, employment prospects improve and young women re-enter the labor market. Other mechanisms consistent with this modified behavior are the introduction of the pill in the early 1960s or changes in education. The latter channel is illustrative of the mechanism that has been proposed as the venue through which declining maternal mortality produced the BabyBust for the younger cohorts (Albanesi and Olivetti, 2014). While the education channel is hard to test as we do not have precise Census data on how education of the same cohort changed overtime, it seems that most women in the 1926-1940 cohorts had largely completed their education by 1960 . Yet, they reduced their post-1960 fertility even when older. ${ }^{28}$

To test whether the retirement of the D-cohort can explain the within-cohort change in fertility we proceed as follows. First, we construct a panel which includes the average fertility

\footnotetext{
${ }^{28}$ For instance, white women 20-24 years old in 1960 had on average 11.54 years of education (IPUMS USA). The same cohort had 11.74 years in 1965, when 25 to 29 years old (March CPS). This amounts to a small increase in the average education of this cohort by 0.2 years.
} 
rate of the 1926-1946 birth cohorts at all points in their lifecycle between the ages of 20 and 34 years old. We also record the calendar year each cohort turned a specific age. Following the same rational as in Sections 4 through 6, we assume that births taking place in the 1940s are predicted by the change in the work shares of the D-cohort between 1930 and 1940, births in the 1950s are similarly predicted by the change in the work shares of the $D$-cohort between 1940 and 1950, while births occurring in the 1960s or later are affected by the retirement of the $D$-cohort captured by changes in its work shares between 1960 and $1970 .^{29}$

Next, we estimate the following baseline specification:

$$
\begin{aligned}
y_{a t s}=\alpha_{o} & +\alpha_{1}\left(C O_{D} \text { or } C_{D}\right)_{\mathrm{st}} * \text { Post }_{t} * \text { Age }_{k, t}+\alpha_{2}\left(C_{D} \text { or }_{C I_{D}}\right)_{\mathrm{st}} * \text { Post }_{t} \\
& +\alpha_{3}\left(C O_{D} \text { or } C I_{D}\right)_{\mathrm{st}} * \text { Age }_{k, t}+\alpha_{4} * \text { Post }_{t} * \text { Age }_{k, t}+\alpha_{5} * \text { Post }_{t}+\alpha_{6} * \text { Age }_{k, t} \\
& +\alpha_{7}\left(C O_{D} \text { or } C I_{D}\right)_{\mathrm{st}}+f_{a}+f_{t}+f_{s}+\varepsilon_{a t s}
\end{aligned}
$$

The dependent variable is the average birth rate in state $s$ of a woman who is of age $\alpha$ in year t. Post is an indicator for whether a woman turned her age after 1960 as opposed to before. Our measure of entry/exit of the $D$-cohort is as defined above. The specification also includes fixed effects for age, calendar year and state. We compare changes in fertility at three points in time: when 20 vs $24(k=24), 25$ vs $29(k=29)$ and 30 vs $34(k=34)$. We also consider a longer time span between the ages of 23 and 34 . Age $e_{k, t}$ is a dummy for the age of the woman in year $t$. The coefficient of interest is that of the triple interaction: $\alpha_{1}$. The latter measures the change in fertility due to our measure between, for instance, the ages of 30 and 34 for a woman that turned 30 or 34 after 1960 relative to another woman that turned these ages before or in 1960. If the exit of the $D$-cohort from the labor market can explain the observed within-cohort fertility decline, then we expect $\alpha_{1}<0$.

The coefficients from the triple interaction are reported in Table 10. We find that the retirement of the $D$-cohort entailed significant post-1960 fertility declines mainly between the ages of 30 and 34. Although the decline appears to have started earlier on, between the ages of 25 and 29, it only becomes statistically distinguishable from zero after the age of 29. This result is in line with the trends depicted in Figures 3 and 9. Figure 3 suggests that, with the exception of the 1936-1940 birth-cohort, there were no substantive differences in the birth rates at age 20 to 24 and 25 to 29 but there were systematic fertility declines across cohorts at ages 30 to 34. Figure 9 also shows that significant differences in cumulative fertility across cohorts are largely due to declines in births after the age of 29. Our findings in Table 10 are

\footnotetext{
${ }^{29}$ In other words, relative to the notation introduced in Section 4, the measure is - $\mathrm{CO}_{1940}$ to predict births in the 1940 s, $-\mathrm{CO}_{1950}$ for births in the 1950s, and $\mathrm{CI}_{1970}$ for births in the 1960 s or later. Hence, as the D-cohort overtime reduces its presence in the market, our measure will turn from negative to positive.
} 
consistent with these trends. ${ }^{30}$

Table 10: The effect of the retirement of the $D$-cohort on changes in within-cohort period fertility

\begin{tabular}{|c|c|c|c|c|}
\hline $\begin{array}{l}\text { Dep. Variable: Period Birth rate } \\
\text { [mean of dep. variable: } 0.150 \text { ] }\end{array}$ & 20 vs 24 & 25 vs 29 & 30 vs 34 & 23 vs 34 \\
\hline Labor supply change (D-cohort) & $\begin{array}{c}0.162 \\
(0.246)\end{array}$ & $\begin{array}{c}-0.064 \\
(0.107)\end{array}$ & $\begin{array}{c}-0.461 \\
(0.142)^{* * *}\end{array}$ & $\begin{array}{c}-0.603 \\
(0.149)^{* * *}\end{array}$ \\
\hline Labor supply change (D-cohort) & $\begin{array}{l}-0.126 \\
(0.218)\end{array}$ & $\begin{array}{l}-0.012 \\
(0.124)\end{array}$ & $\begin{array}{c}-0.449 \\
(0.147)^{* * *}\end{array}$ & $\begin{array}{c}-0.605 \\
(0.156)^{* * *}\end{array}$ \\
\hline Sales ban & $\begin{array}{l}-0.009 \\
(0.007)\end{array}$ & $\begin{array}{l}-0.004 \\
(0.006)\end{array}$ & $\begin{array}{l}-0.004 \\
(0.008)\end{array}$ & $\begin{array}{c}-0.019 \\
(0.009)^{* *}\end{array}$ \\
\hline Fixed Effects & \multicolumn{4}{|c|}{$Y, A, S$} \\
\hline$N$ (state-cohort-age cells) & \multicolumn{4}{|c|}{2058} \\
\hline \multicolumn{5}{|c|}{$\begin{array}{l}\text { Note: OLS estimates from a linear probability model with dependent variable the average birth rate of a given woman in a given age and } \\
\text { year. Average birth rate is measured at all ages between } 20 \text { and } 34 \text { years old. We include women born between } 1926 \text { and 1946. The } \\
\text { labor supply measure is defined as -CO1940 and -CO1950 for births taking place in the 1940s and 1950s respectively and CI1970 for } \\
\text { births in the 1960s (see text for the definitions of the above). Sales ban is an indicator for whether a given state faced repeals of statutes } \\
\text { banning sales of drugs, instruments or articles relating to contraception (see Bailey, 2010). Age-specific mean birth rates are calculated } \\
\text { for white women. Estimates are weighted using the population of a given cohort-group. Standard errors are clustered by state and year. } \\
* * *, * *, * \text { indicate significance at } 1 \%, 5 \% \text { and } 10 \% \text { respectively. Y, A, S stand for year, age and state fixed effects. }\end{array}$} \\
\hline
\end{tabular}

In the second half of Table 10, we check whether access to oral contraception could have also contributed to the shift towards declining own fertility of the baby-boom cohorts. Bailey (2010) shows that the availability of the pill accelerated the post-1960 decline in marital fertility. To do so, and following Bailey (2010), we introduce a policy variable that indicates whether a state ever had statutes banning sales of drugs, instruments or articles relating to contraception ("sales ban”). The later term enters in the same way as our labor supply measure, namely is interacted separately with a dummy for age as well as with the post dummy and there is also a triple interaction among these three terms. The estimated coefficient of the triple interaction is presented in Table 10. As can be seen, explicitly accounting for access to the pill does not minimize the effects of our labor supply measure. We do find, however, that while the pill cannot significantly explain changes in with-cohort fertility taking place within short time intervals, such as between the ages of 20 to 24 or 25 to 29 or 30 to 34, it can account for fertility declines occurring at longer time spans such as between the ages of 23 and 34 years old.

\section{International Evidence}

Our empirical findings highlight the salient role of the Great Depression in the occurrence of the Baby-Boom and Bust in the United States. In this section, we turn to international evidence in order to further assess the role of this event along with that of the subsequent recovery and of WWII on fertility trends across a broader group of countries.

\footnotetext{
${ }^{30}$ The results in Table 10 are robust to the introduction of other covariates, such as controls for changes in the economic conditions, changes to the availability of oral contraception or to the addition of state-specific quadratic time trends.
} 
To do so, we use yearly information on crude birth rates spanning the period 19341975 (Mitchell, 1998) as well information on completed fertility for the 1915-1950 birth cohorts (Observatoire Démographique Européen) across 18 countries: United States, Australia, New Zealand, Canada, Spain, Sweden, Switzerland, Denmark, Finland, France, Iceland, Italy, Netherlands, Norway, Belgium, Greece, United Kingdom and Portugal. ${ }^{31}$ We combine these fertility averages with annual information since the 1900 on the real per capita GDP of these countries (Barro and Ursua, 2008), which allows us to measure the extent of the Depressions they experienced during the early 1930s as well the magnitude of their subsequent recovery. In the Appendix we plot the evolution of crude birth rates, completed fertility and GDP for the considered countries and report the drop in their real per capita GDP experienced during the core years of the Great Depression. Countries that were affected by the 1929 Crash witnessed overall increases in their completed fertility, which magnitude seems to reflect the severity of the national economic contraction. For instance, Sweden, Spain, Iceland (neutral countries during WWII), Norway, Finland and Belgium experienced on average fairly small fertility "booms", as well as less severe Depressions in the 1930s. Italy and Denmark witnessed nearly no decline in their GDP and their completed fertility was mostly flat for the majority of the cohorts involved. On the other hand, Australia, New Zealand, Canada and the United States experienced a pronounced fertility Boom-Bust, and while all four participated to WWII, they also suffered the most significant losses in their GDP during the Great Depression.

We estimate specifications of the following type using crude birth rates (eq. 8) and completed fertility (eq. 9) respectively as dependent variables:

$$
\begin{aligned}
& y_{c t}=\alpha_{o}+\sum_{t=1934}^{1970} \alpha_{1 t} * G D P_{c, 1930-1932} * d_{t}+\alpha_{2} * G D P_{c t}+\alpha_{3} * W W I I_{c t}+f_{t}+g_{c}+\varepsilon_{c t} \\
& y_{c b}=\alpha_{o}+\sum_{b=1915}^{1950} \alpha_{1 b} * G D P_{c, 1930-1932} * d_{b}+\alpha_{2} * G D P_{c b}+\sum_{b=1915}^{1950} \alpha_{3 b} * W W I I_{c} * d_{b}+f_{b}+g_{c}+\varepsilon_{c b}
\end{aligned}
$$

In equation (8), the crude birth rate of country $c$ in year $t(t=1934-1975)$ is expressed as a function of the contemporaneous state of the economy $\left(G D P_{c t}\right)$, of an indicator for the participation of a given country in WWII after $1940\left(W W I I_{c t}\right)$ and of the size of the Depression captured by the change in real per capita GDP between 1930 and $1932 .{ }^{32}$ Since

\footnotetext{
${ }^{31}$ No information on completed fertility is available for the United Kingdom, while for Greece is available for only a subset of more recent cohorts. Hence, these countries are not included in the completed fertility analysis.

${ }^{32}$ The timing of the Depression varied slightly across countries as can be seen from the figures in the Appendix. Our results are very similar when the 1929-1932 declines are instead used.
} 
the latter is constant for a given country over time, this term is multiplied with a set of year dummies in order to make it time-varying. Specification (8) further includes time and country fixed effects. Similarly, in equation (9), the completed fertility of birth cohort $b$ ( $b=1915-1950)$ in country $c$ is regressed on a dummy variable for whether a country ever participated to WWII $\left(W W I I_{c}\right)$, on the average economic conditions a birth cohort experienced since 1935 and till it turned 40, signifying presumably the end of its main fertility cycle $\left(G D P_{c t}\right)$, as well as on the extent of the change in GDP between 1930 and 1932. The time-invariant variables measuring WWII participation and the size of the Depression are interacted with a set of birth-cohort dummies. Finally, the specification also includes birth-cohort and country fixed effects.

In Figures 10 and 11 we plot the coefficients associated with the effects of the Great Depression on fertility ( $d_{t}$ and $d_{b}$ respectively) and with the effects of WWII in the case of completed fertility. We also report the estimates for the impact of WWII (Figure 10) and of current economic conditions on fertility (Figures 10 and 11). Estimates that are statistically significant are circled in black. As can be seen, and in line with our previous analysis, both figures suggest that the Great Depression is an important element in explaining the fertility boom-bust across countries. It significantly explains the timing of the increase/decrease in annual births between 1949 and 1963, the high completed fertility for the 1925-1932 birth cohorts and the declining lifetime fertility of the 1942-1950 bust cohorts. The estimates of the impact of WWII are instead not statistically distinguishable from zero and the same is true for the effect of contemporaneous conditions capturing the post-Depression recovery.

While these results highlight the crucial role of the Great Depression in understanding the fertility Boom-Bust across countries, they do not reveal the channels through which the Great Depression led to the increase and decline in births. According to our findings for the United States, the entry in the market of a group of married, working-age women during the Great Depression and their subsequent stay in the workforce are strongly associated with the rise and fall in fertility of younger cohorts. In the Appendix (Figures A1-A5) we present some aggregate statistics from Canada, New Zealand and the United Kingdom on the labor force participation of women of different ages over time. As can be seen, women increased their presence in the workforce during the Great Depression. Moreover, while the labor supply profile of younger women of prime childbearing age seems to have remained fairly invariant till the late 1950s, the labor supply of the relatively older women, who were at the end or passed their prime fertility years, was markedly increasing even before the advent of WWII. While these observations are purely descriptive, they could be suggestive of a 
mechanism similar to the one we identified for the United States.

Figure 10: Coefficient Estimates of the Impact of the Great Depression

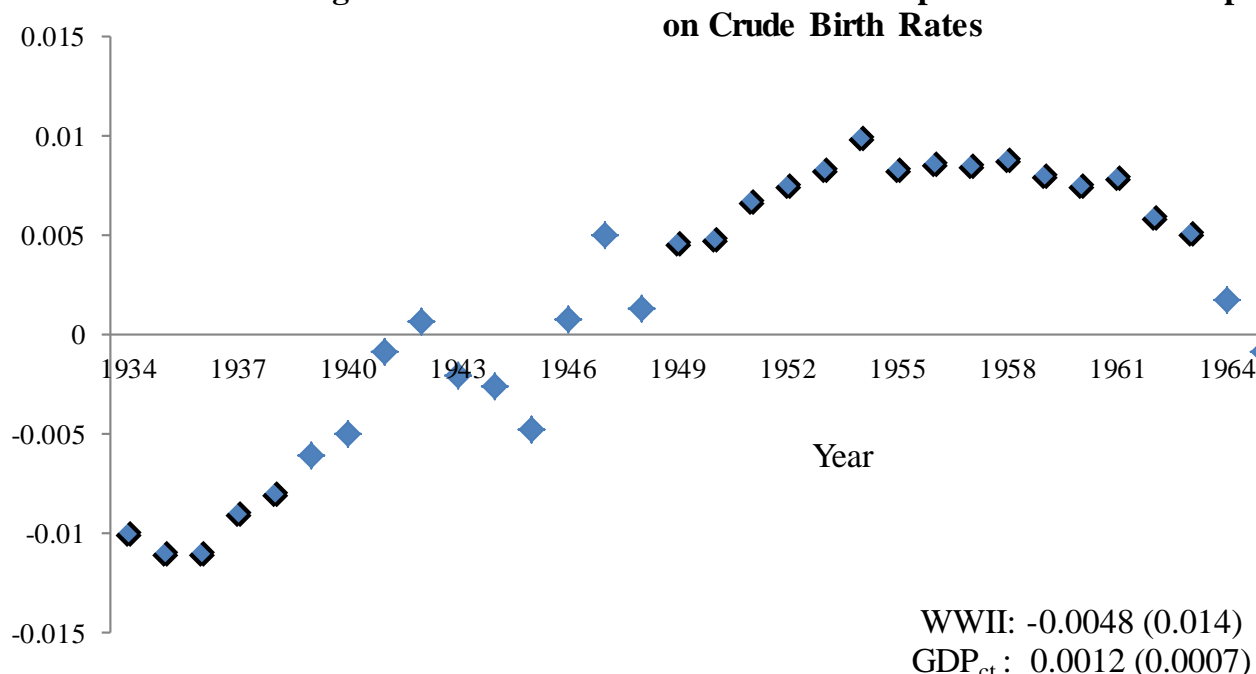

Figure 11: Coefficient Estimates of the Impact of the Great Depression and of WWII on Completed Fertility

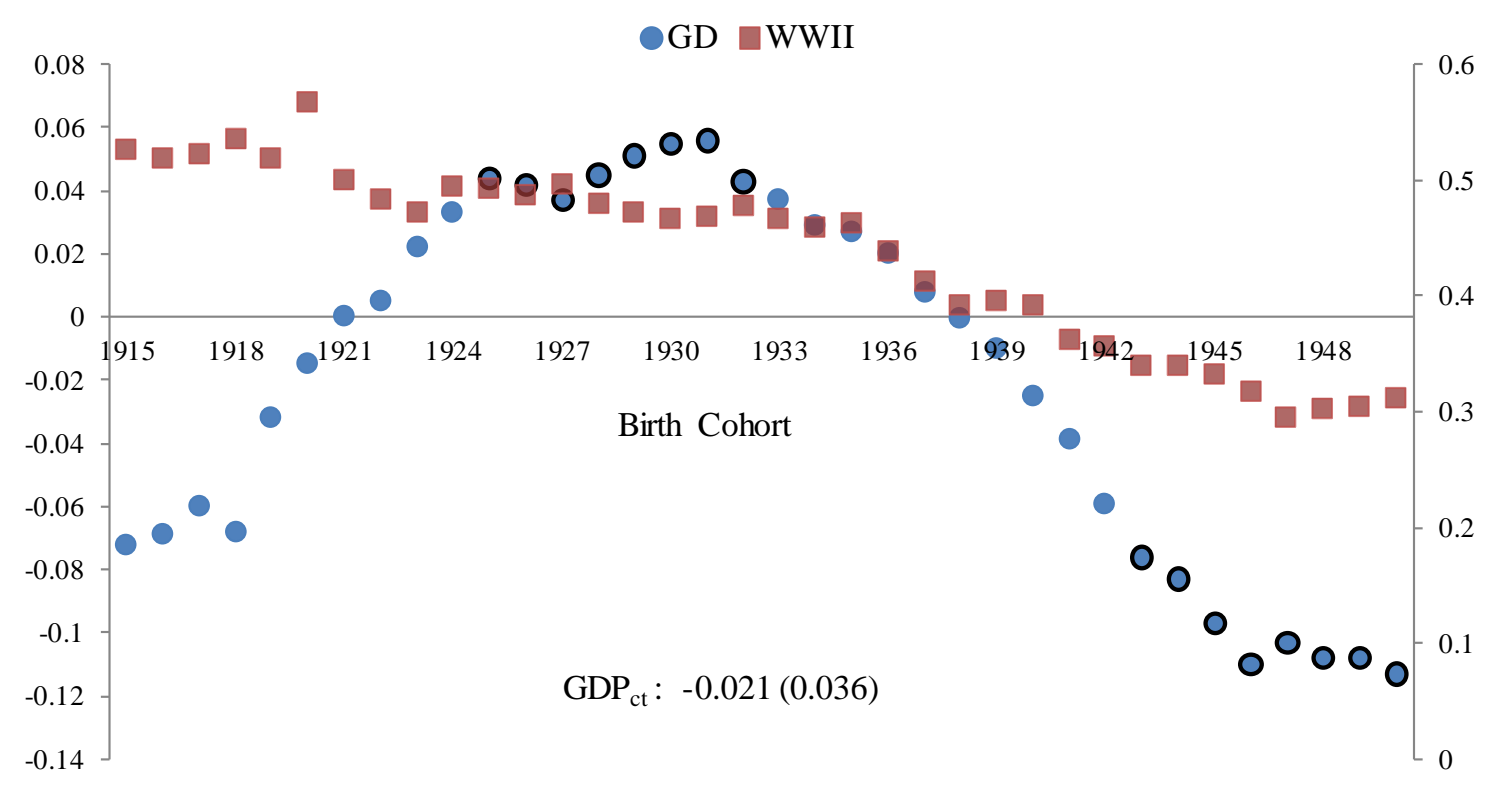

\section{Conclusion}

This paper revisits the determinants of the baby-boom and baby-bust and attributes their origins to the Great Depression. Our story hinges upon the work behavior of women who were of working age during the Great Depression, 20 to 34 years old in 1930 (D-cohort). In the face of the 1929 adverse economic conditions that affected their family resources, these women entered the labor market and kept entering decades later depressing female wages and crowding-out younger women, the mothers of the baby boomers. Their entry is associated 
with more births in the 1950s, while their retirement with a fertility bust in the 1960s. The life cycle labor supply profile of no other contiguous cohort can produce similar effects or mitigate the crowding-out/-in impact of the D-cohort. While this paper does not analyze the mechanisms that fostered and sustained the persistent entry of this cohort decades after the depression years, it is possible that the added worker effect explains the initial entry of married women when their husbands were losing their jobs. Further work will be needed to understand whether their entry in subsequent decades is linked to wealth losses during the Great Depression, a reduction in their permanent income or to a preference shift.

Our theory does not discount the role of other factors that might have also shaped fertility trends in the 1950s and 1960s. An alternative mechanism, however, that confounds our theory, would need to simultaneously reconcile the particular timing and features of both the baby-boom and bust (including the sudden change in fertility of the 1936-1940 birth cohort) as well as several pieces of evidence that we newly document. The latter pertain to the particular employment and wage patterns for women strongly linked to the Great Depression.

\section{References}

Acemoglu, Daron, David H. Autor, and David Lyle (2004). "Women, War and Wages: The Effect of Female Labor Supply on the Wage Structure at Mid-Century,” Journal of Political Economy, 112 (3), pp. 497-551.

Albanesi, Stefania and Claudia Olivetti (2014). "Maternal Health and the Baby Boom,’” Quantitative Economics, 5 (2), pp. 225-269

Bailey Martha J. (2006). "More Power to the Pill: The Impact of Contraceptive Freedom on Women’s Life Cycle Labor Supply,” Quarterly Journal of Economics, 121 (1), pp. 289-320. Bailey Martha J. (2010). “Momma's Got the Pill: How Anthony Comstock and Griswold v. Connecticut Shaped U.S. Childbearing,'’American Economic Review 100 (1), pp. 98-129.

Bailey Martha J. and William J. Collins (2011). "Did Improvements in Household Technology Cause the Baby Boom? Evidence from Electrification, Appliance Diffusion, and the Amish,’' American Economic Journal: Macroeconomics 3 (2), pp. 189-217.

Barro Robert J. and Jose F. Ursua (2008). "Macroeconomic Crises since 1870,” NBER Working Paper 13940.

Becker, Gary S. (1960). “An Economic Analysis of Fertility” in Demographic and Economic Change in Developed Countries, Princeton University Press, for the NBER.

Becker, Gary S., and Lewis, H. Gregg (1973). “On the Interaction Between the Quantity and Quality of Children,” Journal of Political Economy 81(2), pp. S279-S288. 
Doepke Matthias, Hazan M. and Yishay D. Maoz (2013). “The Baby Boom and World War II: A Macroeconomic Analysis,” mimeo.

Easterlin, Richard A. (1961). "The American Baby Boom in Historical Perspective," American Economic Review, 51 (5), pp. 869-911.

Fernandez, Raquel, Alessandra Fogli and Claudia Olivetti (2004). "Mothers and Sons: Preference Formation and Female Labor Force Dynamics,'” Quarterly Journal of Economics, 119(4), pp. 1249-1299.

Finegan, Aldrich T. and Robert A. Margo (1994). "Work Relief and the Labor Force Participation of Married Women in 1940,’’ Journal of Economic History, 54 (1), pp. 64-84.

Goldin, Claudia (1990). “The Role of World War II in the Rise of Women's Employment,” American Economic Review, 81 (4), pp. 741-756.

Goldin, Claudia, and Claudia Olivetti (2013). "Shocking Labor Supply: A Reassessment of the Role of World War II on Women's Labor Supply,” American Economic Review P\&P, 103(3), pp. 257-262.

Greenwood, Jeremy, Ananth Seshadri, and Guillerme Vanderbroucke (2005). “The Baby Boom and the Baby Bust,’’ American Economic Review, 95(1), pp.183-207.

Jones, Larry E., and Schoonbroodt Alice (2014). "Baby Busts and Baby Booms: The Fertility Response to Shocks in Dynastic Models,'” mimeo.

Jones, Larry E., and Michele Tertilt (2008). “An Economic History of Fertility in the United States: 1826-1960,' Chapter 5 of Frontiers of Family Economics, edited by Peter Rupert. Bradford: Emerald.

Macunovich, Diane J. (1998) "Fertility and the Easterlin Hypothesis: An assessment of the Literature,’’ Journal of Population Economics, (1), pp. 53-111.

Mitchell, Brian R. (1998a) “International historical statistics: the Americas, 1750-1988,' 4th Ed. New York: Stockton Press; London: Macmillan

Mitchell, Brian R. (1998b) “International historical statistics: Europe, 1750-1993, 4th Ed. New York: Stockton Press.

Mitchell, Brian R. (1998c) “International historical statistics: Africa, Asia \& Oceania, 17501993,’' 3rd Ed. New York: Stockton Press.

Mulligan Casey B. and Rubinstein Yona (2008). "Selection, Investment, and Women Relative Wages over Time,’’ Quarterly Journal of Economics, 123(3), pp. 1061-1110.

Murphy, Kevin M., Curtis Simon, and Robert Tamura. (2008) "Fertility Decline, Baby Boom, and Economic Growth.” Journal of Human Capital, 2 (3), pp. 262-302.

U.S Census Bureau, Statistical Abstract of the United States (Washington, DC). 
Ruggles, Steven, J. Trent Alexander, Katie Genadek, Ronald Goeken, Matthew B. Schroeder and Matthew Sobek (2010). Integrated Public Use Microdata Series: Version 5.0. Minneapolis: University of Minnesota 


\section{FOR ONLINE PUBLICATION:}

\section{APPENDIX}

\section{Employment: 1920-1930 samples}

As in the 1920 census people were not asked about their employment status, for the 19201930 analysis, our dependent variable is 1 if the individual worked in a gainful occupation, 0 otherwise. ${ }^{33}$ We estimate the following linear probability model:

$$
y_{i t s}=\alpha_{o}+\alpha_{1} \text { Failures }_{t s}+\alpha_{2} \text { Failures }_{t s} * \text { Married }_{i t s}+\left(\varphi_{i a}+f_{s}+g_{t}\right) * \text { Married }_{i t s}+\varepsilon_{i t s}
$$

$y_{i t s}$ is an indicator for whether a woman $i$ in state of residence $s$ reports a gainful occupation in year $t(t=1920,1930), \phi_{i a}, f_{s}$ and $g_{t}$ are respectively, age and its square, state of residence,

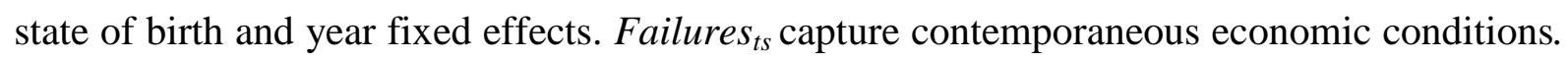
They are state-level average commercial failures over a 3-year period: 1928 through 1930 when $t=1930$ and symmetrically 1918 through 1920 when $t=1920$. A positive estimate means that a worsening of economic conditions increases participation. Since the extent to which women's labor supply responds to changes in the state of the economy may vary depending on their marital status, we interact business failures and the remaining covariates with a dummy variable, Married, in order to capture potential differential effects. The latter takes the value of 1 if a woman is married at the time of the survey and 0 otherwise. The coefficient $\alpha_{1}$ measures the common impact of varying economic conditions on the participation margin of all women, $\alpha_{2}$ picks up the differential labor supply response of married women and their sum, $\alpha_{1}+\alpha_{2}$, the overall effect of changing economic conditions on the participation of married women.

We examine the differential effect of the Great Depression on women in 1930 relative to women in the same age brackets in 1920. Table A1 presents the results. We start by estimating a version that does not depend on the woman's marital status (Married $=0$ ). For women in the $D$-cohort the coefficient is negative and significant, implying that increased failures decreased their presence in the labor market. Next, we re-estimate (1) allowing for interactions between all covariates and the dummy Married. We do so for women that were 25 and above years old in 1930 and 1920 respectively in order to reduce potential bias stemming from the impact of deteriorating conditions on the marriage decision. A significant

\footnotetext{
${ }^{33}$ (i) IPUMS also provides the variable "labforce", to measure labor force participation. Applying this definition produced very similar results. (ii) Our analysis of the 1920-1930 panels includes women in both farm and non-farm households. Due to the high rate of farm rural bank failures in the twenties, farm status between 1920 and 1930 could be endogenous to failures. In our post-1930 analysis we focus on individuals residing in non-farm households. This will limit potential misreporting of the employment status by the respondent. In unreported regressions, we re-estimate (1) for the panel 1920-1930 by farm status and find that our results are predominantly driven by women residing in non-farm households. Results are available upon request.
} 
share of 25 to 29 years old women in 1930 were already married before the advent of the 1929 Crash and even more in the 30 to 34 years old range. Below the estimates, we report whether $\alpha_{1}+\alpha_{2}$ is statistically different from zero $(y)$ or not $(n)$. Our results suggest that, while unmarried women in the D-cohort were less likely to participate, married women were significantly more likely to enter the workforce in response to the economic downturn ( $\alpha_{1}+\alpha_{2}$ is significant and positive). Quantitatively, the deterioration in economic conditions between 1920 and 1930 predicts an increase in the labor force participation of the relatively older women married women in the D-cohort (25 to 34 years old in 1930) of approximately 23\% relative to $1920 .{ }^{34}$ This is consistent with the 1929 Crash inducing an added worker effect, whereby married women, previously not working, had to enter the market and make up for the loss in family income produced when primary breadwinners became unemployed or faced significant wage cuts. Finally, older cohorts generally do not alter their participation with the exception of the 45 to 54 year-olds who also increase their presence in the labor market.

Next, we provide a series of robustness checks of the above findings. ${ }^{35}$ First, we reestimate (1) using an average of pre-1929 instead of current failures in order to establish whether the increased participation of the $D$-cohort reflects pre-Depression business cycle trends. We use average failures from 1924 to 1926 for 1930 and from 1914 to 1916 for 1920. Failures on average declined during this decade. We find no effects of past conditions on the participation of married women. Second, we estimate (1) for men. We find that both unmarried and married men decreased their presence in the labor market as failures in the late 1920s increased. Third, we check the robustness of our results to the way we measure changing economic conditions, using instead of failures, the unemployment rate. To calculate unemployment rate, we use the IPUMS variable "empstat" and we restrict attention to individuals 16 to 64 years old not in group quarters. As the variable above is not reported in the 1920 IPUMS, we impute 1920 unemployment rate using linear interpolation. We obtain again strikingly similar patterns. ${ }^{36}$ Overall, these results suggest a unique pattern of entry for young married women at the start of the Great Depression.

\footnotetext{
${ }^{34}$ We estimated (1) for married women 25 to 34 years old. The obtained coefficients for the uninteracted and interacted failure terms are $0.052(0.018)$ and $0.071(0.018)$ respectively. Next, we obtained the reported number as follows: $(0.071-0.052) * 0.63 / 0.052$ where 0.052 is the labor force participation of married women 25 to 34 years old in 1920. Between 1920 and 1930 the participation of this group increased from 0.052 to 0.098 .

${ }^{35}$ The 1920-1940 panels reveal a similar entry pattern for married women in the D-cohort, a pattern that is not found for men. These results are available upon request.

${ }^{36}$ When we use men instead of women, as before we find that male labor market participation decreases in states with higher unemployment during the early stage of the Great Depression. Results are available upon request.
} 
Table A1: Female Labor Force Participation \& Commercial Failures: 1920-1930

Dependent Variable $=$ Women in the labor Force (1 if reporting a gainful occupation)

D-Cohort (in 1930)

\begin{tabular}{|c|c|c|c|c|c|c|}
\hline $\begin{array}{l}\text { Ages in } 1920 \text { and 1930: } \\
\text { (Dep. Var: } 1920 \text { mean) }\end{array}$ & $\begin{array}{c}20-24 \\
(0.369) \\
\end{array}$ & $\begin{array}{c}25-29 \\
(0.247) \\
\end{array}$ & $\begin{array}{c}30-34 \\
(0.193) \\
\end{array}$ & $\begin{array}{c}35-44 \\
(0.172) \\
\end{array}$ & $\begin{array}{c}45-54 \\
(0.159) \\
\end{array}$ & $\begin{array}{c}55-64 \\
(0.132) \\
\end{array}$ \\
\hline $\begin{array}{c}\text { Failures_1930 } \\
\text { (avg 1928-1930 in } 1930 \text { and avg 1918-1920 in 1920) } \\
\text { (Change between } 1930 \text { and 1920: 0.63) } \\
\end{array}$ & $\begin{array}{c}-0.048 \\
(0.015)^{* * *}\end{array}$ & $\begin{array}{c}-0.037 \\
(0.010)^{* * *}\end{array}$ & $\begin{array}{l}-0.013 \\
(0.010)\end{array}$ & $\begin{array}{l}-0.009 \\
(0.008)\end{array}$ & $\begin{array}{c}0.028 \\
(0.011)^{* *}\end{array}$ & $\begin{array}{c}0.013 \\
(0.011)\end{array}$ \\
\hline $\begin{array}{c}\text { Failures_1930 } \\
\text { (see above) }\end{array}$ & & $\begin{array}{l}-0.041 \\
(0.027)\end{array}$ & $\begin{array}{c}-0.068 \\
(0.020)^{* * *}\end{array}$ & $\begin{array}{c}0.014 \\
(0.019)\end{array}$ & $\begin{array}{c}0.052 \\
(0.021)^{* *}\end{array}$ & $\begin{array}{c}0.022 \\
(0.024)\end{array}$ \\
\hline Failures_1930*Married & & $\begin{array}{c}0.055 \\
(0.031)^{*}\end{array}$ & $\begin{array}{c}0.094 \\
(0.021)^{* * *}\end{array}$ & $\begin{array}{l}-0.013 \\
(0.022)\end{array}$ & $\begin{array}{l}-0.033 \\
(0.021)\end{array}$ & $\begin{array}{l}-0.014 \\
(0.024)\end{array}$ \\
\hline sum different from zero & & $n$ & $y$ & $n$ & $y$ & $n$ \\
\hline & & & Falsification & $\underline{\underline{\text { ustness }}}$ & & \\
\hline $\begin{array}{c}\text { Failures_1920 } \\
\text { (avg 1924-1926 in } 1930 \text { and avg 1914-1916 in 1920) }\end{array}$ & & $\begin{array}{l}-0.042 \\
(0.014)^{* * *}\end{array}$ & $\begin{array}{c}-0.048 \\
(0.016)^{* * *}\end{array}$ & $\begin{array}{c}0.024 \\
(0.012)^{*}\end{array}$ & $\begin{array}{c}0.009 \\
(0.017)\end{array}$ & $\begin{array}{c}0.023 \\
(0.013)^{*}\end{array}$ \\
\hline Failures_1920*Married & & $\begin{array}{c}0.044 \\
(0.016)^{* *}\end{array}$ & $\begin{array}{c}0.049 \\
(0.018)^{* *}\end{array}$ & $\begin{array}{l}-0.020 \\
(0.016)\end{array}$ & $\begin{array}{l}-0.009 \\
(0.013)\end{array}$ & $\begin{array}{l}-0.023 \\
(0.014)\end{array}$ \\
\hline sum different from zero & & $n$ & $n$ & $n$ & $n$ & $n$ \\
\hline$N$ & & 68530 & 60690 & 103519 & 73584 & 47126 \\
\hline \multicolumn{7}{|c|}{ Dependent Variable = Men in the labor Force (1 if reporting a gainful occupation) } \\
\hline $\begin{array}{l}\text { Failures_1930 } \\
\quad \text { (see above) }\end{array}$ & & $\begin{array}{c}-0.042 \\
(0.007)^{* * *}\end{array}$ & $\begin{array}{c}-0.027 \\
(0.013)^{*}\end{array}$ & $\begin{array}{c}0.015 \\
(0.008)^{*}\end{array}$ & $\begin{array}{l}-0.005 \\
(0.012)\end{array}$ & $\begin{array}{c}-0.040 \\
(0.022)^{*}\end{array}$ \\
\hline Failures_1930*Married & & $\begin{array}{c}0.038 \\
(0.006)^{* * *}\end{array}$ & $\begin{array}{c}0.023 \\
(0.014)\end{array}$ & $\begin{array}{c}-0.018 \\
(0.009)^{*}\end{array}$ & $\begin{array}{l}-0.009 \\
(0.015)\end{array}$ & $\begin{array}{c}0.009 \\
(0.028)\end{array}$ \\
\hline sum different from zero & & $n$ & $n$ & $n$ & $y$ & $y$ \\
\hline$N$ & & 64925 & 57874 & 102557 & 76914 & 49400 \\
\hline $\begin{array}{c}\text { Dependent Variable }=\text { Women in the labor Force (1 } \\
\text { Unemployment } \\
\text { (1930 unemployment for } 1930 \\
1920 \text { unemployment for 1920) }\end{array}$ & $\begin{array}{l}\text { labor force) } \\
\quad 0.275 \\
(0.184)\end{array}$ & $\begin{array}{c}-0.528 \\
(0.152)^{* * *}\end{array}$ & $\begin{array}{c}-0.624 \\
(0.224)^{* * *}\end{array}$ & $\begin{array}{c}-0.262 \\
(0.117)^{* *}\end{array}$ & $\begin{array}{c}0.068 \\
(0.161)\end{array}$ & $\begin{array}{l}-0.072 \\
(0.185)\end{array}$ \\
\hline \multicolumn{7}{|c|}{ Dependent Variable = Women in the labor Force (1 if reporting a gainful occupation) } \\
\hline $\begin{array}{l}\text { Unemployment } \\
\text { (1930 unemployment for } 1930 \\
1920 \text { unemployment for 1920) }\end{array}$ & & $\begin{array}{c}-1.169 \\
(0.370)^{* * *}\end{array}$ & $\begin{array}{c}-1.321 \\
(0.484)^{* *}\end{array}$ & $\begin{array}{c}0.136 \\
(0.308)\end{array}$ & $\begin{array}{c}0.431 \\
(0.323)^{* *}\end{array}$ & $\begin{array}{c}0.147 \\
(0.487)\end{array}$ \\
\hline Unemployment*Married & & $\begin{array}{c}1.704 \\
(0.411)^{* * *}\end{array}$ & $\begin{array}{c}1.420 \\
(0.484)^{* *}\end{array}$ & $\begin{array}{l}-0.194 \\
(0.336)\end{array}$ & $\begin{array}{c}-0.373 \\
(0.327)^{* *}\end{array}$ & $\begin{array}{l}-0.435 \\
(0.493)\end{array}$ \\
\hline sum different from zero & & $y$ & $n$ & $n$ & $n$ & $y$ \\
\hline$N$ & & 68570 & 60732 & 103593 & 73606 & 47140 \\
\hline
\end{tabular}

Notes: Coefficients from OLS regression of an indicator variable for participation in the labor force on current commercial failures, age, current birth state and year fixed effects. All covariates (with the exception of the first and last specifications) are interacted with a dummy variable indicating whether the individual is currently married. The dependent variable is 1 if the individual reported working in a gainful occupation (IPUMS variable OCC1950). Sample includes white women born in the United States. Failures_1930 and Failures_1920 are constructed symmetrically Failures_1930: is a vector with average failures between 1928 and 1930, for 1930 and average failures between 1918 and 1920, for 1920; Failures_1920: are average failures between 1924 and 1926, for 1930 and average failures between 1914 and 1916, for 1920. The change in Failures_1930 between 1930 and 1920 is 0.63, the change in Failures_1920, -0,16. Standard errors (parenthesis) are clustered by state-year. ***. **. * indicate significance at $1 \% .5 \%$ and $10 \%$ 


\section{Employment: 1940-1950-1960 samples}

The robustness exercises reported in the Table A2, A3 and A4 are as follows.

Table A2: Estimates of eq. (3) for the 1940-1960 and for different age groups. The sample includes women of all races, nationalities and of all farm statuses. All reported variables are as described in the text.

Table A3: Estimates of eq. (3) for the 1940-1950-1960 using wages as the dependent variable. Estimates are corrected for selection using the Heckman two-step procedure.

Table A4: First, we re-estimate eq. (1) in the text using an average of past instead of current failures in order to establish whether the increased participation of the D-cohort reflects preDepression business cycle trends. We use average failures from 1920 to 1922 for 1960 and symmetrically from 1900 to 1902 for 1940. Second, instead of the participation of women in the $D$-cohort in 1930, we use the participation of men in the same age bracket in 1930. 
Table A2: 1940-1960 Female Employment - Sample Robustness (women of all races \& nationalities, households of all farm statuses)

\begin{tabular}{|c|c|c|c|c|c|c|c|c|c|c|c|c|}
\hline \\
\hline \multicolumn{4}{|c|}{$\begin{array}{l}\text { Dep. Variable = } 1 \text { if currently employed } \\
\text { Age groups: }\end{array}$} & \multicolumn{3}{|c|}{$\underline{25-29}$} & \multicolumn{3}{|c|}{$\underline{30-39}$} & \multicolumn{3}{|c|}{$\underline{25-35}$} \\
\hline mobilization & $\begin{array}{l}-0.173 \\
(0.143)\end{array}$ & $\begin{array}{l}-0.038 \\
(0.014)\end{array}$ & $\begin{array}{c}0.356 \\
(0.160)^{* *}\end{array}$ & $\begin{array}{c}-0.744 \\
(0.167)^{* * * *}\end{array}$ & $\begin{array}{c}-0.598 \\
(0.150)^{* * * *}\end{array}$ & $\begin{array}{c}-0.482 \\
(0.219)^{* *}\end{array}$ & $\begin{array}{l}-0.115 \\
(0.104)\end{array}$ & $\begin{array}{l}-0.022 \\
(0.109)\end{array}$ & $\begin{array}{c}0.284 \\
(0.144)^{*}\end{array}$ & $\begin{array}{c}-0.519 \\
(0.139)^{* * *}\end{array}$ & $\begin{array}{c}-0.386 \\
(0.131)^{* * *}\end{array}$ & $\begin{array}{l}-0.074 \\
(0.182)\end{array}$ \\
\hline current failures & & $\begin{array}{l}0.014 \\
(0.02)\end{array}$ & $\begin{array}{c}0.032 \\
(0.019)^{*}\end{array}$ & & $\begin{array}{c}0.037 \\
(0.018)^{* *}\end{array}$ & $\begin{array}{c}0.032 \\
(0.019)^{*}\end{array}$ & & $\begin{array}{c}0.004 \\
(0.015)\end{array}$ & $\begin{array}{c}0.007 \\
(0.013)\end{array}$ & & $\begin{array}{c}0.030 \\
(0.014)^{* *}\end{array}$ & $\begin{array}{c}0.031 \\
(0.014)^{* *}\end{array}$ \\
\hline past failures & & $\begin{array}{c}-0.052 \\
(0.018)^{* * *}\end{array}$ & $\begin{array}{c}-0.032 \\
(0.017)^{*}\end{array}$ & & $\begin{array}{c}-0.065 \\
(0.015)^{* * *}\end{array}$ & $\begin{array}{c}-0.064 \\
(0.014)^{* * *}\end{array}$ & & $\begin{array}{c}-0.034 \\
(0.011)^{* * *}\end{array}$ & $\begin{array}{c}-0.02 \\
(0.011)^{*}\end{array}$ & & $\begin{array}{c}-0.058 \\
(0.012)^{* * *}\end{array}$ & $\begin{array}{c}-0.044 \\
(0.010)^{* * *}\end{array}$ \\
\hline observations & \multicolumn{3}{|c|}{67770} & \multicolumn{3}{|c|}{70449} & \multicolumn{3}{|c|}{150837} & \multicolumn{3}{|c|}{160352} \\
\hline individual covariates & yes & yes & yes & yes & yes & yes & yes & yes & yes & yes & yes & yes \\
\hline 1940 state covariates & no & no & yes & no & no & yes & no & no & yes & no & no & yes \\
\hline Age groups: & \multicolumn{3}{|c|}{$\underline{40-49}$} & \multicolumn{3}{|c|}{$\underline{50-64}$} & \multicolumn{3}{|c|}{ 50-64 ever married } & \multicolumn{3}{|c|}{$\underline{45-55}$} \\
\hline mobilization & $\begin{array}{c}0.084 \\
(0.113)\end{array}$ & $\begin{array}{c}0.05 \\
(0.10)\end{array}$ & $\begin{array}{c}-0.330 \\
(0.087)^{* * *}\end{array}$ & $\begin{array}{c}0.442 \\
(0.151)^{* * *}\end{array}$ & $\begin{array}{c}0.279 \\
(0.125)^{* *}\end{array}$ & $\begin{array}{l}-0.252 \\
(0.178)\end{array}$ & $\begin{array}{c}0.538 \\
(0.152)^{* * *}\end{array}$ & $\begin{array}{c}0.370 \\
(0.120)^{* * * *}\end{array}$ & $\begin{array}{l}-0.164 \\
(0.157)\end{array}$ & $\begin{array}{c}0.329 \\
(0.147)^{* *}\end{array}$ & $\begin{array}{c}0.162 \\
(0.125)\end{array}$ & $\begin{array}{c}-0.362 \\
(0.176)^{* *}\end{array}$ \\
\hline current failures & & $\begin{array}{c}-0.033 \\
(0.010)^{* * *}\end{array}$ & $\begin{array}{c}-0.045 \\
(0.010)^{* * *}\end{array}$ & & $\begin{array}{c}-0.022 \\
(0.011)^{* *}\end{array}$ & $\begin{array}{c}-0.046 \\
(0.011)^{* * *}\end{array}$ & & $\begin{array}{c}-0.025 \\
(0.009)^{* * *}\end{array}$ & $\begin{array}{c}-0.046 \\
(0.009)^{* * *}\end{array}$ & & $\begin{array}{c}-0.030 \\
(0.014)^{* *}\end{array}$ & $\begin{array}{c}-0.047 \\
(0.014)^{* * *}\end{array}$ \\
\hline past failures & & $\begin{array}{c}0.026 \\
(0.009)^{* * *}\end{array}$ & $\begin{array}{l}-0.003 \\
(0.010)\end{array}$ & & $\begin{array}{c}0.071 \\
(0.011)^{* * *}\end{array}$ & $\begin{array}{c}0.027 \\
(0.010)^{* * *}\end{array}$ & & $\begin{array}{c}0.075 \\
(0.010)^{* * *}\end{array}$ & $\begin{array}{c}0.032 \\
(0.009)^{* * *}\end{array}$ & & $\begin{array}{c}0.075 \\
(0.010)^{* * *}\end{array}$ & $\begin{array}{c}0.035 \\
(0.010)\end{array}$ \\
\hline observations & \multicolumn{3}{|c|}{136767} & \multicolumn{3}{|c|}{157070} & \multicolumn{3}{|c|}{145148} & \multicolumn{3}{|c|}{136727} \\
\hline individual covariates & yes & yes & yes & yes & yes & yes & yes & yes & yes & yes & yes & yes \\
\hline 1940 state covariates & no & no & yes & no & no & yes & no & no & yes & no & no & yes \\
\hline
\end{tabular}

Table A3: Wages: 1940-1950 and 1940-1960 - Heckman Correction Dependent Variable: Log Real Weekly Female Wages

Panel 1940-1950

Middle-

$\overbrace{20-29}^{\text {B-Cohort in } 1950} \overbrace{\mid 30-39}^{\text {Cohort in } 1950} \overbrace{40-54}^{\text {D-Cohort in } 1950}$

Ages in 1940 and 1950 (left section): Ages in 1940 and 1960 (right section):

Failures

(see Table 3)

Failures_1930

(see Table 3)

Failures

(see Table 3)

Failures_1930

(see Table 3)

Mills Ratio

\begin{tabular}{|c|c|c|c|c|c|c|c|}
\hline \multicolumn{8}{|c|}{ Baseline OLS Estimates } \\
\hline $\begin{array}{c}-0.007 \\
(0.015)^{*}\end{array}$ & $\begin{array}{l}-0.018 \\
(0.031)\end{array}$ & $\begin{array}{c}0.096 \\
(0.031)^{* * *}\end{array}$ & $\begin{array}{c}0.075 \\
(0.049)\end{array}$ & $\begin{array}{c}-0.057 \\
(0.021)^{* * *}\end{array}$ & $\begin{array}{l}-0.003 \\
(0.042)\end{array}$ & $\begin{array}{l}-0.037 \\
(0.053)\end{array}$ & $\begin{array}{c}0.092 \\
(0.073)\end{array}$ \\
\hline $\begin{array}{c}-0.152 \\
(0.020)^{* * *}\end{array}$ & $\begin{array}{l}-0.023 \\
(0.041)\end{array}$ & $\begin{array}{l}-0.050 \\
(0.051)\end{array}$ & $\begin{array}{l}-0.091 \\
(0.061)\end{array}$ & $\begin{array}{c}-0.084 \\
(0.024)^{* * *}\end{array}$ & $\begin{array}{c}-0.061 \\
(0.039)^{* * *}\end{array}$ & $\begin{array}{l}-0.067 \\
(0.053)\end{array}$ & $\begin{array}{l}-0.043 \\
(0.060)\end{array}$ \\
\hline \multicolumn{8}{|c|}{ Heckman Correction Estimates } \\
\hline $\begin{array}{c}-0.034 \\
(0.019)^{*}\end{array}$ & $\begin{array}{l}-0.047 \\
(0.034)\end{array}$ & $\begin{array}{c}0.052 \\
(0.044)\end{array}$ & $\begin{array}{c}0.028 \\
(0.069)\end{array}$ & $\begin{array}{c}-0.099 \\
(0.034)^{* * *}\end{array}$ & $\begin{array}{l}-0.014 \\
(0.043)\end{array}$ & $\begin{array}{l}-0.018 \\
(0.052)\end{array}$ & $\begin{array}{c}0.095 \\
(0.061)\end{array}$ \\
\hline $\begin{array}{c}-0.168 \\
(0.021)^{* * *}\end{array}$ & $\begin{array}{l}-0.072 \\
(0.048) \\
\end{array}$ & $\begin{array}{c}-0.109 \\
(0.051)^{* *}\end{array}$ & $\begin{array}{c}-0.184 \\
(0.061)^{* * *}\end{array}$ & $\begin{array}{c}-0.104 \\
(0.033)^{* * *} \\
\end{array}$ & $\begin{array}{c}-0.122 \\
(0.046)^{* * *}\end{array}$ & $\begin{array}{c}-0.081 \\
(0.049)^{*}\end{array}$ & $\begin{array}{c}-0.143 \\
(0.063)^{* *}\end{array}$ \\
\hline $\begin{array}{c}-0.254 \\
(0.042)^{* * *}\end{array}$ & $\begin{array}{c}-0.660 \\
(0.049)^{* * *}\end{array}$ & $\begin{array}{c}-0.893 \\
(0.027)^{* * *} \\
\end{array}$ & $\begin{array}{c}-0.934 \\
(0.029)^{* * *}\end{array}$ & $\begin{array}{c}-0.541 \\
(0.033)^{* * *}\end{array}$ & $\begin{array}{c}-0.843 \\
(0.031)^{* * *}\end{array}$ & $\begin{array}{c}-0.889 \\
(0.015)^{* * *}\end{array}$ & $\begin{array}{c}-0.993 \\
(0.022)^{* * *}\end{array}$ \\
\hline 22354 & 14730 & 15388 & 9208 & 50564 & 43118 & 43230 & 38664 \\
\hline
\end{tabular}

Panel 1940-1960

Middle- $\quad$ D-Cohort Cohort in 1960 in 1960

$\overbrace{20-29}^{\text {B-Cohort in } 1960} \overbrace{30-39}^{\text {Cohort in } 1960} \overbrace{\mid 40-49}^{\text {in } 1960}$

Notes: Heckman correction estimates are produced using the number of own children present in the household as an exclusion restriction in the first stage. Individual controls: age, education dummies and their interactions with year fixed effects. State controls: WWII mobilization rate, 1940 average male education, 1940 share of nonwhite males, 1940 share of males that are farmers. All state controls are interacted with year fixed effects. All specifications also control for state of residence, state of birth and year fixed effects. Sample includes white women, born in the US and not living in farm households. Standard errors (parentheses) are clustered by state of residence and year. ***, **, * indicate significance at $1 \%, 5 \%$ and $10 \%$ respectively. 
Table A4: Female Employment - Falsification Checks: 1940-1960

\begin{tabular}{|c|c|c|c|c|c|c|c|c|c|c|c|c|}
\hline \multicolumn{13}{|l|}{ Dep. Variable $=1$ if currently employed } \\
\hline \multirow[b]{2}{*}{ Ages in 1940 and 1960: } & \multicolumn{2}{|c|}{ B-Cohort in 1960} & \multicolumn{2}{|c|}{ D-Cohort in 1960} & \multicolumn{2}{|c|}{$\mathrm{P}^{\text {B-Cohort in } 1960}$} & \multicolumn{2}{|c|}{ D-Cohort in 1960} & \multicolumn{2}{|c|}{$\mathrm{P}^{\text {B-Cohort in } 1960}$} & \multicolumn{2}{|c|}{$\mathrm{P}^{\mathrm{D} \text {-Cohort in } 1960}$} \\
\hline & $\begin{array}{c}20-29 \\
\text { all }\end{array}$ & $\begin{array}{c}\text { 30-39 } \\
\text { all }\end{array}$ & $\begin{array}{c}50-64 \\
\text { all }\end{array}$ & $\begin{array}{c}50-64 \\
\text { ever } \\
\text { married }\end{array}$ & $\begin{array}{c}20-29 \\
\text { all }\end{array}$ & $\begin{array}{c}30-39 \\
\text { all }\end{array}$ & $\begin{array}{c}50-64 \\
\text { all }\end{array}$ & $\begin{array}{c}50-64 \\
\text { ever } \\
\text { married }\end{array}$ & $\begin{array}{c}20-29 \\
\text { all }\end{array}$ & $\begin{array}{c}\text { 30-39 } \\
\text { all }\end{array}$ & $\begin{array}{c}50-64 \\
\text { all }\end{array}$ & $\begin{array}{c}50-64 \\
\text { ever } \\
\text { married }\end{array}$ \\
\hline Mobrate & $\begin{array}{c}0.308 \\
(0.186)^{*}\end{array}$ & $\begin{array}{c}0.613 \\
(0.180)^{* * *}\end{array}$ & $\begin{array}{l}-0.290 \\
(0.210)\end{array}$ & $\begin{array}{l}-0.221 \\
(0.197)\end{array}$ & $\begin{array}{c}0.166 \\
(0.174)\end{array}$ & $\begin{array}{c}0.547 \\
(0.173)^{* * *}\end{array}$ & $\begin{array}{l}-0.208 \\
(0.219)\end{array}$ & $\begin{array}{l}-0.105 \\
(0.191)\end{array}$ & $\begin{array}{c}0.380 \\
(0.177)^{* * *}\end{array}$ & $\begin{array}{c}0.715 \\
(0.142)^{* * *}\end{array}$ & $\begin{array}{c}-0.490 \\
(0.213)^{* *}\end{array}$ & $\begin{array}{c}-0.362 \\
(0.176)^{* *}\end{array}$ \\
\hline $\begin{array}{c}\text { Failures } \\
\text { (see Table 4) }\end{array}$ & $\begin{array}{c}0.073 \\
(0.019)^{* * *}\end{array}$ & $\begin{array}{c}0.014 \\
(0.014)\end{array}$ & $\begin{array}{c}-0.072 \\
(0.013)^{* * *}\end{array}$ & $\begin{array}{c}-0.074 \\
(0.013)^{* * *}\end{array}$ & $\begin{array}{c}0.051 \\
(0.018)^{* * *}\end{array}$ & $\begin{array}{c}0.005 \\
(0.016)\end{array}$ & $\begin{array}{c}-0.062 \\
(0.013)^{* * *}\end{array}$ & $\begin{array}{c}-0.062 \\
(0.012)^{* * *}\end{array}$ & $\begin{array}{c}0.067 \\
(0.017)^{* * *}\end{array}$ & $\begin{array}{c}0.012 \\
(0.011)\end{array}$ & $\begin{array}{c}-0.059 \\
(0.016)^{* * *}\end{array}$ & $\begin{array}{c}-0.067 \\
(0.013)^{* * *}\end{array}$ \\
\hline $\begin{array}{c}\text { Failures_1930 } \\
\text { (see Table 4) }\end{array}$ & & & & & $\begin{array}{c}-0.061 \\
(0.015)^{* * *} \\
\end{array}$ & $\begin{array}{c}-0.026 \\
(0.013)^{* *} \\
\end{array}$ & $\begin{array}{c}0.032 \\
(0.013)^{* *}\end{array}$ & $\begin{array}{c}0.043 \\
(0.012)^{* * *} \\
\end{array}$ & & & & \\
\hline $\begin{array}{c}\text { Failures_1920 } \\
\text { (see Table 4) }\end{array}$ & $\begin{array}{l}-0.005 \\
(0.011) \\
\end{array}$ & $\begin{array}{l}-0.002 \\
(0.009) \\
\end{array}$ & $\begin{array}{c}0.021 \\
(0.012)^{*} \\
\end{array}$ & $\begin{array}{c}0.015 \\
(0.010) \\
\end{array}$ & $\begin{array}{c}0.007 \\
(0.010) \\
\end{array}$ & $\begin{array}{c}0.002 \\
(0.010) \\
\end{array}$ & $\begin{array}{r}0.015 \\
(0.011) \\
\end{array}$ & $\begin{array}{c}0.006 \\
(0.010) \\
\end{array}$ & & & & \\
\hline \multirow{3}{*}{ 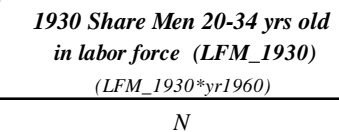 } & & & & & & & & & $\begin{array}{c}0.244 \\
(0.346) \\
\end{array}$ & $\begin{array}{c}0.395 \\
(0.272) \\
\end{array}$ & $\begin{array}{l}-0.311 \\
(0.396) \\
\end{array}$ & $\begin{array}{l}-0.241 \\
(0.350)\end{array}$ \\
\hline & & & & & & & & & & & & \\
\hline & 103667 & 111985 & 105650 & 96771 & 103667 & 111985 & 105650 & 96771 & 103784 & 112067 & 105712 & 96828 \\
\hline
\end{tabular}

Notes: See footnote to Table 3. 


\section{III: Yearly Births: 1940-1960 samples - Robustness}

Table A5: Annual Births of 20-24 years old in 1940 and 1960 (white) women: 1940-1960 (Robustness)

\begin{tabular}{|c|c|c|c|c|c|c|c|c|c|c|c|}
\hline & 1050 & 1051 & & & & & & \multicolumn{4}{|c|}{ Dep. Variable $=1$ if a birth took place in a given year (base year 1940) } \\
\hline \multicolumn{11}{|l|}{ Ige in 1940: 20 to 24 yrs old } & 1960 \\
\hline & \multicolumn{11}{|c|}{ "All Cohorts minus Older" and "Older Cohort" } \\
\hline All Cohorts minus Older & $\begin{array}{c}0.262 \\
(0.113)^{* *}\end{array}$ & $\begin{array}{c}0.361 \\
(0.130)^{* * *}\end{array}$ & $\begin{array}{c}0.352 \\
(0.132)^{* * *}\end{array}$ & $\begin{array}{c}0.397 \\
(0.120)^{* * *}\end{array}$ & $\begin{array}{c}0.338 \\
(0.117)^{* * *}\end{array}$ & $\begin{array}{c}0.488 \\
(0.111)^{* * *}\end{array}$ & $\begin{array}{c}0.659 \\
(0.108)^{* * *}\end{array}$ & $\begin{array}{c}0.420 \\
(0.136)^{* * *}\end{array}$ & $\begin{array}{c}0.570 \\
(0.137)^{* * *}\end{array}$ & $\begin{array}{c}0.336 \\
(0.171)^{*}\end{array}$ & $\begin{array}{c}0.325 \\
(0.275)\end{array}$ \\
\hline Older Cohort & $\begin{array}{c}0.105 \\
(0.070)\end{array}$ & $\begin{array}{c}0.210 \\
(0.079)^{* * *}\end{array}$ & $\begin{array}{c}0.142 \\
(0.080)^{*}\end{array}$ & $\begin{array}{c}0.166 \\
(0.068)^{* *}\end{array}$ & $\begin{array}{c}0.165 \\
(0.069)^{* *}\end{array}$ & $\begin{array}{c}0.079 \\
(0.081)\end{array}$ & $\begin{array}{c}0.162 \\
(0.063)^{* *}\end{array}$ & $\begin{array}{c}0.113 \\
(0.071)\end{array}$ & $\begin{array}{c}0.191 \\
(0.078)^{* *}\end{array}$ & $\begin{array}{c}0.129 \\
(0.089)\end{array}$ & $\begin{array}{c}0.057 \\
(0.141)\end{array}$ \\
\hline & \multicolumn{11}{|c|}{ Role of D-cohort when we include other cohorts ("All Cohorts minus Older" and "Older Cohort") } \\
\hline All Cohorts minus Older & $\begin{array}{c}0.025 \\
(0.180)\end{array}$ & $\begin{array}{c}0.118 \\
(0.186)\end{array}$ & $\begin{array}{c}0.132 \\
(0.177)\end{array}$ & $\begin{array}{c}0.189 \\
(0.126)\end{array}$ & $\begin{array}{c}0.012 \\
(0.147)\end{array}$ & $\begin{array}{c}0.103 \\
(0.195)\end{array}$ & $\begin{array}{c}0.497 \\
(0.163)^{* * *}\end{array}$ & $\begin{array}{c}0.019 \\
(0.203)\end{array}$ & $\begin{array}{c}0.189 \\
(0.184)\end{array}$ & $\begin{array}{c}-0.359 \\
(0.156)^{* *}\end{array}$ & $\begin{array}{l}-0.252 \\
(0.283)\end{array}$ \\
\hline Older Cohort & $\begin{array}{c}0.084 \\
(0.071)\end{array}$ & $\begin{array}{c}0.180 \\
(0.088)^{* *}\end{array}$ & $\begin{array}{c}0.115 \\
(0.083)\end{array}$ & $\begin{array}{c}0.140 \\
(0.072)^{*}\end{array}$ & $\begin{array}{c}0.127 \\
(0.076)^{*}\end{array}$ & $\begin{array}{c}0.024 \\
(0.090)\end{array}$ & $\begin{array}{c}0.142 \\
(0.068)^{* *}\end{array}$ & $\begin{array}{c}0.066 \\
(0.077)\end{array}$ & $\begin{array}{c}0.163 \\
(0.079)^{* *}\end{array}$ & $\begin{array}{c}0.090 \\
(0.083)\end{array}$ & $\begin{array}{c}0.029 \\
(0.146)\end{array}$ \\
\hline$N$ & 62056 & 61183 & 60157 & 58760 & 58330 & 57731 & 57339 & 56724 & 56935 & 56364 & 56242 \\
\hline
\end{tabular}

Table A6: Annual Births of 25-29 years old in 1940 and 1960 (white) women: 1940-1960 (Robustness)

Dep. Variable = 1 if a birth took place in a given year (base year 1940)

\begin{tabular}{|c|c|c|c|c|c|c|c|c|c|c|c|}
\hline $\begin{array}{c}\text { Age } 25 \text { to } 29 \text { yrs old in: } \\
\text { Ige in 1940: } 25 \text { to } 29 \text { yrs old }\end{array}$ & 1950 & 1951 & 1952 & 1953 & 1954 & 1955 & 1956 & 1957 & 1958 & 1959 & 1960 \\
\hline & \multicolumn{11}{|c|}{ "All Cohorts minus Older" and "Older Cohort" } \\
\hline All Cohorts minus Older & $\begin{array}{c}0.003 \\
(0.133)\end{array}$ & $\begin{array}{c}0.144 \\
(0.112)\end{array}$ & $\begin{array}{c}-0.342 \\
(0.154)^{* *}\end{array}$ & $\begin{array}{c}0.313 \\
(0.132)^{* *}\end{array}$ & $\begin{array}{l}-0.021 \\
(0.160)\end{array}$ & $\begin{array}{l}-0.050 \\
(0.155)\end{array}$ & $\begin{array}{c}0.104 \\
(0.162)\end{array}$ & $\begin{array}{l}-0.107 \\
(0.166)\end{array}$ & $\begin{array}{c}0.095 \\
(0.186)\end{array}$ & $\begin{array}{l}0.0009 \\
(0.153)\end{array}$ & $\begin{array}{c}-0.383 \\
(0.221)^{*}\end{array}$ \\
\hline \multirow[t]{2}{*}{ Older Cohort } & $\begin{array}{l}-0.164 \\
(0.118)\end{array}$ & $\begin{array}{l}-0.054 \\
(0.098)\end{array}$ & $\begin{array}{l}-0.082 \\
(0.103)\end{array}$ & $\begin{array}{c}0.051 \\
(0.119)\end{array}$ & $\begin{array}{l}-0.045 \\
(0.127)\end{array}$ & $\begin{array}{c}0.010 \\
(0.108)\end{array}$ & $\begin{array}{l}-0.024 \\
(0.112)\end{array}$ & $\begin{array}{c}0.011 \\
(0.118)\end{array}$ & $\begin{array}{c}0.015 \\
(0.116)\end{array}$ & $\begin{array}{c}0.020 \\
(0.116)\end{array}$ & $\begin{array}{l}-0.015 \\
(0.169)\end{array}$ \\
\hline & \multicolumn{11}{|c|}{ Role of D-cohort when we include other cohorts ("All Cohorts minus Older" and "Older Cohort") } \\
\hline All Cohorts minus Older & $\begin{array}{l}-0.246 \\
(0.169)\end{array}$ & $\begin{array}{l}-0.191 \\
(0.166)\end{array}$ & $\begin{array}{c}-0.744 \\
(0.205)^{* * *}\end{array}$ & $\begin{array}{l}-0.029 \\
(0.157)\end{array}$ & $\begin{array}{c}-0.536 \\
(0.226)^{* *}\end{array}$ & $\begin{array}{l}-0.425 \\
(0.231)^{*}\end{array}$ & $\begin{array}{c}-0.504 \\
(0.221)^{* *}\end{array}$ & $\begin{array}{c}-0.671 \\
(0.212)^{* * *}\end{array}$ & $\begin{array}{c}-0.394 \\
(0.229)^{*}\end{array}$ & $\begin{array}{l}-0.285 \\
(0.182)\end{array}$ & $\begin{array}{c}-1.070 \\
(0.244)^{* * *}\end{array}$ \\
\hline Older Cohort & $\begin{array}{l}-0.181 \\
(0.119)\end{array}$ & $\begin{array}{l}-0.091 \\
(0.100)\end{array}$ & $\begin{array}{l}-0.123 \\
(0.109)\end{array}$ & $\begin{array}{c}0.014 \\
(0.124)\end{array}$ & $\begin{array}{l}-0.094 \\
(0.138)\end{array}$ & $\begin{array}{l}-0.039 \\
(0.117)\end{array}$ & $\begin{array}{l}-0.093 \\
(0.122)\end{array}$ & $\begin{array}{l}-0.052 \\
(0.117)\end{array}$ & $\begin{array}{l}-0.015 \\
(0.118)\end{array}$ & $\begin{array}{c}0.008 \\
(0.119)\end{array}$ & $\begin{array}{l}-0.039 \\
(0.170)\end{array}$ \\
\hline $\begin{array}{c}\text { D-Cohort } \\
\text { Crowding-Out (CO) }\end{array}$ & $\begin{array}{c}0.210 \\
(0.093)^{* *}\end{array}$ & $\begin{array}{c}0.267 \\
(0.107)^{* *}\end{array}$ & $\begin{array}{c}0.330 \\
(0.121)^{* * *}\end{array}$ & $\begin{array}{c}0.288 \\
(0.103)^{* * *}\end{array}$ & $\begin{array}{c}0.429 \\
(0.139)^{* * *}\end{array}$ & $\begin{array}{c}0.301 \\
(0.112)^{* * *}\end{array}$ & $\begin{array}{c}0.496 \\
(0.123)^{* * *}\end{array}$ & $\begin{array}{c}0.473 \\
(0.139)^{* * *}\end{array}$ & $\begin{array}{c}0.411 \\
(0.110)^{* * *}\end{array}$ & $\begin{array}{c}0.252 \\
(0.109)^{* *}\end{array}$ & $\begin{array}{c}0.575 \\
(0.138)^{* * *}\end{array}$ \\
\hline
\end{tabular}

\begin{tabular}{lllllllllll}
\hline$N$ & 66216 & 65207 & 64797 & 64232 & 62841 & 61858 & 60985 & 59959 & 58562 & 58132 \\
\hline
\end{tabular}

Notes: Reported coefficients are OLS estimates from a regression of an indicator of whether a birth took place in a given year (1940-1951, 1940-1952, ..., 1940-1960 with 1940 being the year of reference) on WWII mobilization rate, business failures in the year prior to birth year and a measure of the change in work behavior of various cohorts of women (see below for definition of different measures). The Dcohort consists of women 20-34 years old in 1930. See text for a detailed definition of the crowding out variable. Other controls: age dymmies, 1940 share of men that are farmers, 1940 share of nonwhite men, average male education in 1940, state of residence and state of birth dummies, year fixed effects. All controls (except the state, year dummies and the work measures) are interacted with a year dummy. Sample includes white women born in the United States. Standard errors are clustered at the state of residence-year level. ***, **, * refer to $1 \%, 5 \%$ and $10 \%$ significance level respectively.

\section{Definitions:}

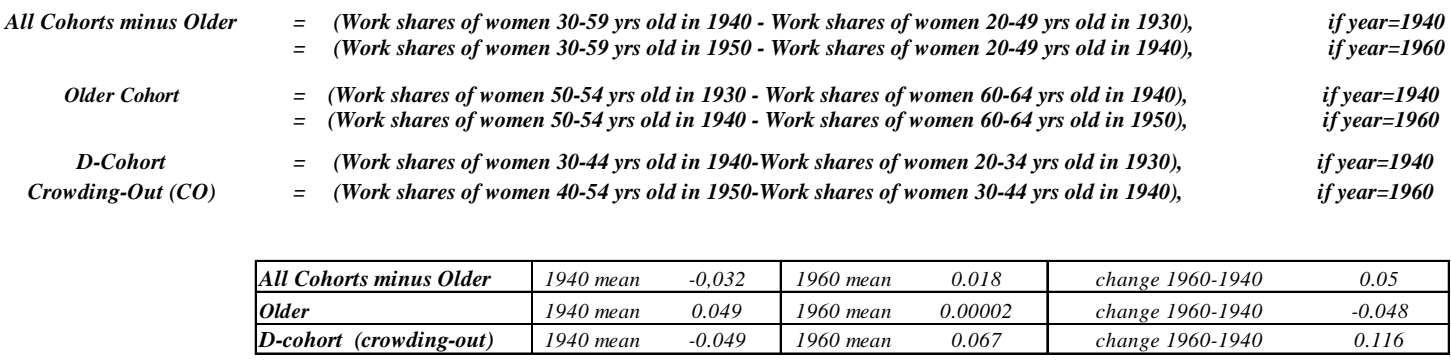




\section{III: Yearly Births: 1940-1970 samples - Robustness}

Table A7: Annual Births of 20-24 years old in 1940 and 1970 (white) women: 1940-1970 (Robustness)

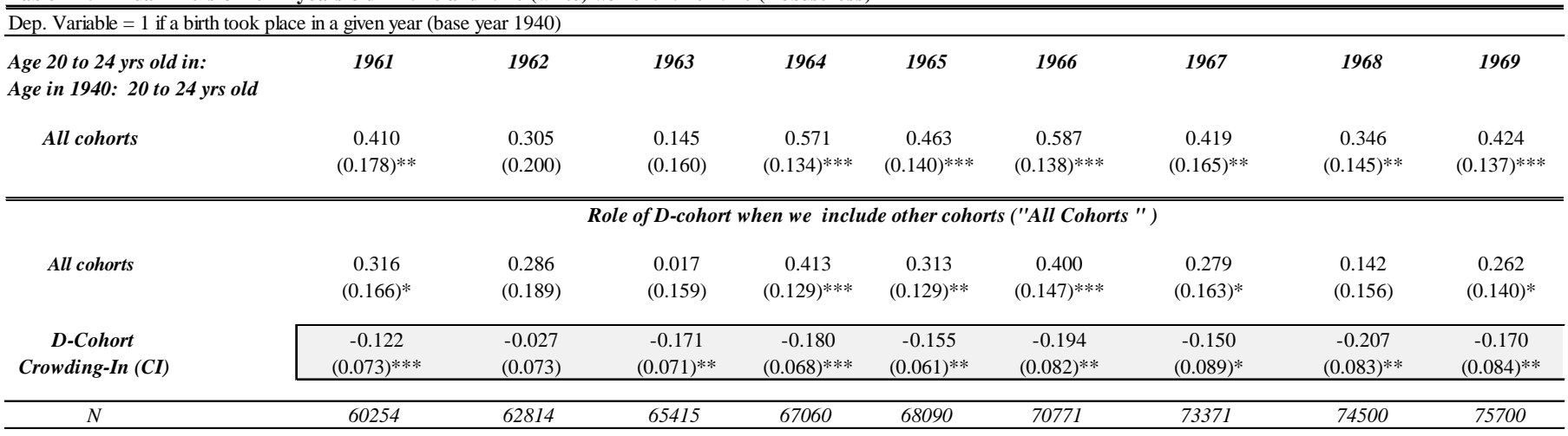

Notes: See notes to Table A7.

Table A8: Annual Births of 25-29 years old in 1940 and 1970 (white) women: 1940-1970 (Robustness)

Dep. Variable $=1$ if a birth took place in a given year (base year 1940)

\begin{tabular}{|c|c|c|c|c|c|c|c|c|c|}
\hline $\begin{array}{l}\text { Age } 25 \text { to } 29 \text { yrs old in: } \\
\text { Age in 1940: } 25 \text { to } 29 \text { yrs old } \\
\quad \text { All cohorts }\end{array}$ & $\begin{array}{l}-0.104 \\
(0.263)\end{array}$ & $\begin{array}{l}-0.062 \\
(0.231)\end{array}$ & $\begin{array}{c}0.099 \\
(0.239)\end{array}$ & $\begin{array}{c}0.145 \\
(0.226)\end{array}$ & $\begin{array}{c}0.037 \\
(0.193)\end{array}$ & $\begin{array}{l}-0.020 \\
(0.188)\end{array}$ & $\begin{array}{l}-0.041 \\
(0.183)\end{array}$ & $\begin{array}{l}-0.069 \\
(0.185)\end{array}$ & $\begin{array}{l}-0.068 \\
(0.177)\end{array}$ \\
\hline \multicolumn{10}{|c|}{ Role of D-cohort when we include other cohorts ("All Cohorts ") } \\
\hline All cohorts & $\begin{array}{l}-0.362 \\
(0.230)\end{array}$ & $\begin{array}{l}-0.230 \\
(0.217)\end{array}$ & $\begin{array}{l}-0.133 \\
(0.221)\end{array}$ & $\begin{array}{l}-0.015 \\
(0.221)\end{array}$ & $\begin{array}{l}-0.303 \\
(0.188)\end{array}$ & $\begin{array}{l}-0.185 \\
(0.196)\end{array}$ & $\begin{array}{c}-0.416 \\
(0.183)^{* *}\end{array}$ & $\begin{array}{l}-0.311 \\
(0.206)\end{array}$ & $\begin{array}{c}-0.405 \\
(0.192)^{* *}\end{array}$ \\
\hline $\begin{array}{c}\text { D-Cohort } \\
\text { Crowding-In (CI) }\end{array}$ & $\begin{array}{c}-0.346 \\
(0.090)^{* * *}\end{array}$ & $\begin{array}{c}-0.262 \\
(0.094) * * *\end{array}$ & $\begin{array}{c}-0.330 \\
(0.096)^{* * *}\end{array}$ & $\begin{array}{c}-0.189 \\
(0.082)^{* *}\end{array}$ & $\begin{array}{c}-0.356 \\
(0.079)^{* * *}\end{array}$ & $\begin{array}{c}-0.176 \\
(0.087)^{* *}\end{array}$ & $\begin{array}{c}-0.408 \\
(0.091)^{* * *}\end{array}$ & $\begin{array}{c}-0.243 \\
(0.093)^{* *}\end{array}$ & $\begin{array}{c}-0.358 \\
(0.091)^{* * *}\end{array}$ \\
\hline$N$ & 56926 & 56812 & 57314 & 57987 & 58754 & 60056 & 62616 & 65217 & 66862 \\
\hline
\end{tabular}

Notes : Reported coefficients are OLS estimates from a regression of an indicator of whether a birth took place in a given year (1940-1961, 1940-1962,... with 1940 being the year of reference) on WWII mobilization rate, business failures in the year prior to birth year and a measure of the change in work behavior of various cohorts of women (see above for definition of different measures). The $D$-cohort consists of women 20-34 years old in 1930. See text for a detailed definition of the crowding out variable. Other controls: age dymmies, 1940 share of men that are farmers, 1940 share of nonwhite men, average male education in 1940, state of residence and state of birth dummies, year fixed effects. All controls (except the state, year dummies and the work measures) are interacted with a year dummy. Sample includes white women born in the United States. Standard errors are clustered at the state of residence-year level. ***, **, * refer to $1 \%, 5 \%$ and $10 \%$ significance level respectively.

\section{Definitions:}

\begin{tabular}{|c|c|c|c|c|c|c|c|}
\hline \multirow{2}{*}{$\begin{array}{c}\text { All Cohorts } \\
\text { D-Cohort } \\
\text { Crowding-In (CI) }\end{array}$} & \multirow[t]{2}{*}{$=$} & \multicolumn{5}{|c|}{$\begin{array}{l}\text { (Work shares of women 30-64 yrs old in } 1940 \text { - Work shares of women 20-54 yrs old in 1930), } \\
\text { (Work shares of women 30-64 yrs old in } 1960 \text { - Work shares of women 20-54 yrs old in 1950), }\end{array}$} & $\begin{array}{l}\text { if year }=1940 \\
\text { if year }=1970 \\
\text { if year }=1940\end{array}$ \\
\hline & & $\begin{array}{l}\text { (Work shares of } \\
\text { (Work shares of }\end{array}$ & $0-34$ yrs & $\begin{array}{l}\text { 1930-Work } \\
\text { 1970-Work }\end{array}$ & $\begin{array}{l}\text { of won } \\
\text { of won }\end{array}$ & $\begin{array}{l}4 \text { yrs old in 1940), } \\
4 \text { yrs old in 1960), }\end{array}$ & $\begin{array}{l}\text { if year }=1940 \\
\text { if year }=1970\end{array}$ \\
\hline IIl Cohorts & & 1940 mean & $-0,032$ & 1970 mean & 0.054 & change 1970-1940 & 0.086 \\
\hline -cohort (crowding-in) & & 1940 mean & 0.051 & 1970 mean & 0.157 & change 1970-1940 & 0.106 \\
\hline
\end{tabular}




\section{$\underline{\text { IV. Completed Fertility: 1940-1960-1970 samples }}$}

Table A9: Cumulative Fertility (white women) 25 to 29 years old: Crowding-Out \& Crowding-In

Number of Children

Dep. Variable:

Completed Fertility

More than 3

More than 2

[1940 mean: women 25 to 29 years old in 1940]

[1.431]

[0.086]

[0.184]

Panel 1940-1960: Age 25 to 29 yrs old in 1960 and 1940:

D-Cohort
Crowding-Out (CO)

[change 1950-1940: 0.116]

predicted change relative to 1940

$N$

51568
0,318

$(0.087)^{* * *}$

$43 \%$

51568

51568

Panel 1940-1970: Age 25 to 29 yrs old in 1970 and 1940:

Specification I:

D-Cohort

Crowding-In (CI)

[change 1960-1970: 0.106]

\begin{tabular}{|lll|}
\hline-1.125 & -0.183 & -0.303 \\
$(0.760)$ & $(0.131)$ & $(0.219)$ \\
\hline
\end{tabular}

Specification II:

D-Cohort (younger group)

Crowding-In (CI)

[change 1960-1970: 0.07]

predicted change relative to 1940

$N$

\begin{tabular}{|ccc|}
\hline-1.199 & -0.203 & -0.335 \\
$(0.497)^{* *}$ & $(0.086)^{* *}$ & $(0.146)^{* *}$ \\
\hline
\end{tabular}

$-6 \%-17 \% \quad-13 \%$

59164

59164

59164

Notes: See notes to Table 8. D-Cohort (younger group) only include women who are 20 to 30 years old in 1930, while the $D$-cohort includes all women 20 to 34 years old in 1930. 


\section{Crude Birth Rates, Completed Fertility and GDP across countries}
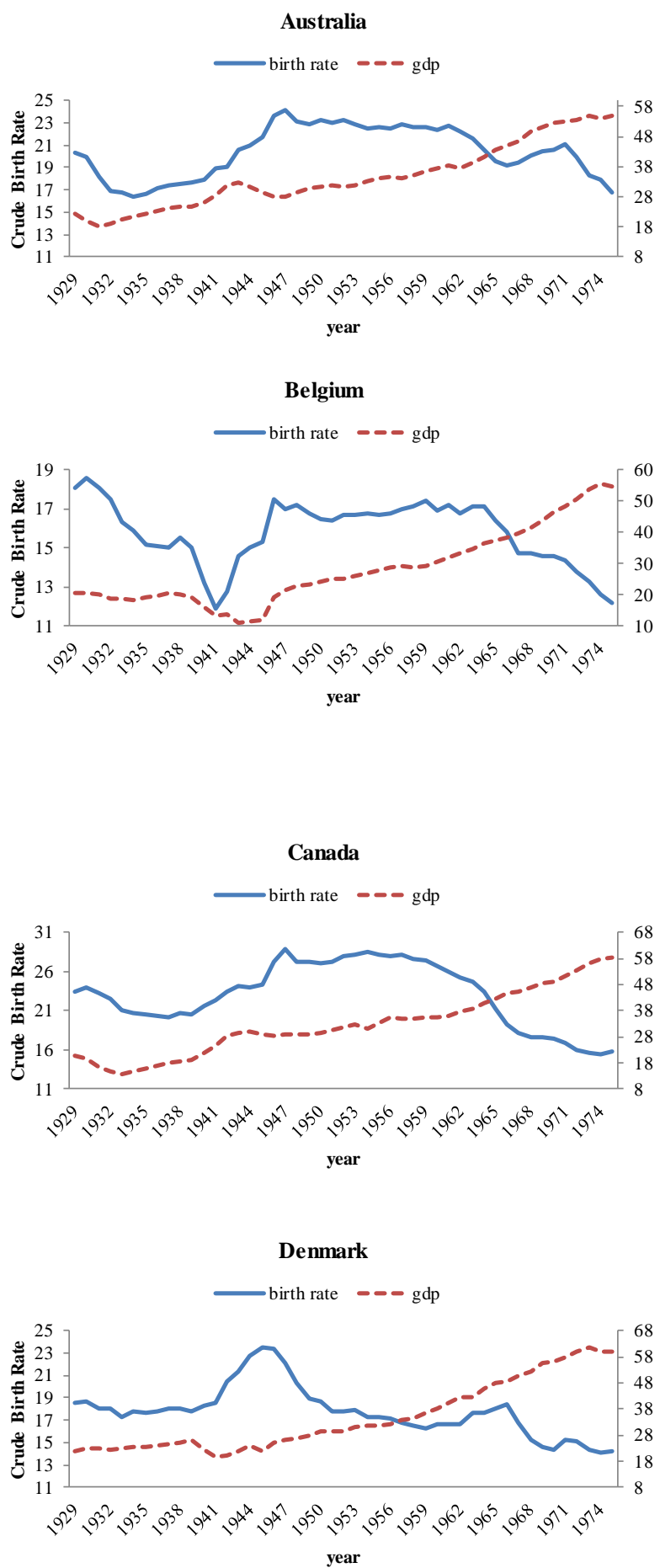
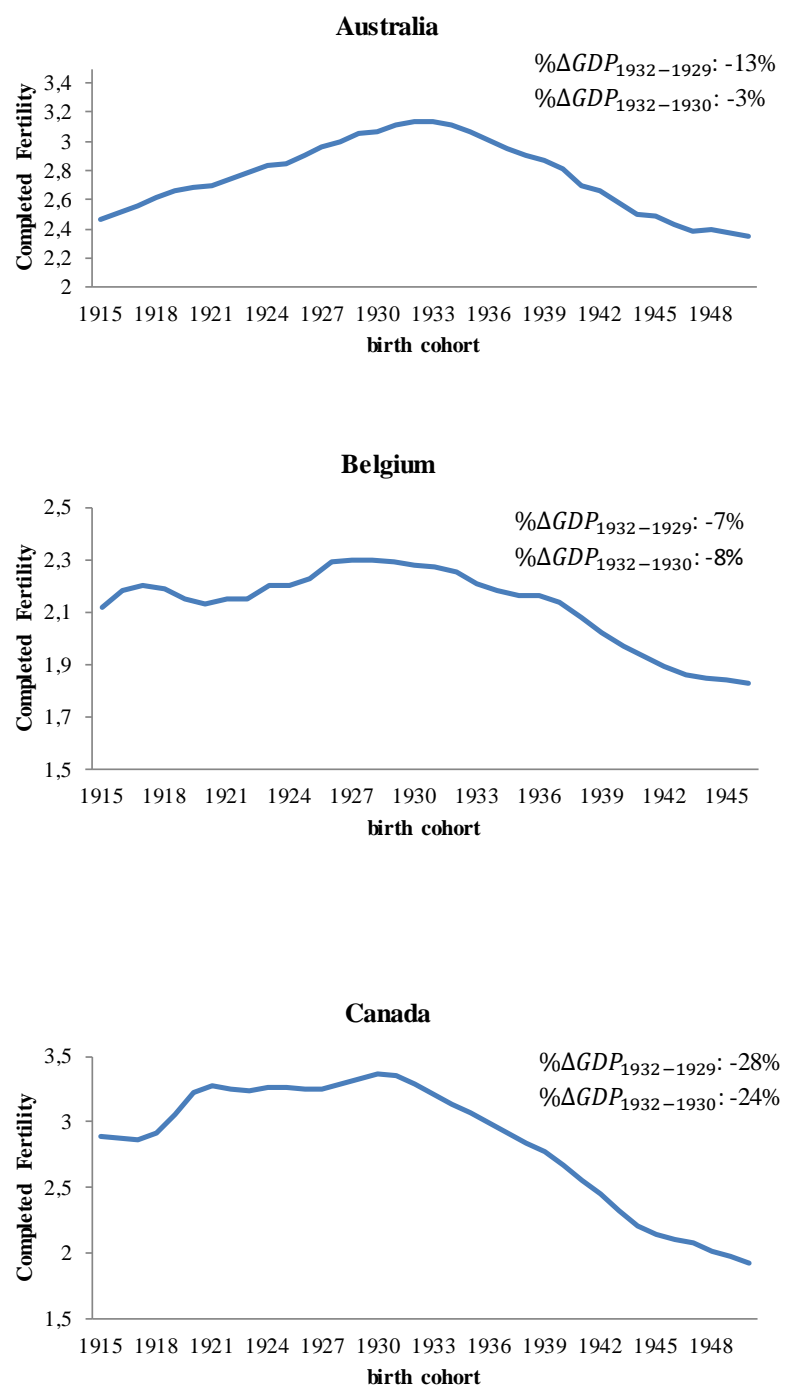

Denmark

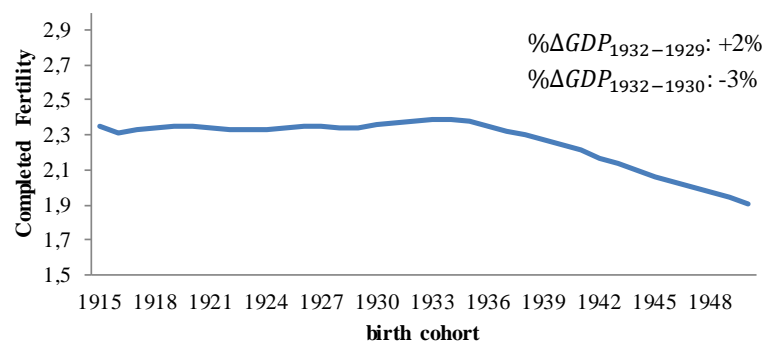


Finland

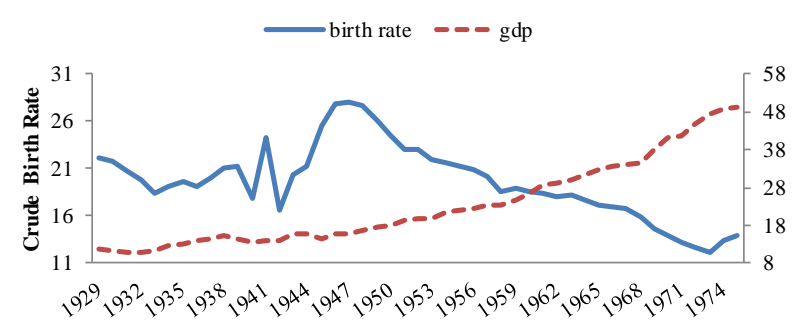

year

\section{France}

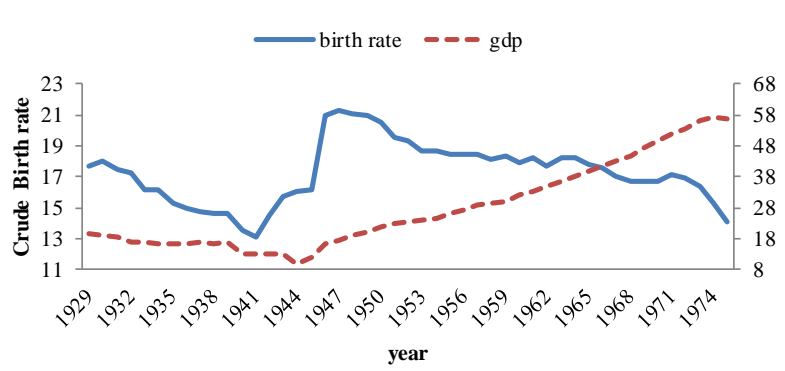

Greece

$\% \triangle G D P_{1932-1929}: 0 \%$ $\% \triangle G D P_{1932-1930}:-6 \%$

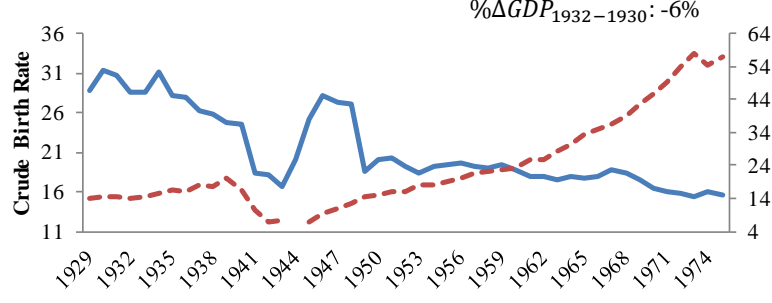

year

birth rate $\quad$ - - gdp

Iceland

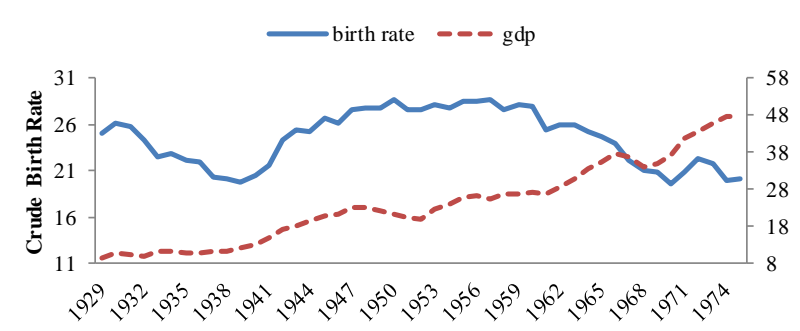

year
Finland

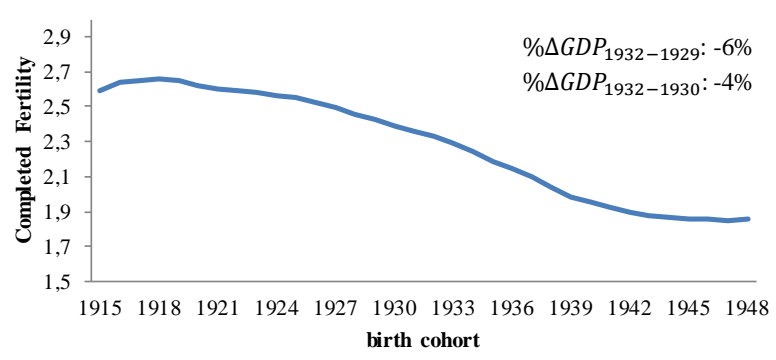

France

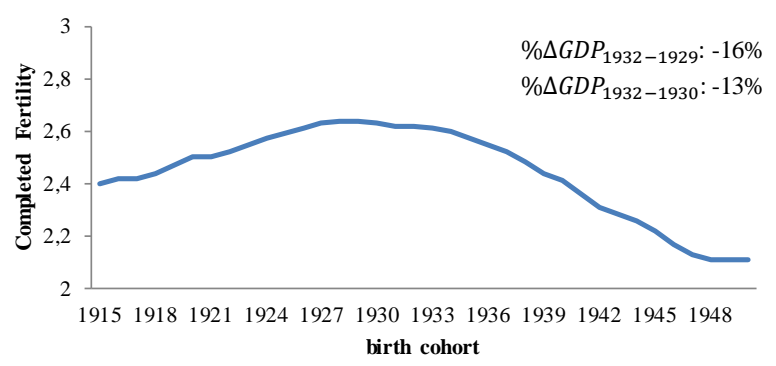

United Kingdom

$\% \Delta G D P_{1932-1929}:-6 \%$

$\% \Delta G D P_{1932-1930}:-5 \%$

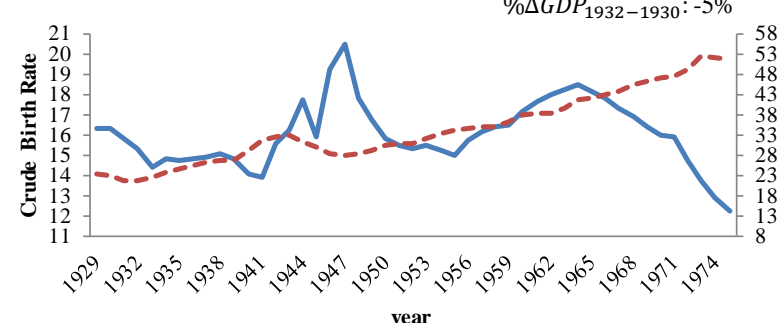

birth rate $\quad--$ gdp

Iceland

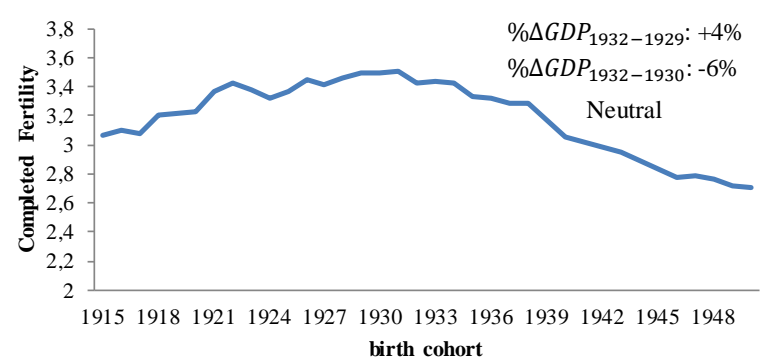




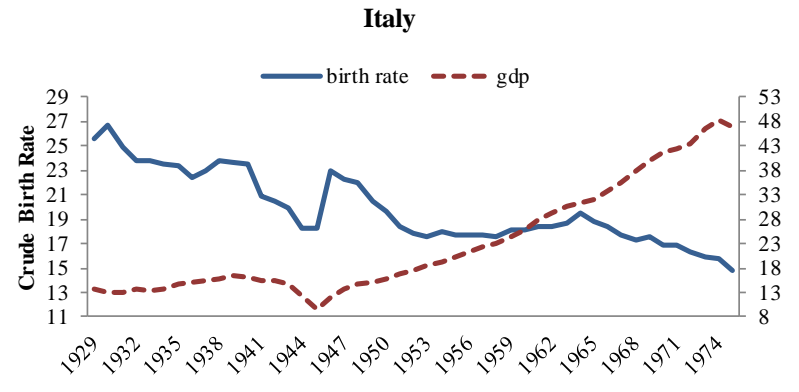

year

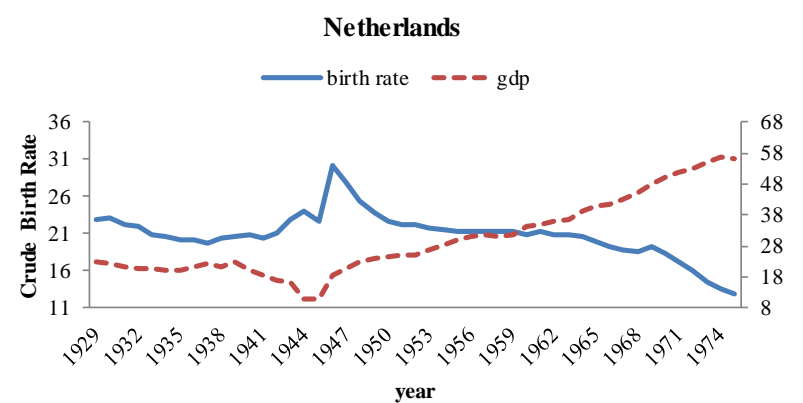

New Zealand

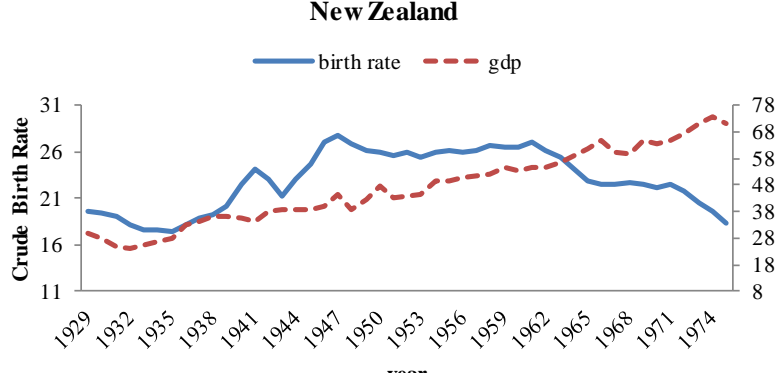

year

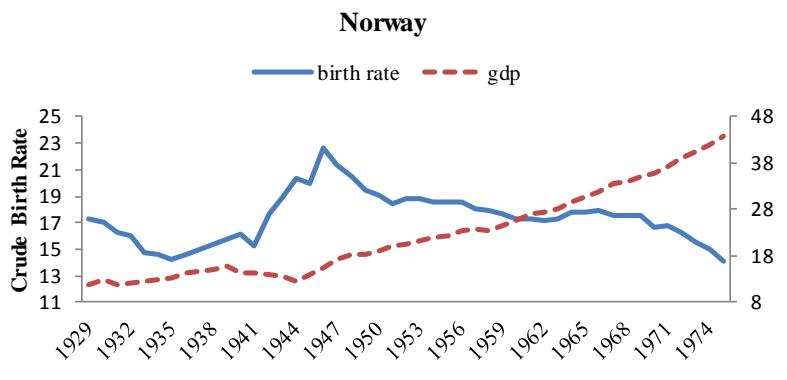

year
Italy

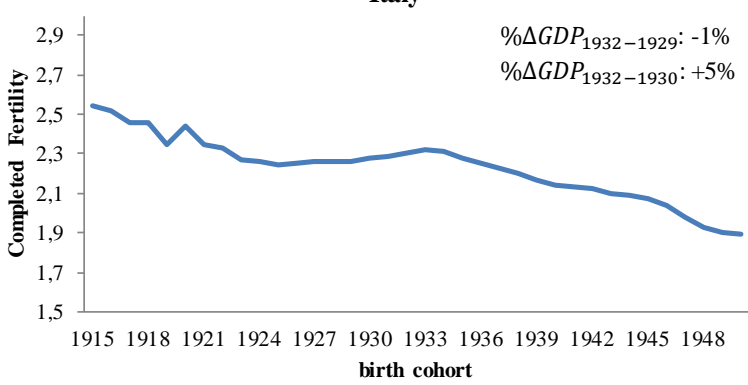

Netherlands

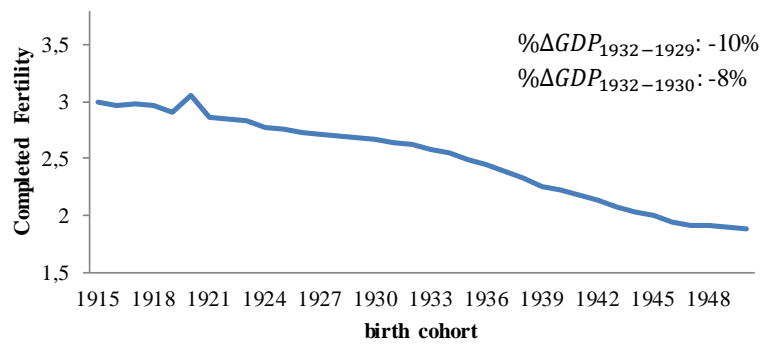

New Zealand

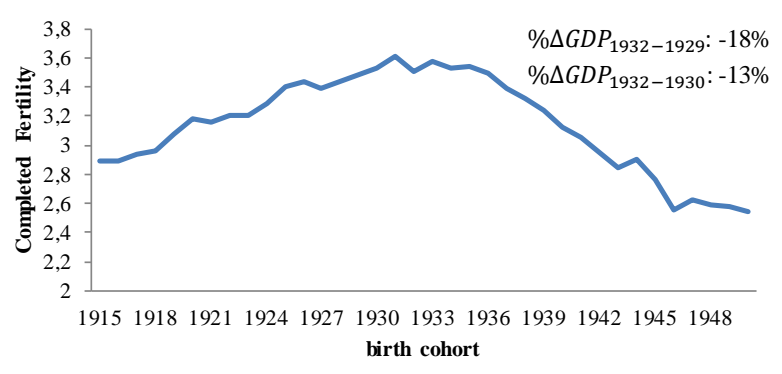

Norway

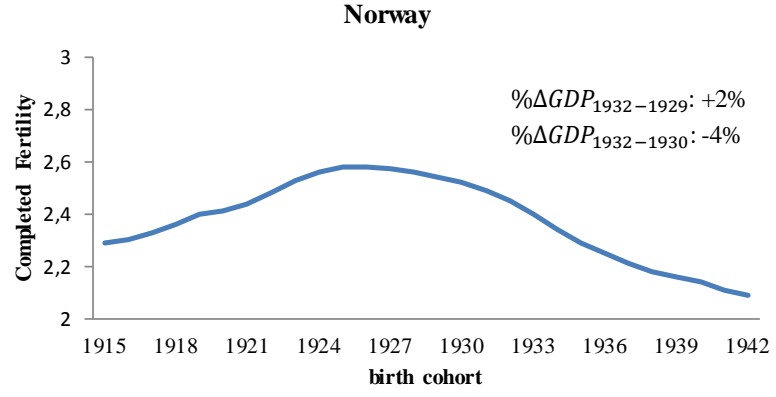


Portugal

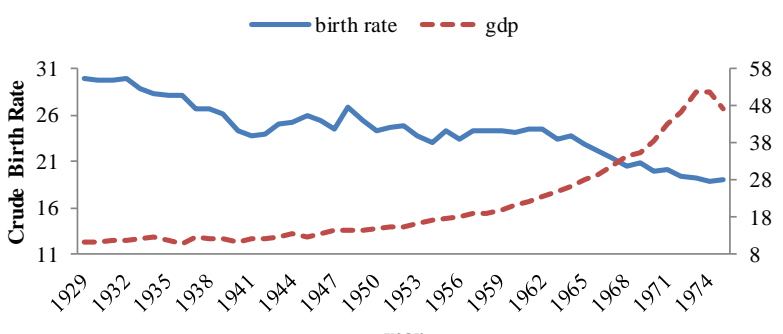

year

Spain

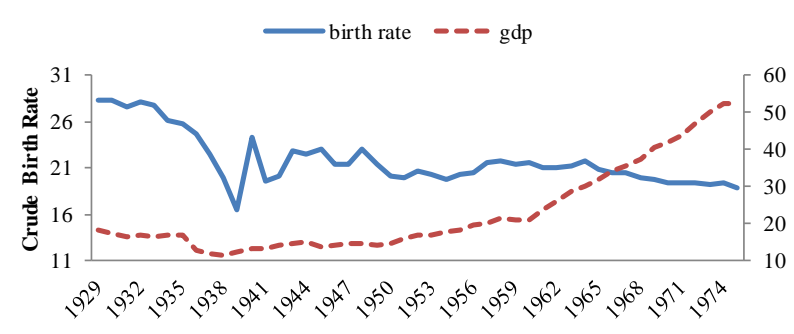

year

Sweden

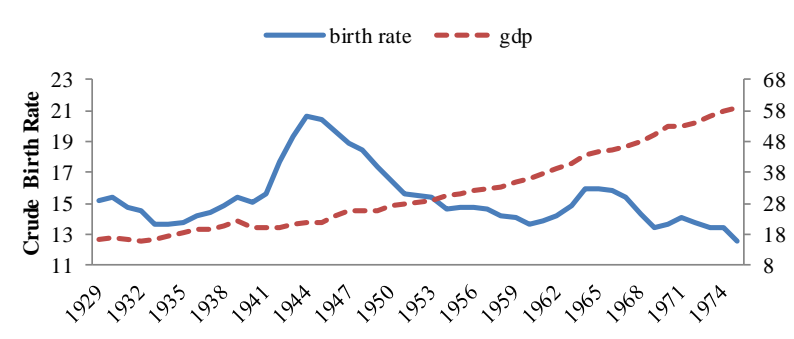

year

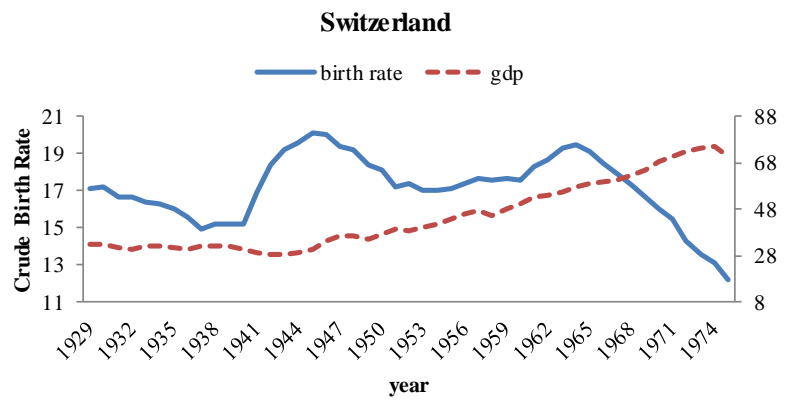

United States

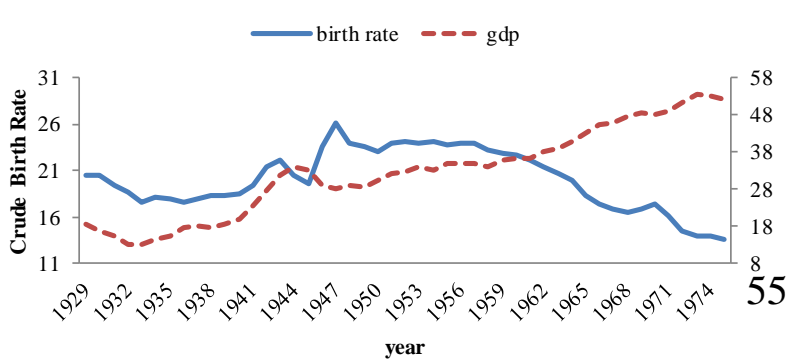

Portugal

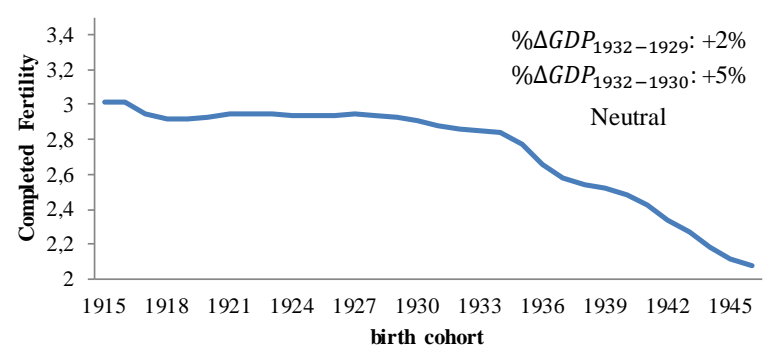

Spain

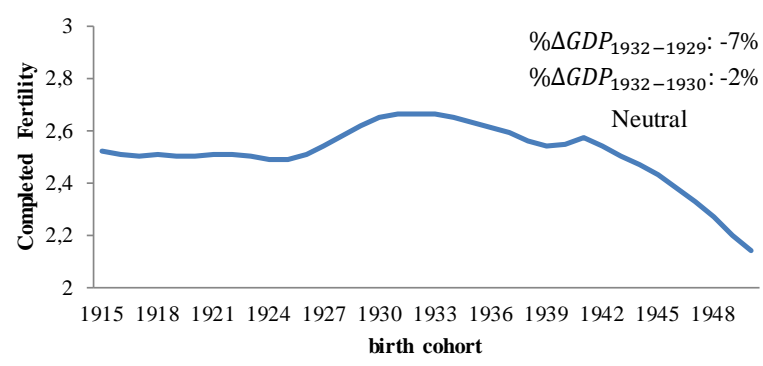

Sweden

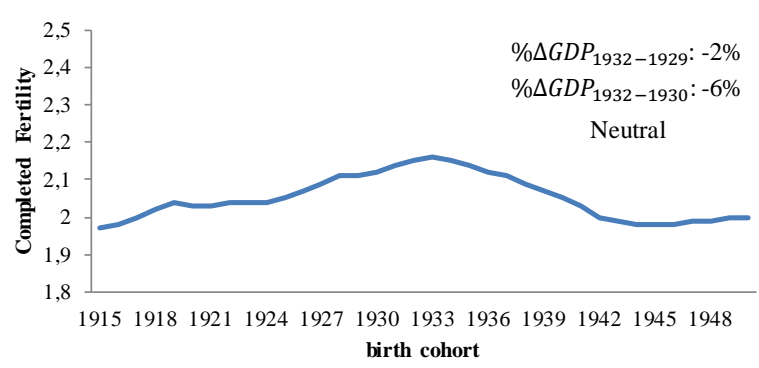

Switzerland

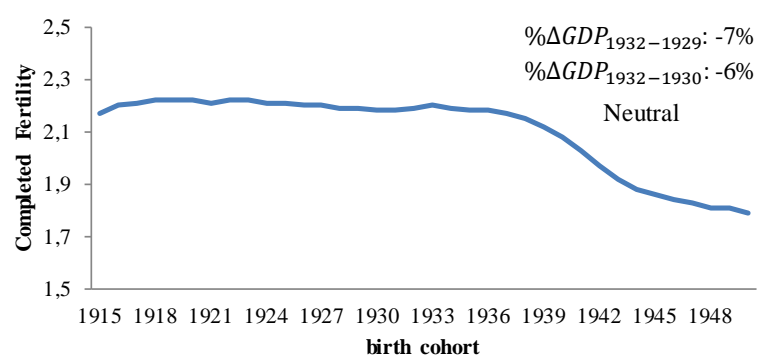

United States

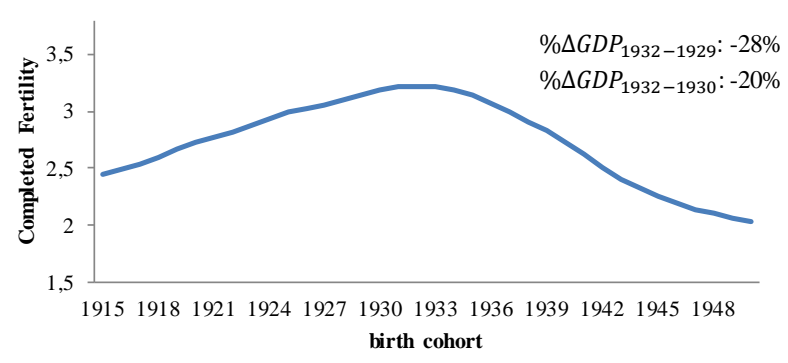


Figure A1: Female Labor Force Participation Rates

(Canada)

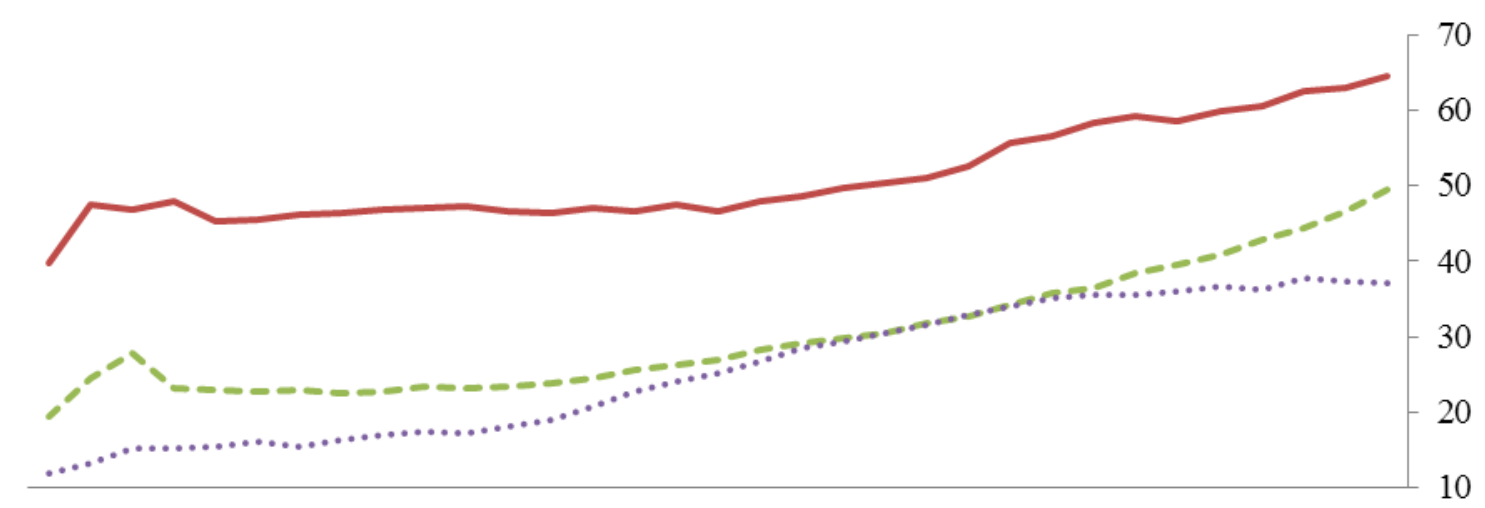

19211941194719491951195319551957195919611963196519671969197119731975

year

$-20-24$ yrs old $\quad----25-44$ yrs old $\ldots . .45-64$ yrs old

Figure A2: Female Labor Force Participation Rates (New Zealand)

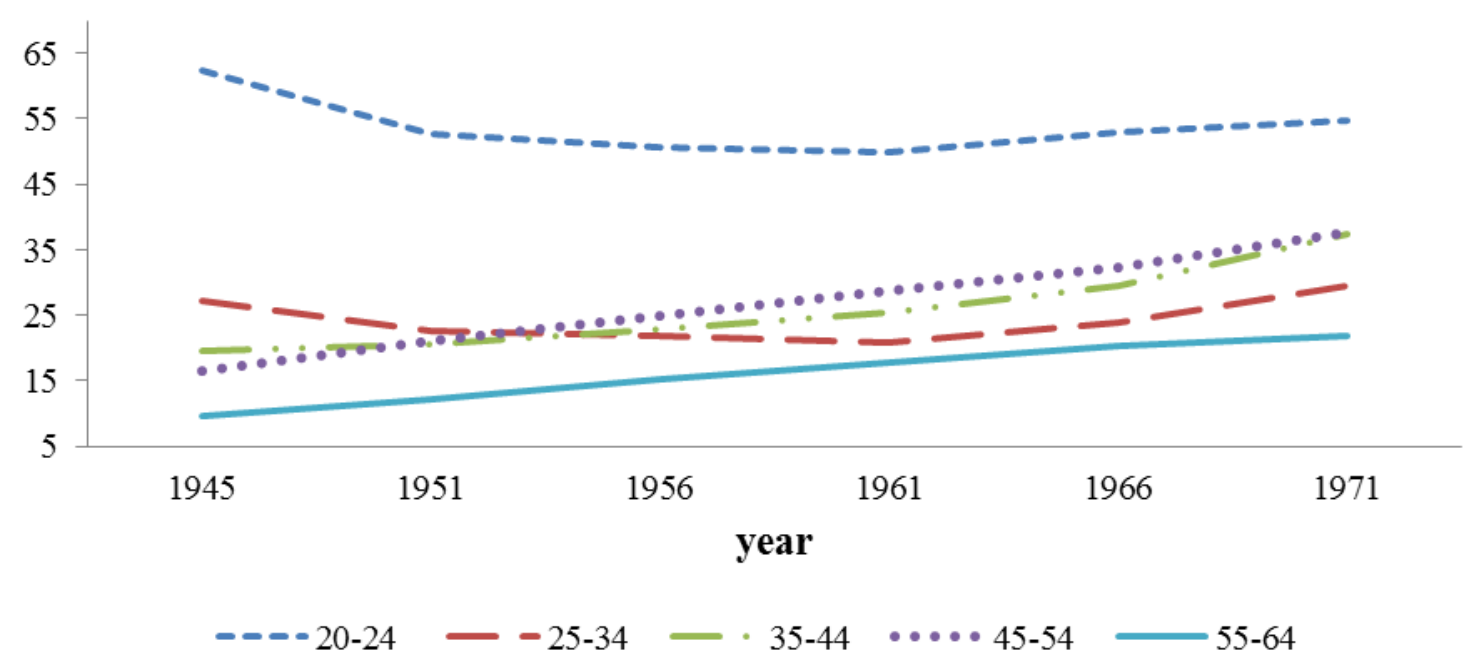


Figure A3: Female Labor Force Participation - Married Women (New Zealand)

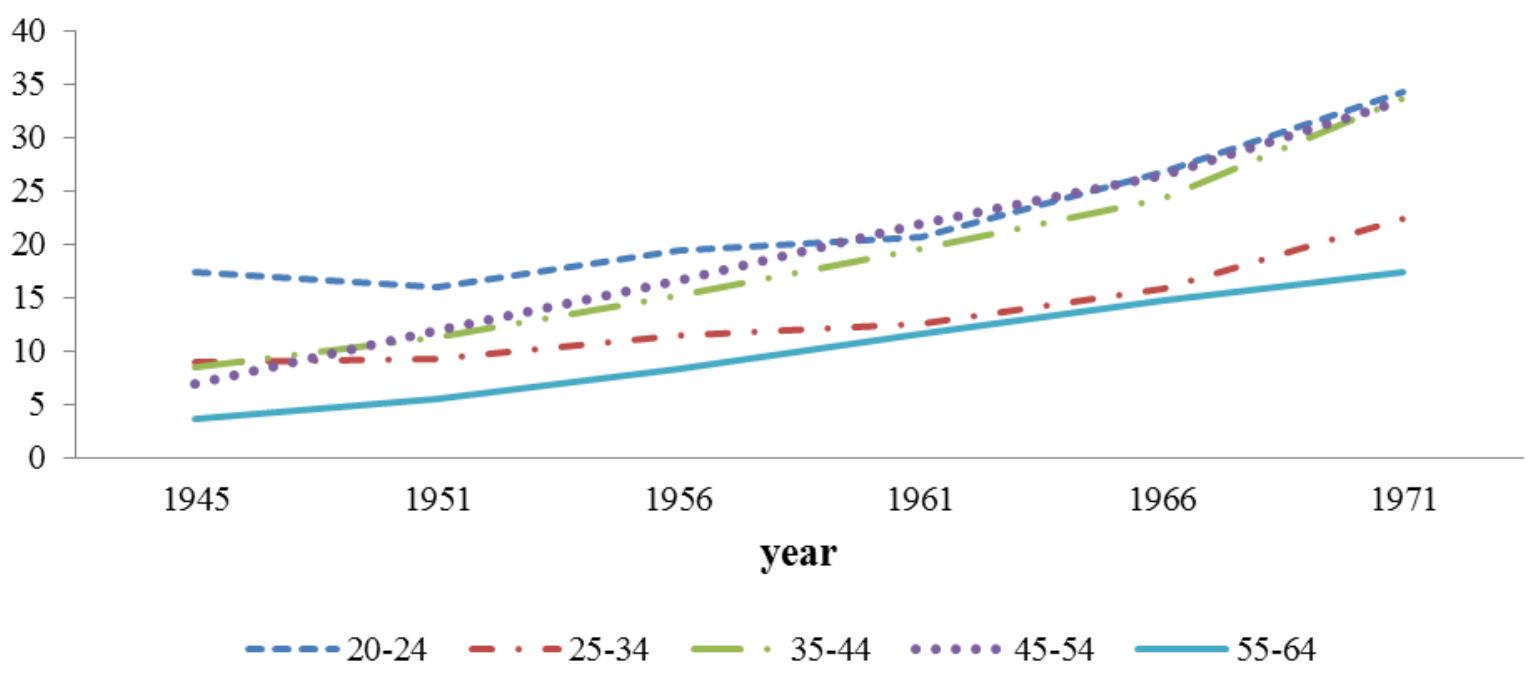

Figure A4: Share of men and women in the workforce (New Zealand)

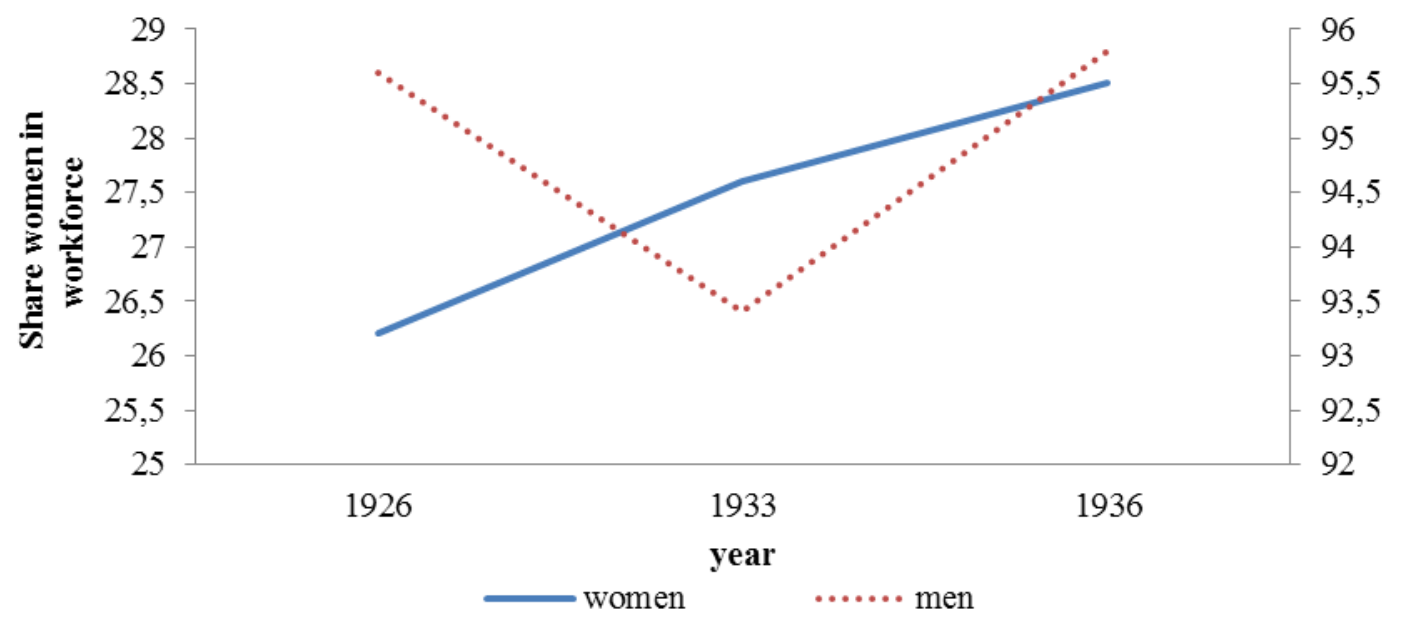


Figure A5: Female Labor Force Participation Rates (United Kingdom)

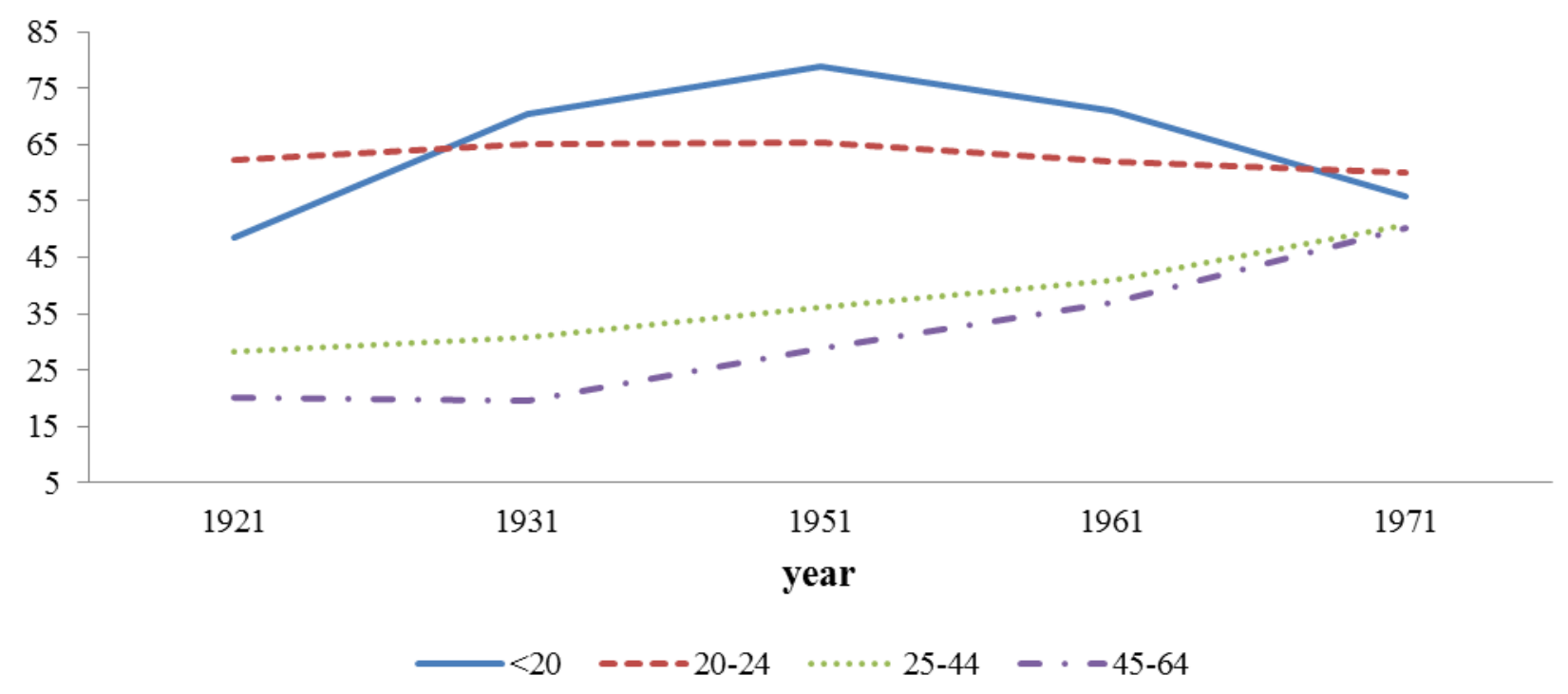

